NBER WORKING PAPER SERIES

\title{
WHAT DIFFERENCE DOES A DIAGNOSIS MAKE? EVIDENCE FROM MARGINAL PATIENTS
}

\author{
Mattan Alalouf \\ Sarah Miller \\ Laura R. Wherry \\ Working Paper 26363 \\ http://www.nber.org/papers/w26363
}

\author{
NATIONAL BUREAU OF ECONOMIC RESEARCH \\ 1050 Massachusetts Avenue \\ Cambridge, MA 02138 \\ October 2019
}

This work benefited from helpful comments from seminar participants at the University of Michigan, UCLA, Harvard Kennedy School, UC Santa Barbara, CU Denver and the NBER Health Economics Summer Institute group. We would also like to thank Doug Bell, Marianne Bitler, John Mafi, Tannaz Moin, and Yusuke Tsugawa for helpful conversations, as well as Amanda Do, Rob Follett, and Javier Sanz for their help in accessing and interpreting the UCLA medical records data. An additional thank you to Sonia Iyengar for research assistance. Laura Wherry benefited from non-financial support from the California Center for Population Research at UCLA (CCPR), which receives core support (R24-HD041022) from the Eunice Kennedy Shriver National Institute of Child Health and Human Development (NICHD). Research with UCLA medical records data was supported by NIH National Center for Advancing Translational Science (NCATS) UCLA CTSI Grant Number UL1TR001881. Mattan Alalouf was supported by the National Institute on Aging of the National Institutes of Health under Award Number T32AG000221. The content is solely the responsibility of the authors and does not necessarily represent the official views of the National Institutes of Health. The views expressed herein are those of the authors and do not necessarily reflect the views of the National Bureau of Economic Research.

NBER working papers are circulated for discussion and comment purposes. They have not been peer-reviewed or been subject to the review by the NBER Board of Directors that accompanies official NBER publications.

(C) 2019 by Mattan Alalouf, Sarah Miller, and Laura R. Wherry. All rights reserved. Short sections of text, not to exceed two paragraphs, may be quoted without explicit permission provided that full credit, including $(\odot$ notice, is given to the source. 
What Difference Does a Diagnosis Make? Evidence from Marginal Patients

Mattan Alalouf, Sarah Miller, and Laura R. Wherry

NBER Working Paper No. 26363

October 2019

JEL No. I1,I12

\begin{abstract}
$\underline{\text { ABSTRACT }}$
Over the past 30 years, the criteria used to diagnose many illnesses have been relaxed, resulting in millions more relatively healthy individuals receiving treatment. This paper explores the impact of receiving a diagnosis of a common disease among such "marginally ill" patients. We apply a regression discontinuity design to the cutoff in blood sugar levels used to classify patients as having diabetes. We find that a marginally diagnosed patient with diabetes spends \$1,097 more on drugs and diabetes-related care annually after diagnosis, but find no corresponding changes in self-reported health or healthy behaviors. These increases in spending persist over the 6-year period we observe the patients. These marginally diagnosed patients experience improved blood sugar after the first year of diagnosis, but this improvement does not persist in subsequent years. Other clinical measures of health, such as BMI, blood pressure, cholesterol, and mortality show no improvement. The diagnosis rates for preventable disease-related conditions such as diabetic retinopathy, neuropathy, and kidney disease increase following a diagnosis, likely due to more intensive screening. Our results imply that a small relaxation in the diagnosis cutoff would increase total spending on diabetes-related care by about $\$ 2.4$ billion annually and minimally impact patient health.
\end{abstract}

Mattan Alalouf

University of Michigan

mattan@umich.edu

Sarah Miller

Ross School of Business

University of Michigan

701 Tappan Street Ann

Arbor, MI 48109 and

NBER

mille@umich.edu
Laura R. Wherry

University of California at Los Angeles

lwherry@mednet.ucla.edu 
Since the late 1990s, the criteria for diagnosing several chronic diseases have been relaxed, creating millions of new patients who were considered healthy under previous diagnosis guidelines. For example, new guidelines on diagnosing hypertension outlined by the American College of Cardiology and the American Heart Association in 2017 increased the number of patients with hypertension by over 40 percent, resulting in an additional 31 million Americans recommended to receive treatment for the disease (Muntner et al., 2018; Whelton et al., 2018). These guideline redefinitions can have outsized impacts on the composition of sick patients because patients diagnosed with an illness disproportionately have lab values that fall near the threshold for diagnosis. The trend towards diagnosing and treating progressively healthier patients has led some researchers in the medical field to express concern that such interventions may be, at best, wasteful, if not actually harmful and counterproductive (Welch et al., 2011).

This paper explores the impact of a diagnosis on such "marginally" sick patients by exploiting a cutoff in the diagnosis criteria for a common chronic illness, diabetes mellitus. Diabetes is a condition characterized by the body's inability to regulate blood sugar and its diagnosis presents an ideal scenario in which to explore the treatment of marginally diagnosed patients for several reasons. First, it is a common disease, making it an empirically relevant example; over 24 million individuals in the United States are currently diagnosed with diabetes, and annual spending on medical care related to diabetes and complications of diabetes is estimated at $\$ 237$ billion, with over $\$ 50$ billion spent on insulin and diabetes-controlling drugs alone (American Diabetes Association, 2018b). Second, diabetes is diagnosed using a sharp cutoff in blood sugar levels, which are smoothly distributed in the population, allowing us to compare the effect of diagnosis for patients with similar underlying health. The American Diabetes Association (ADA) recommends diagnosing diabetes in patients whose glycated hemoglobin (A1c) levels are at or above 6.5\% (American Diabetes Association, 2018b). Patients with A1c values just below this threshold are otherwise similar to those with A1c values just above the threshold, but may receive very different types of care because they are not considered to have diabetes. Finally, the blood test used to diagnosis diabetes is difficult to manipulate, making both self-selection by patients and strategic coding by providers extremely unlikely.

Marginally diagnosed patients are a relevant group to study because they represent a large fraction of those diagnosed with any given disease due to the underlying distribution of health in the population (Welch et al., 2011). In our setting, most people have blood glucose levels in or near the normal range, and blood glucose levels in the extremes are rare. As a result, even though spending is 
relatively low among the "marginal" patients with diabetes whose A1c falls just above the threshold, they have an outsized impact on total costs due to their large numbers. The distribution of A1c values makes it clear why patients near the cutoff are disproportionately represented among those with diabetes: in our data, over one quarter of all patients whose first A1c test puts them in the diabetes range have an A1c value within 0.1 percentage points of the cutoff, and over 15 percent have an A1c value of $6.5 \%$, the lowest possible value one can receive and still be considered to have diabetes.

We use claims data from a large national insurer to examine the impact of receiving a diagnosis of diabetes on such marginally diagnosed patients. We explore the impact of a diagnosis on different types of spending, use of care, and on clinical measures of health (blood sugar, cholesterol, and mortality). We also use matched survey data to examine how the diagnosis affects self-reported health and healthy behaviors. In addition, we examine data from electronic health records to measure the impact of a diagnosis on two additional clinical measures of health, BMI and blood pressure. We implement this analysis with a regression discontinuity design using A1c values from an initial blood test and follow patients' outcomes over the next six years. We require individuals to be in the sample for at least one year prior to the initial A1c test in order to exclude those with previous diagnoses of diabetes. This also allows us to test for and rule out pre-test differences in utilization for patients on either side of the cutoff.

We find that patients with initial A1c values that fall right above the $6.5 \%$ threshold are 11 percentage points more likely to have a diabetes diagnosis appear on their health insurance claim in the first year following the initial test. ${ }^{1}$ Receiving a diagnosis at the cutoff is associated with approximately \$1,097 additional spending on recommended diabetes-related care and \$139 in endocrinology specialty care during that first year. Spending increases related to office-based care and laboratory tests are particularly large (representing most of the observed increase in spending), although we also detect increases in the probability of purchasing a diabetes-related drugs and spending on vision screening. Notably, this elevated rate of spending for patients with A1c values just above the threshold persists for all six years that we observe patients; there is no evidence that patients with slightly lower A1c values catch up, despite the natural progression of disease that leads many who were initially below the cutoff to be diagnosed at later points during our study period. It appears that receiving a "marginal" diagnosis sets patients on a path of persistently higher spending.

The rates of diagnoses for complications related to diabetes (diabetic retinopathy, neuropathy, and

\footnotetext{
${ }^{1} \mathrm{~A}$ patient who receives an A1c value at or above $6.5 \%$ may not be counted in this diagnosis if, for example, their provider chose not to classify them as having diabetes or if the patient did not seek any follow-up care that would result in a claim.
} 
diabetic kidney disease) also increase for individuals right above the cutoff, likely due to increased interaction with the health care system and more intensive screening. We see no evidence that diagnosis rates for these complications fall over time among the marginally diagnosed group, nor do we find changes in the rates of serious, life-threatening complications related to diabetes (diabetic coma and ketoacidosis). We also find no evidence of changes in self-reported health or in healthy behaviors such as diet, exercise, drinking alcohol, or smoking following the initial lab test, even though clinical practice recommendations include lifestyle education and management for patients regarding diet, exercise, alcohol intake and smoking. We find short-term improvements in blood sugar among marginally diagnosed patients, but these improvements do not persist past the first year, despite the persistence of higher levels of diabetes-related medical spending over the entire period. We also find no evidence of improvements in total cholesterol or mortality. Using electronic health records data available for up to three years following the initial lab test, we find no evidence of improvements in BMI or blood pressure during this period.

Taken together, our results imply that further relaxation of the diagnosis guidelines would result in higher costs with minimal health improvements in the short term. Our spending results suggest that relaxing the diagnosis threshold further, from 6.5 to 6.4 , would increase diabetes-related spending by at least $\$ 2.4$ billion annually and generate only short-lived improvements in patient health over a 6-year period. At the same time, tightening the diagnosis criteria by moving the threshold from 6.5 to 6.6 would reduce spending by about $\$ 1.8$ billion annually.

Our analysis builds on existing work in economics that evaluates the impact of diagnoses and subsequent care on health. One of the first studies in this literature documents that infants born near the diagnosis threshold for "very low birthweight" (birthweights of less than 1500g) receive more intensive medical care and experience a reduction in infant mortality (Almond et al., 2010). ${ }^{2}$ More recent work examining other types of medical conditions also highlights that there may important effects on patient behavior, as well as psychological effects of diagnosis. For instance, among female students in New York City who receive BMI report cards with weight classifications, those with values of BMI just above an "overweight" threshold experience small increases in BMI and body weight during the subsequent year compared to those just below the threshold (Almond et al., 2016). However, individuals receiving a diagnosis of abdominal aortic aneurysm and told they will receive increased

\footnotetext{
${ }^{2}$ Follow up work has found evidence of longer-run effects of this diagnosis on health and human capital outcomes in the U.S., Chile, and Norway (Bharadwaj et al., 2013; Chyn et al., 2019), indicating high cumulative returns to spending on this margin.
} 
monitoring in a Swedish screening program have improved psychological well-being, compared to those just missing the diagnosis criteria but informed that they are at risk (Dahlberg et al., 2016). ${ }^{3}$

Most relevant to this paper, recent work by Iizuka et al. (2017) uses an identification strategy similar to ours to examine the use of health care around the diabetes and lower "pre-diabetes" thresholds using data from Japan. The authors find that patients who exceed the pre-diabetes threshold have small but statistically significant increases in diabetes-related doctor visits and outpatient medical spending in the following year. They find no evidence, however, that this increased utilization leads to improvements in health over the short- or medium-term. In addition, the authors find no evidence that patients with test values above the diabetes threshold receive more care or see health improvements. However, they provide evidence that this latter diagnostic threshold is not frequently used in their setting.

In addition, using a similar design, Kim et al. (2019) examine the effects of diagnoses of diabetes, obesity, and hyperlipidemia under a national health screening program in Korea on health, healthy behaviors, and health care utilization. The authors test for discontinuities at "medium risk" and "high risk" thresholds for diabetes, noting that individuals diagnosed as high risk are also prompted to undergo a free secondary examination with recommendations for treatment, if needed. They find that high risk individuals are more likely to take diabetes medication and experience weight loss in the short-run. The authors find no effects on healthy behaviors and the effects on weight loss appear to dissipate in the long-run (3-4 years after testing). They find no effects for individuals receiving a medium risk diagnosis for diabetes, and little evidence of effects of diagnoses of obesity or hyperlipidemia.

Our work is similar to these studies but differs in several important ways. In contrast to lizuka et al. (2017), we focus on the higher cutoff for the actual diagnosis of diabetes and its treatment, rather than pre-diabetes and the use of preventive care. While the standard of care for pre-diabetes in Japan is limited to a recommended physician visit (Iizuka et al., 2017), a diagnosis of diabetes in the U.S. carries recommendations for more extensive intervention including comprehensive and ongoing surveillance and management, initiation of drug therapy, aggressive treatment for comorbidities such as hypertension, and significant lifestyle changes that may be more relevant for long-term health. Indeed, we observe increases in spending at the diabetes diagnosis threshold that are 11 to 18 times larger in size

\footnotetext{
${ }^{3}$ Other examples include: Zhao et al. (2013) find that individuals in China with systolic blood pressure above the hypertension diagnosis cutoff reduce their fat intake upon receiving a diagnosis; and, Oster (2018) documents that U.S. households in which someone was recently diagnosed with diabetes exhibit small reductions in their purchases of unhealthy food.
} 
than those documented in Iizuka et al. (2017) at the prediabetes threshold. ${ }^{4}$ Our paper also contrasts with Kim et al. (2019) in that we are able to incorporate information on costs of care to document changes in spending; we also have a much larger sample (approximately 142,500 individuals with lab values near the diabetes cutoff versus fewer than 5,000 in Kim et al., 2019), which provides more power to detect changes in health measures (e.g. blood sugar, cholesterol) that were not statistically significant in their analysis. In addition, our context is the United States, which differs substantially from Japan and Korea both in terms of health policy and population health. Finally, our paper builds on this prior work by extending the period of analysis to six years after the patient receives her first lab test. We show that even over this longer time horizon, the spending effects of a diagnosis persist without any sustained improvements in the health outcomes observed in the data.

Finally, our work also contributes to a literature in economics devoted to measuring the marginal impact of additional medical care. This work seeks to disentangle patient selection into care from the benefit of the care itself, usually with the goal of determining whether certain types of care reflect wasteful "flat of the curve" spending. In general, the results that have been previously documented on this topic are mixed, with some studies showing large benefits of additional medical spending (e.g. Doyle, 2011; Doyle et al., 2015) and other papers showing limited or no benefit associated with additional spending (e.g. Fisher et al., 2003a,b; Frakes, 2013). A limitation in the existing literature is that much of it focuses on care for the onset of acute conditions (such as heart attack or hip fracture) and mortality, with very little attention to treatment for chronic illnesses and more intermediate outcomes. This paper contributes to this literature in three ways: first, we evaluate the marginal benefit of disease care and management for a common chronic illness that affects a large share of the population. Understanding the marginal impact of this type of care is particularly relevant given that treatment for chronic illnesses represents a substantial fraction of total medical spending (e.g. 86 percent of health care spending is for patients with one or more chronic illnesses, see Gerteis et al., 2014) and that over 100 million individuals in the United States are diagnosed with diabetes or pre-diabetes (Centers for Disease Control and Prevention, 2017). Second, our data permit us to observe a variety of intermediate outcomes, such as blood sugar, cholesterol, and disease complications, that may be more responsive to interventions than mortality. Finally, we are able to look at the benefits of medical intervention over a longer time horizon to understand the dynamic nature of these types of health investments.

\footnotetext{
${ }^{4}$ Table 2 in lizuka et al. (2017) reports effects on diabetes-related outpatient spending ranging from 1249 Japanese Yen, or $\$ 11.43$, to 1968 Japanese Yen, or $\$ 18.01$. In contrast, we find a reduced form increase in spending of $\$ 207.61$ at the diabetes cutoff.
} 


\section{Background}

Many chronic illnesses are diagnosed by comparing the outcome of a laboratory test to a "cutoff" value specified in guidelines created by health or medical associations. ${ }^{5}$ To diagnose type 2 diabetes, physicians primarily rely on a measure of blood sugar called glycated hemoglobin A1c ("A1c"), which is collected via a blood draw. A1c measures the exposure of hemoglobin cells to plasma glucose (blood sugar) over the past three months. Normal A1c levels range from 4.0\% to 5.6\%. High A1c levels are considered a marker of diabetes, as they indicate poor control of glucose.

Although diabetes may be diagnosed using alternative tests of single or episodic glucose levels, A1c tests are considered the preferred diagnostic tool since they measure chronic glycemic exposure. ${ }^{6}$ The International Expert Committee recommended A1c as a superior method to diagnose diabetes in a 2009 consensus report, noting that it is convenient (does not require the patient to fast) and more stable (less fluctuation within and between days). ${ }^{7}$ Using data from cross-sectional epidemiological studies, this committee observed that the rate of any retinopathy, a long-term complication of diabetes, "increases substantially at A1c values starting between 6.0 and 7.0\%." The committee also noted that when A1c levels were examined in $0.5 \%$ increments, the incidence of diabetes-specific "moderate" retinopathy noticeably increases at A1c levels $\geq 6.5 \% .^{8}$ They concluded that this justifies assigning an A1c cutoff value of $\geq 6.5 \%$ for the diagnosis of diabetes, although they note that "this cut point should not be construed as an absolute dividing line between normal glycemia and diabetes." The committee also emphasized that while there is evidence for a continuum of risk for the development of diabetes based on A1c levels, "there does not appear to be a specific level at which risk for diabetes clearly begins" (The International Expert Committee, 2009). ${ }^{9}$

Concordant with the IEC guidelines, the American Diabetes Association subsequently issued the

\footnotetext{
${ }^{5}$ Interestingly, recent work suggests that additional discontinuities may also exist in terms of who is tested due to rules of thumb used by physicians for administering diagnostic tests. Coussens (2018) finds that, in the emergency department setting, physicians use heuristics based on patient age when determining whether to test for ischemic heart disease, resulting in a discontinuity in diagnosis for this condition.

${ }^{6}$ Other tests that can be used to screen for diabetes are the measurement of fasting plasma glucose (FPG) and plasma glucose during a two-hour oral glucose tolerance test (OGTT). The OGTT is not commonly used other than among pregnant women to screen for gestational diabetes.

${ }^{7}$ The IEC was convened in 2008 to consider the diagnosis of diabetes among nonpregnant individuals. Members were appointed by the American Diabetes Association, the European Association for the Study of Diabetes, and the International Diabetes Federation.

${ }^{8}$ The analysis included data on approximately 28,000 individuals from nine countries. The IEC also considered specificity and sensitivity and relied on a receiver operating characteristic curve analysis when determining the optimal cutpoint.

${ }^{9} \mathrm{~A}$ study by Tsugawa et al. (2012) examines the validity of the new diagnostic threshold by examining the association between A1c values and the 3-year incidence of retinopathy among a cohort of Japanese adults. The authors do find an increase in risk for those with A1c levels of 6.5-6.9\% relative to 5.0-5.4\%. However they do not find evidence of an explicit threshold effect of A1c.
} 
recommendation of a diagnosis of diabetes if a patient's A1c is greater than or equal to 6.5\% (American Diabetes Association, 2010). ${ }^{10}$ Once diagnosed, recommended care includes a comprehensive medical evaluation to form a care management plan, annual diagnostic tests (urinary albumin, lipid panel, glomerular filtration rate) to detect comorbid conditions or complications, A1c monitoring at least twice per year, antidiabetic medication, statin therapy (for those age 40 and above), ${ }^{11}$ annual assessment for diabetic retinopathy by an ophthalmologist, annual comprehensive foot evaluation, and receipt of flu, pneumonia, and hepatitis B vaccines (American Diabetes Association, 2017). Patients are also advised to engage in regular exercise (2-3 times per week), decrease sedantary behavior, eat a healthful diet, and quit smoking if relevant. In addition, the ADA recommends that patients with diabetes receive more aggressive treatment for comorbid conditions. For example, patients with diabetes with blood pressure above $140 / 90 \mathrm{mmHg}$ should have prompt initiation of drug therapy at the "maximum tolerated dose" to achieve blood pressure goals, while patients at high risk for kidney disease require additional monitoring and treatment.

Because individuals with A1c values falling just below or above the 6.5 threshold have similar underlying health, we can use the cutoff in diabetes classification to evaluate the impact of receiving a diabetes diagnosis on the health care utilization and associated costs, health, and behaviors for patients at the margin of being diagnosed. Patients whose A1c falls below 6.5, but at or above 5.7, are considered to have "pre-diabetes," with impaired glucose tolerance and at a higher risk of developing diabetes in the future. As such, they also receive some care aimed at lowering their risk for developing diabetes; specifically, the ADA recommends that the patients have their A1c tested annually and that the provider counsel them to make lifestyle changes such as losing weight and increasing exercise. The ADA also recommends that drug therapy should be discussed as an option for certain risk groups (e.g., those with a BMI of at least 35). Our analyses will document the average difference in utilization and spending for individuals on the margin of receiving diagnoses of pre-diabetes versus diabetes.

Understanding the effect of a diabetes diagnosis for a marginally diagnosed patient is particularly interesting because of the underlying distribution of A1c in the population of those who are tested. In our data, comprised of claims from a large health insurer, among patients receiving a test and whose A1c level meets the diagnostic threshold for diabetes, over 25 percent have a blood test between $6.5 \%$

\footnotetext{
${ }^{10}$ Beginning in 2011, the ADA guidelines specify a value of $6.5 \%$ or higher on two separate tests be used to diagnose diabetes, unless the patient exhibits "unequivocal" hyperglycemia. However, in practice, we do not find that patients are receiving multiple tests. For example, in our data, less than $0.5 \%$ of patients who received an A1c value of 6.5 received a follow-up test within two weeks.

${ }^{11}$ This guideline for statin therapy was recommended in 2013 by the American College of Cardiology and the American Heart Association and confirmed by the American Diabetes Association at the end of 2014.
} 
and $6.6 \%$, inclusive. Although these patients are the healthiest within the diabetes group, they have the potential to have an outsized impact on total spending because of their large numbers. In addition, most discussions about changing treatment guidelines involve adjusting diagnosis criteria around the "margins" of existing rules.

\section{Data}

\subsection{OptumInsight Claims}

To assess the impact of a diagnosis on health care utilization and spending, self-reported health and healthy behaviors, and subsequent lab values (blood sugar and total cholesterol), we use the OptumInsight (Optum) database from 2009 to 2017. ${ }^{12}$ Optum provides claims data from a large health insurance company; over our sample period, 61 million patients are included in these data. The data include all claims associated with these patients that are paid for by the health insurance company. The claims data include procedure and diagnosis codes, as well as the date the procedure occurred and the cost of the claim (including the amount paid by the patient and by the insurance company); for pharmacy claims, the data include the national drug code, quantity dispensed, and cost. Additionally, the data contain some limited information on demographic characteristics of the patient, such as age and gender. Optum data are primarily composed of private or employer-sponsored health insurance plans, but includes some Medicare Advantage plans as well (see Table 1).

When an A1c test is used for diagnosis, the provider sends a blood sample to a lab for evaluation. In the Optum data, we observe the lab test results for laboratories that are affiliated with Optum. We do not observe test results for unaffiliated laboratories, although we do see spending associated with these tests. In nearly all cases, lab test results are rounded to the nearest 0.1 percent; for the small number of lab results that are reported with greater precision, we round to the nearest 0.1 percent so the data are comparable across all labs reported.

The data include unique patient identifiers that allow us to track patient spending and utilization over time. We are able to track patient spending if patients change insurance plans as long as the insurance plan is offered by an insurance company associated with Optum. If patients drop their insurance coverage, or switch to an insurance plan offered by a different company, we are no longer able to observe them in the data. However, Optum provides records of patients' enrollment, so we

\footnotetext{
${ }^{12}$ Although OptumInsight data are available for earlier years, we use only individuals with the initial A1c test taken in 2009 or later because this was the first year that the A1c test was recommended for the diagnosis of diabetes.
} 
can distinguish patients who dropped coverage from patients who had no claims in a given year. We do not find any evidence of differential attrition from the sample based on A1c value relative to the diagnosis threshold (see Section 5.2). Therefore, as described in more detail below, we include patients in analyses for all years when they are enrolled in an Optum plan, regardless of whether they exit at a later point during the sample period. In Section 5, we examine the sensitivity of our estimates to restricting the analysis to members enrolled during the entire sample period.

To construct our sample, we pull all adult patients in Optum who have an A1c test at an Optum affiliated lab during our study period. From this group, we drop individuals who had a diagnosis of diabetes on their claim at any time before their first observed A1c test in order to eliminate patients who are receiving the test for monitoring, rather than the diagnosis of, diabetes. ${ }^{13}$ We also exclude individuals with a pregnancy-related diagnosis during the year prior to their first A1c test in order to drop cases associated with gestational diabetes, which has different treatment and diagnostic guidelines than type 2 diabetes (Vandorsten et al., 2013). We further restrict to patients who are in the sample at least 12 months prior to and 12 months following the initial lab test in order to observe their annual spending before and after the test. This leaves us with 142,541 patients in year 1 (the calendar year following the initial lab test). Figure A1 in the Appendix provides a diagram of our sample definition with patient counts for each exclusion criterion.

We observe patients for up to 6 years following their initial test. For subsequent years following the initial test, we require that patients are enrolled in an Optum plan for at least half the year to be included in the analysis. We define year relative to the date of the initial test. For example, if an individual was tested on March 1, 2010 we would consider the first year after the test to be March 2, 2010 through March 1, 2011. For patients enrolled in an Optum plan for less than a year, we scale their spending proportionally to their enrollment time in order to annualize the outcome. For example, if the patient is enrolled for 6 months and spends $\$ 300$, we double spending to $\$ 600$ to account for the fact that we observe only one half of the year's spending.

In our first stage analysis, we estimate the change in the diagnosis of diabetes at the A1c cutoff value of $6.5 \%$. We define the diagnosis of diabetes as the presence of any claim with a diagnosis code for diabetes during the first year following the test. In later analyses, we also examine how the likelihood of diagnosis evolves over time by looking at the cumulative likelihood of diagnosis through year 2, year 3, etc. Our primary outcome measures look at spending for all types of care

\footnotetext{
${ }^{13}$ Although we are examining A1c tests starting in 2009 only, we have Optum claims dating back to 2001 and the entire period of claims data is used to implement this sample restriction.
} 
recommended for patients with diabetes by the American Diabetes Association (ADA). This includes doctor office visits and consultations related to diabetes; spending on diabetes-controlling drugs such as metformin; spending on two other types of drugs that are commonly prescribed for diabetes: statins and ACE inhibitors; lab tests for relevant conditions; and spending related to vision testing for diabetic retinopathy. We examine total spending on recommended care as well as each category individually. We also examine spending on endocrinology specialty care, which is not specifically recommended, but that may be affected by a diabetes diagnosis. In addition, we evaluate how receiving a diagnosis affects the quantity of care received by looking at the number of diabetes-related visits, the number of A1c or glucose lab tests, indicators that either of these two outcomes are positive, and an indicator for the presence of any spending on diabetes-controlling drugs.

Next, we evaluate changes in diabetes-related conditions and overall health at the cutoff. We first examine indicators for diagnoses of five conditions associated with uncontrolled diabetes: diabetic retinopathy, neuropathy, kidney disease, diabetic coma, and diabetic ketoacidosis. Finally, we examine changes in individuals' A1c scores and total cholesterol from their baseline levels taken on the date of the first test (for A1c) or the year prior to the first test (for total cholesterol). Individuals with initial A1c test values just above the diagnostic cutoff have a significantly greater number of A1c tests in subsequent years but are not more likely to have any A1c test (see Appendix Table A17). To address this, we randomly select one A1c test per individual per year. For consistency across measures, we similarly select a random total cholesterol value in each year following the initial A1c test, although there does not appear to be a statistically significant larger number of tests for this measure at the diagnosis cutoff (see Appendix Table A17). Since we require individuals to be in the sample for at least one year following the initial test, we examine mortality in years 2 and later. Additional details on the diagnosis and procedure codes used to construct the outcome variables may be found in Appendix Table A1. Table 1 presents descriptive statistics for the Optum patients in the left panel. Of these patients, 52 percent are female, average age is 51.1 years, and 28 percent are enrolled in a Medicare Advantage plan with the remaining on individual private plans (such as those purchased from the Affordable Care Act health insurance exchanges) or employer-sponsored insurance. Women are slightly over-represented relative to men, likely because screening is recommended for women with a previous diagnosis of gestational diabetes. 


\subsection{Health Risk Assessment Data}

A small subset of Optum enrollees completes a Health Risk Assessment (HRA) survey in any given year. ${ }^{14}$ This survey asks a wide range of questions about self-assessed health and behaviors and is typically administered by the insurance company at the behest of an employer. As such, patients who take the HRA are not necessarily representative of patients in the Optum database. The middle panel of Table 1 presents statistics for the HRA sample. Because the HRA tends to be administered for employers, the sample is composed almost entirely of individuals enrolled in private (non-Medicare) insurance plans. This sample is also somewhat younger (44.2 years old on average) and more female (55.4 percent). However, the characteristics of individuals who take the HRA appear to be balanced across the A1c threshold (see Section 5). Therefore, our estimates provide an internally valid measure of these self-assessed outcomes within the HRA subsample.

A full list of variables considered from the HRA is found in Appendix Section 2. In order to avoid conducting an excessive number of statistical tests, which might generate a large number of false positives, and to improve our statistical power, we construct four summary indices for the following question domains: self-assessed health, physical and emotional well-being, healthy diet and exercise behavior, and smoking and drinking behavior. We do this by constructing a standardized z-score (subtracting the mean and dividing by the standard deviation) for each component and taking the average. This applies equal weight to each index component and is similar to the approach used in Finkelstein et al. (2012) and Kling et al. (2007). Positive values of the index indicate better outcomes (i.e., better health or lower rates of unhealthy behavior).

\subsection{Electronic Health Records Data}

We supplement our analysis of the Optum data with information on additional health outcomes from electronic health records (EHR) for patients receiving care in the University of California, Los Angeles health system. UCLA implemented its current EHR program CareConnect, which uses Epic Systems technology, on March 2, 2013. Our analysis uses UCLA data available after this date through 2016. Like the Optum data, the UCLA data allow us to follow individual patients over time. We are able to track a patient as long as they continue to have encounters within the UCLA health system, which includes two large hospitals and over 170 primary care and specialty practices. There are records for

\footnotetext{
${ }^{14}$ Since HRA survey responses are typically observed only once per year, we do not impose the 6-month enrollment requirement described above for the Optum claims data; we include any patient with a survey response in any given year for analyses using the HRA data.
} 
approximately 1.2 million distinct patients during this period and these data include clinical health measures recorded any time a patient visits a UCLA medical provider. We limit our sample to patients with a primary care provider (PCP) at UCLA in order to increase the likelihood that we observe their ongoing care. We explore differential attrition in Section 5.2 below.

We construct an analytic sample using similar criteria to those used with the Optum data (see appendix for additional details and Appendix Figure A2 for a flowchart). We present results for individuals with A1c tests conducted in 2013 and later, allowing for up to 3 years of follow up. Our outcomes of interest are two measures that are collected for a large percent of patients: body mass index and blood pressure. The data also include some information on utilization of services (number of encounters within the UCLA system), diagnoses, procedures, and prescription drugs, although they do not include cost measures.

Descriptive statistics from the UCLA data are presented in the third column of Table 1. The individuals in the UCLA data are relatively similar to those in the Optum data, although the average age at first encounter is slightly lower at 47.2 years and small shares of the sample pay for care with Medicaid or out of pocket.

\section{Empirical Strategy}

We use a regression discontinuity (RD) design framework to analyze the impact of a diagnosis of diabetes across patients with similar underlying health. This is an example of a "fuzzy" regression discontinuity design since a diabetes diagnosis may depend on patient- and physician-specific factors separate from an A1c value. We estimate two versions of this model. The first version is a "reduced form" model that looks at the change in the outcome at the cutoff. The second version is an instrumental variables estimate of the effect of receiving a diagnosis of diabetes, using the diagnostic cutoff as an instrument for being diagnosed. To implement these analyses, we use local linear regression and the Fuji et al. (2009) optimal bandwidth selector, although we also assess the sensitivity of our results to alternative specification and bandwidths.

If all patients with A1c values below the cutoff were not diagnosed with diabetes, and all patients above the cutoff did receive a diagnosis, the reduced form and IV estimates would be identical. However, the change in the prevalence of a diagnosis does not change from 0 to 1 at the $6.5 \%$ threshold. As will be seen in the analysis that follows, a non-trivial share of patients with an A1c value below the threshold receive a diabetes diagnosis within the first year. This may be due to physician discre- 
tion, but it may also the result of a later positive test. Clinical guidelines recommend that physicians repeat the test in 3 to 6 months for patients with test values close to the threshold (American Diabetes Association, 2018a).

It is also the case that a sizeable share of individuals with values above the cutoff do not receive a diabetes diagnosis. This may also result from physician discretion in assigning a diagnosis, but it could also be due to measurement error. For instance, if physicians do not record the diagnosis of diabetes on the claim or medical record, or a patient does not seek additional care after learning about the diagnosis (and thus never generates additional claims), we would not be able to observe that the patient is diagnosed. That is, some patients may not appear to have received the diagnosis when, in fact, they did. In this case, our first stage would be attenuated and the IV estimate biased upwards, as it scales the reduced form estimate by the observed (not actual) change in diagnosis prevalence. To explore this further, we conduct a bounding exercise for the IV estimate in Appendix Table A14 that assumes that all patients with A1c values at 6.5 and above receive a diabetes diagnosis, regardless of whether we observe a diabetes diagnosis in their claims or medical record. This approach naturally results in a larger first stage and smaller IV estimates; however, our results still indicate that meaningful increases in spending occur at the diagnosis cutoff.

A potential concern about the validity of our design is whether or not patients or physicians can manipulate the test score in some way so as to generate selection across the threshold. However, due to the nature of the test, this is unlikely in our setting. The patient's A1c reflects the plasma glucose levels of the patient during the past 3 months, making the test difficult to manipulate with short term changes to diet or exercise. In addition, the test values are reported to Optum or recorded in the patient's medical record directly from the lab, making physician or patient manipulation impossible.

The absence of manipulation is also apparent in the first panel of Figure 1, which shows the sample size in the Optum data for each A1c value from the initial lab test. There are three noticeable features. First, the density is smooth across the threshold, with no apparent evidence of bunching on either side. Second, given the shape of the distribution of A1c values within the population of test takers, a substantial fraction of patients whose A1c is at or above the threshold fall very close to the threshold. Indeed, 15 percent of patients with A1c at or above 6.5\% in the Optum data have an A1c of $6.5 \%$ exactly; over 25 percent have an A1c value of $6.5 \%$ or $6.6 \%$.

We see similar patterns in the EHR data, presented in the second panel of Figure 1. The UCLA sample appears healthier overall, with more of the distribution falling in the normal A1c range. This 
could reflect differences in the underlying health of the UCLA population relative to the national population captured in the Optum database, or it could reflect more aggressive A1c testing within the UCLA health system. While these differences do not affect the internal validity of our estimates, they could affect the generalizability of the results to other settings.

An initial investigation revealed that there were some differences in baseline (pre-test) outcomes measured during the year prior to the lab test associated with the diagnosis cutoff in the UCLA data. We did not see a similar pattern in the Optum data (see later discussion of these tests in Section 5.1). To account for this, we control for pre-test values of the outcome variable in all models with the UCLA data. Similarly, the RD figures for this data source plot the residual from a regression on the pre-test outcome measures.

\section{Results}

\subsection{Short Run Effects: Year 1}

We first analyze the impact of having an A1c value exceeding the $6.5 \%$ threshold on diabetes diagnosis and medical care spending in the first 12 months following the initial lab test. The first panel of Figure 2 plots the rates of diagnosis by A1c value for the year following the initial test. We see a large and discontinuous increase in diagnosis rates at the cutoff value of $6.5 \%$. At the $6.5 \%$ value, diagnosis rates jump by over 10 percentage points. The second panel of Figure 2 shows average spending on all recommended diabetes care. Here, we observe a clear discontinuous increase in spending at the diagnosis threshold. The subsequent panels show the results for spending on specific types of diabetes-related care: office-based care (consultations and evaluation), vision care, lab test spending, and endocrinology specialty care. We observe noticeable jumps in all outcomes, although spending on endocrinology specialty care is particularly noisy.

Figure 3 displays similar graphs for two other measures of utilization: number of diabetes-related office visits and number of labs for glucose or A1c. The figure also displays graphs for spending on drugs that are commonly prescribed to patients with diabetes: antiglycemic medications such as metformin, statins, and ACE inhibitors. We observe noticeable jumps for the first two outcomes, but less evidence of an increase in prescription drug spending in the first year. Because the first-line diabetes controlling drug, metformin, is available as an inexpensive generic (about $\$ 4$ for a 30-day supply), it may be difficult to observe spending increases even if use of this drug increases. For that reason, we also examine an indicator that the patient has any spending for a diabetes-controlling drug; 
this indicator exhibits a small but less obvious jump at the diagnosis threshold. In the next two plots, we see some evidence of an increase in spending for statins and ACE inhibitors, with a larger jump for the latter drug.

Table 2 presents the local linear regression estimates associated with the outcomes in Figure 2. We see a statistically significant increase in the presence of a diabetes diagnosis of 10.8 percentage points (row 1). The next row shows the effect of crossing the diagnosis threshold on spending on recommended care, as defined by the ADA recommendations. At the cutoff of A1c equal to 6.5\%, we observe a discontinuous increase in spending of $\$ 208$. We scale this increase in spending by the fraction of the sample who gain a diagnosis of diabetes at the cutoff with an IV estimate in column 2. This estimate shows that a diagnosis of diabetes is associated with approximately $\$ 1,097$ of additional spending on recommended care. ${ }^{15}$ When we break this spending down into subcategories, we see that the spending increase in the first year is split primarily between office consultations and evaluations, which exhibit an increase of $\$ 508$ associated with a marginal diagnosis, and spending related to lab work, which experiences an increase of $\$ 505$. We also see a significant increase in spending related to screening for diabetic retinopathy, of \$28 in the first year. In addition, we estimate a marginally significant increase in spending on endocrinology specialty care (\$139) among the marginally diagnosed.

Table 3 presents similar results for the additional measures of utilization and drug spending. We find that a diagnosis of diabetes is associated with about 3 additional office visits for diabetes-related care in the 12 months following diagnosis and about 0.4 more A1c or glucose labs. A diagnosis of diabetes also significantly increases the probability that a patient takes a diabetes-controlling drug by 4.3 percentage points. We also find increases in total spending on ACE inhibitors, but no significant effect on spending on statins or the amount spent on diabetes-controlling drugs.

We next examine complications related to diabetes and health outcomes in the Optum data. Figure 4 shows the effect of receiving an A1c value above the diabetes diagnosis cutoff on the incidence of preventable conditions associated with diabetes: diabetic retinopathy (eye damage), diabetic neuropathy (nerve damage), diabetic kidney disease, ketoacidosis, and diabetic coma. The incidences of diabetic neuropathy and diabetic kidney disease appear to increase at the A1c cutoff. This is not necessarily surprising given that the ADA guidelines stipulate that much of the recommended care for diabetes involves screening for these conditions. Changes at the cutoff in rates of ketoacidosis and diabetic coma are substantially noisier and harder to discern; these conditions are more serious and

\footnotetext{
${ }^{15}$ Note that because the bandwidth selector chooses a different bandwidth for every outcome based on the variance of that outcome, the "first stage" varies across rows.
} 
also very rare. The remaining panels display the results for the direct health outcomes we measure in the Optum data: change in A1c from the initial test value, change in total cholesterol from pre-test values, and mortality. There appears to be a larger negative value in the difference between current and initial A1c levels, indicating greater improvement relative to the initial test for those above the cutoff $^{16}$ relative to those just below. We see no visible evidence of a change in mortality.

The associated estimates are reported in Table 4 . We find statistically significant increases in the diagnoses of retinopathy, neuropathy, and diabetic kidney disease, but no change in the two most life-threatening (and rare) complications associated with diabetes, ketoacidosis and diabetic coma. The bottom two rows of Table 4 present the results for the health outcomes derived from the Optum claims data. First, we look at the change in A1c from the initial test for patients who received an A1c test from an Optum-affiliated laboratory (i.e., for patients for whom we can observe the lab result). We see that A1c relative to the prior year falls by about 0.06 percentage points for patients at the cutoff, and is associated with a reduction in A1c of about 0.34 percentage points for the marginally diagnosed. For context, metformin, a drug commonly provided to newly diagnosed patients with diabetes, typically lowers A1c by a bit over 1 percentage point in clinical trials (Hirst et al., 2012), so a reduction in A1c of 0.34 is within the range of what might be expected with the initiation of drug therapy. We find no effect on changes in total cholesterol (relative to levels observed prior to the initial test), nor do we find an effect on mortality.

The results from the Optum claims data demonstrate substantial increases in spending associated with the A1c $6.5 \%$ cutoff value, indicating that patients with otherwise similar underlying health are treated differently depending on where their A1c falls relative to the diagnostic guideline. Next, we evaluate whether these additional interventions affect other clinical measures of health reported on the UCLA electronic health record. We examine the effect of a diabetes diagnosis on BMI, systolic, and diastolic blood pressure. Since patients often have more than one reading for each of these measures during a given year, we use the average value. We also create binary variables indicating that BMI falls in the "normal," "overweight," or "obese" range, and that blood pressure falls in the "high blood pressure" range. ${ }^{17}$

\footnotetext{
${ }^{16}$ Recall that those right below or right above the cutoff are equally likely to receive any A1c test, but those right above the cutoff tend to receive more A1c tests in a given year (see Appendix Table A17). We address this by selecting one A1c test result at random for those with more than one A1c value available.

${ }^{17}$ We define high blood pressure as 140/90 millimeters of mercury $(\mathrm{mm} \mathrm{Hg})$ and higher, which was the definition at the start of our project. The guideline for diagnosis by the American Heart Association and the American College of Cardiology has since been updated to 130/80 mm Hg, although 140/90 mm Hg is the cutoff used for Stage 2 Hypertension (American College of Cardiology, 2017).
} 
The figures associated with these outcomes, as well as a plot for the diagnosis of diabetes, are presented in Figure 5. Despite a large increase in diabetes diagnoses, there is no visible change in any of the clinical health measures at the cutoff. Table 5 presents the regression discontinuity estimates from this analysis. In the first row, we find a significant increase in the diagnosis of diabetes at the cutoff A1c value of 29 percentage points. In the subsequent rows, we show that the diabetes diagnosis is not associated with changes in any of the health outcomes. The estimated coefficients are small relative to the control mean and statistically insignificant.

Finally, we examine the effect of diabetes diagnosis on measures of self-reported health and healthy behaviors in the Optum Health Risk Assessment (Figure 6 and Table 6). As with the other two samples, we observe a significant increase in the incidence of diabetes diagnosis in this sample (by 16 percentage points). However, we do not find any statistically significant changes in selfreported health or healthy behaviors associated with the diagnosis of diabetes. In fact, the direction of the coefficient estimates suggest that the marginally diagnosed report worse subjective health and healthy behaviors. Results for the components of these indices also indicate no effect of diagnosis on self-reported health or behaviors; these are reported in Appendix Table A2.

\subsection{Medium Run Effects: Years 2 through 6}

The initial effects of a diabetes diagnosis may not persist if, for example, those with A1c values directly below the cutoff gain a diagnosis relatively soon after the initial test. Therefore, we first examine the likelihood of later diagnosis in each year. We also examine the persistence of spending and health effects by re-estimating our IV model using outcomes from years 2 to 6 following the initial test. These estimates demonstrate how a diagnosis in year 1 affects spending in subsequent years.

Figure 7 shows how diagnosis and spending evolves over time, in years 2 through 6 following the initial lab test. The first panel shows the reduced form estimates on the probability of ever being diagnosed with diabetes by each subsequent year. After the initial year, the difference in diagnosis rates across the threshold closes somewhat but does not entirely disappear until year 6; we observe significantly higher diagnosis rates 3 years after the initial test and positive point estimates for the first 5 years.

The second panel of Figure 7 shows the effect of diagnosis in year 1 on spending on subsequent years (i.e. IV estimates). In contrast to the diagnosis estimates, which show convergence between the marginally diagnosed and marginally undiagnosed, we see fairly stable impacts of a year 1 diagno- 
sis on spending on recommended care in each subsequent year, with little evidence that the gap in spending between those above and below the threshold closes. The estimates become less precise due to some individuals leaving the sample over the study period, but we see consistently positive effects for all years and a statistically significant effect even five years after the initial test. Our estimated effects on spending related to lab and office-based care are similarly stable over time. Spending on vision care for retinopathy screening appears to increase over time, with higher spending observed in later years. In contrast, spending on endocrinology specialist care is not consistently higher in the years following the initial test.

We document similar results when examining the effect of a diabetes diagnosis on our other utilization measures in Figure 8. The increased number of diabetes-related office visits and glucose/A1c labs remain stable, for the most part, for all 6 years following the test. The effect of a diagnosis on spending on diabetes-controlling drugs increases over time, as does the probability a patient takes any diabetes-controlling drug. In contrast, we do not find any evidence that statin or ACE inhibitor spending are larger in years 2-6 as a result of diagnosis.

Overall, our results using claims data show large increases in spending and use of care among those marginally diagnosed in year 1 . These spending increases stay relatively stable or, in the case of drug spending and vision care, appear to grow larger over time. This pattern is consistent with physicians delaying pharmacologic treatment if first recommending lifestyle changes, or starting with the inexpensive first-line therapy (metformin) and later switching to more expensive drug therapies. These results also support the hypothesis that receiving a diagnosis puts a patient on a path to persistently higher spending.

Next, we examine how the impact of a diabetes diagnosis affects the diagnosis of complications related to diabetes and health as measured in the Optum dataset. These results, displayed in Figure 9, show significantly higher diagnoses of neuropathy and diabetic kidney disease in year 2. Subsequent years show neither statistically significant increases nor reductions in the rates of complications related to diabetes. Note that because ketoacidosis and diabetic coma are rare conditions and we have smaller samples in later years, we are unable to estimate an effect of diabetes diagnosis on these conditions after five years (for ketoacidosis) or four years (for diabetic coma) following the initial test due to insufficient variation to compute the optimal bandwidth. The estimates show no change in these conditions, although the effect for later years is imprecisely estimated. Finally, the last four panels of Figure 9 show the effects on changes in A1c, total cholesterol, and mortality in the years following 
the test. In contrast to the spending effects, which persisted over the entire period, the improvement in A1c observed in the first year does not continue in subsequent years. We also do not observe any changes in total cholesterol or mortality in subsequent years.

We also use the EHR data to evaluate whether improvements in clinical health emerge in later years. For these measures, we observe only 3 years of data after the initial test. Effects are similar across all three years, indicating no health improvements associated with a diabetes diagnosis for marginal patients (Figure 10). Finally, we look at the impact of a diagnosis on the self-reported outcomes in the health risk assessment survey. We continue to find no statistically significant effect on these outcomes in subsequent years, but our confidence intervals are large. These results are reported in the Appendix in Figure A3.

To summarize, we find that the diagnosis of diabetes for individuals with A1c values just above the diagnosis cutoff leads to greater spending on diabetes-related medical care. This spending increase is not only present in the year following the test but persists over time. Our point estimates suggest a cumulative $\$ 8,107.86$ in additional spending on recommended care over 6 years, in present value terms. We can use this estimate in a back-of-the-envelope calculation to explore how tightening the diagnosis threshold, from $6.5 \%$ to $6.6 \%$, would affect total U.S. spending on diabetes-related care. The ADA estimates that 1.4 million individuals are newly diagnosed with diabetes each year. If we assume that the distribution of A1c values among the population being tested is similar to that observed in the Optum data, this suggests that 15.4 percent, or 216,000, of these individuals have A1c values of $6.5 \%$. Moving the diagnosis threshold to $6.6 \%$ would, therefore, be expected to decrease diabetesrelated spending over the next 6 years for each of these individuals, for a total reduction in spending of $\$ 1.75$ billion $(=\$ 8,107.86 \times 216,000)$. This calculation assumes that spending is only elevated for the initial 6 years following a diagnosis and falls to zero in subsequent years. A similar exercise may be performed for a scenario that relaxes the diagnosis cutoff from $6.5 \%$ to $6.4 \%$. Assuming that the change in spending would be similar for the newly and previously marginally diagnosed, this would suggest an increase in spending of $\$ 2.4$ billion associated with the nearly 300,000 additional individuals who would be diagnosed each year. 


\section{Specification Checks and Additional Analyses}

\subsection{Checking for Discontinuities in Baseline Characteristics}

The regression discontinuity model relies on the assumption that patients with A1c values near the threshold differ only in the way they are treated by the medical system; i.e., that there are no systematic underlying differences between patients with A1c values just above and just below the $6.5 \%$ cutoff. We can assess this empirically by evaluating whether there are discontinuities in demographic characteristics, spending, and health measures at the cutoff in the year prior to the initial test. These variables are not expected to change at the diagnosis threshold, providing a check on the assumption behind our research design. If we find discontinuities in these characteristics, it suggests that there may be pre-existing differences in individuals above and below the cutoff.

We conduct this test by evaluating whether age, gender, race (available in the EHR sample only), and insurance type (Medicare versus non-Medicare) change discontinuously at the cutoff (results in the top panel of Table 7). In the second panel, we conduct a similar test using spending measures observed in the year prior to the initial lab test. We examine total spending, spending on recommended care, statins, ACE inhibitors, and endocrinology specialty care. We operationalize this test by using each of these demographic, insurance, and spending characteristics as a dependent variable in our reduced form model for each of the study samples.

We do not find statistically significant discontinuities in any of the five demographic characteristics we consider, although we do find a statistically significant reduction in Medicare coverage and baseline total spending at the cutoff in the Optum sample. This indicates that individuals with A1c values just above the cutoff had less medical spending in the year prior to the test and were slightly less likely to have Medicare coverage. To evaluate whether these differential characteristics affect our results, we have re-estimated our spending models to include these covariates. The inclusion of these variables have little effect on our results, suggesting that the spending effects are not driven by differential baseline characteristics (see Appendix Tables A3 and A4). We do not see any significant effects in the other four spending variables we examine. Taken together this information suggests that there are not systematic differences in patient characteristics at the diabetes diagnosis threshold that are confounding our analysis.

As mentioned earlier, we did find evidence of pre-existing discontinuities in outcomes during the baseline year for the UCLA clinical health measures. For this reason, we have included baseline mea- 
sures as control variables in our regression analyses with the UCLA data. We are unable to rule out, however, that there might remain some unobserved differences in the characteristics of individuals on either side of the cutoff.

\subsection{Sample Attrition}

\subsubsection{Testing for Discontinuities in Sample Inclusion by Year}

The sample sizes for our analyses decline with each year of observation for two reasons. First, the length of follow up for each patient depends on the timing of their initial A1c test. For example, if a patient has her initial test in 2016, we are only able to observe one post-test year (2017), so the patient will not be in the sample for regressions that estimate effects in year 2 and beyond. Second, both our Optum and UCLA samples are comprised only of patients who are associated with these organizations. Some patients leave Optum-associated plans or the UCLA health care system before the end of our study period. These types of attrition should only be a concern for our research design to the extent that patients on either side of the cutoff are differentially more likely to exit the sample over time. For example, if a diabetes diagnosis causes patients to switch out of Optum-associated plans or out of the UCLA health system, this could affect the interpretation of our outcomes for later years.

We test for differential attrition and report the results in Table 8. Our dependent variable in these models is whether or not the individual appears in the sample in each subsequent year (i.e. years 2-6). We find no significant discontinuities in the probability of attrition for either the UCLA or the Optum sample, demonstrating that selective attrition out of the sample based on A1c relative to the diagnosis cutoff is unlikely. The results from these tests indicate that differential selection at the cutoff is not a threat to the internal validity of our estimates. We should note, however, that it is necessarily the case that the estimates of the long-term effects of diagnosis rely on the sample of patients who were tested during the earlier part of the sample period. To the extent that the treatment of diabetes (or pre-diabetes) has changed since 2009, this limits the generalizability of the results to individuals who are currently screened for diabetes. However, we have little reason to think that physician practice has changed noticeably since $2009 .^{18}$

\footnotetext{
${ }^{18}$ Practice guidelines for the treatment of diabetes have not changed considerably since then; essentially the only practice guideline that meaningfully changed was the recommendation to initiate statin therapy for all patients with diabetes age 40 and older regardless of cholesterol levels beginning in 2013.
} 


\subsubsection{Balanced panel}

Although we find no evidence of sample attrition associated with the diagnosis cutoff, it could be the case that individuals who remain in our sample all six years vary systematically from those we only observe for one or two years. As a result, the effects we estimate in years 2-6 following the initial lab test may reflect changes in the underlying sample rather than time-varying treatment effects. We examine this by comparing the results obtained from our main (unbalanced) sample, from those we

obtain when we restrict the sample to only those who remain enrolled all 6 years (balanced). The results of this exercise are presented in Figures 11 and 12, which plot the coefficient in each year for the unbalanced panel (black) against those obtained in the balanced panel (red). We provide results just for the spending and utilization outcomes, given the low rates of mortality and some of the preventable conditions, and the relatively small size of the balanced panel. Although the balanced panel has much larger confidence intervals, the point estimates indicate that diagnosis rates and spending are similar across the two samples. Similar analysis of the UCLA (Figure 13) data shows that results remain null for all three years in the version of the sample that uses a balanced panel. Based on these analyses, there do not appear to be systematic differences in the effect of diabetes diagnosis across the groups that remain in the sample continuously and the main sample.

\subsection{Alternative Specifications, Samples, and Variable Definitions}

In this section, we conduct several additional analyses to probe the robustness of our results to different variable definition and model specification choices. First, we examine the extent to which the increase in diabetes-related care represents new utilization, or simply a different focus or style of treatment that largely occurs during interactions with the health care system that would take place regardless of the diagnosis. For example, diabetes and non-diabetes patients may have the same number of office visits, but diabetes patients receive information and treatment specific to their illness and physicians now code these visits as diabetes-related. We assess this in two ways. First, we look at the total number of office visits for evaluation and management and total spending on this category, including visits unrelated to diabetes. These results are presented in the first panel in Appendix Table A5. We find no significant change in the total number of office visits or total spending on office visits, despite the fact that we see increases in visits and spending for diabetes-related care; our standard errors are such that we cannot reject that large increases or decreases occurred. This suggests that, at least for office visits, diabetes-related care could be delivered in the context of existing health care interactions. 
Next, we examine diabetes-related care that more clearly represents new utilization by focusing on the elements of recommended care that are not identified by a diagnosis code: spending on statins, ACE inhibitors, diabetes-controlling drugs, endocrinology specialist care, and spending on glucose labs. Among this subset of recommended care, we find that diagnosis results in a statistically significant increase in spending of about $\$ 250$ in the first year, which represents about one-quarter of our main spending estimate. Thus, we find clear evidence of an increase in "new" utilization associated with a diabetes diagnosis, although we are unable to rule out that some care is provided in the context of office visits that may have otherwise occurred in the absence of diagnosis.

We next conduct additional analyses to compare the UCLA EHR and Optum data results. Since these are very different samples, the lack of health effects in the EHR data may be less likely to translate to the Optum setting if the treatment patterns for diabetes diagnosis are very different. While, the UCLA EHR data do not contain information on spending (making it difficult to produce similar estimates as those presented in Table 2 for the Optum sample), they do contain some information on utilization that can be used to assess changes at the cutoff. The effect of a diabetes diagnosis on such utilization measures are presented in Appendix Table A6. We find that a diagnosis of diabetes is associated with 4.5 additional ambulatory encounters for diabetes care, 0.4 additional A1c labs, and a 14 percentage point increase in the probability of taking a diabetes-controlling drug during the first 12 months following the initial test. These estimates are similar to those in the Optum sample and indicate a clear increase in utilization following diagnosis. In addition, the EHR data allow physicians to note health problems of patients on a "problem list." In addition to seeing a higher probability of having a diabetes diagnosis associated with an encounter, we see a higher probability that diabetes is on a patient's problem list at the diagnosis cutoff. The probability of a diabetes diagnosis on the problem list increases by 31 percentage points for the marginally diagnosed.

Next, we assess the robustness of our results to using a quadratic model and alternative bandwidths in the local linear model, reported in Appendix Tables A7-A10. In the first column, we rereport the results from our main reduced form specification to facilitate comparison. We then report the results from a model that estimates the RD effect using a quadratic in initial lab value that is allowed to vary at the cutoff. Results with this model are very similar to our baseline estimates for most outcomes in the Optum data (Appendix Tables A7-A8). We no longer find a decrease in A1c associated with diabetes diagnosis in the first year, however. Subsequent columns show the results for larger (twice) and smaller (one half) multiples of the optimal bandwidth. Results are very similar both 
quantitatively and qualitatively when alternative bandwidths are used, although larger bandwidths tend to result in somewhat larger estimates. For our estimates of the change in A1c from its baseline value, however, we find a larger decline under a smaller bandwidth, suggesting that the difference in values is most apparent for those individuals closest to the threshold. The estimates for preventable conditions, clinical health measures, and self-reported health measures (Appendix Tables A9-A10) look, for the most part, similar across specifications.

We also examine the sensitivity of our results to our sample inclusion criteria. In particular, we require that individuals be enrolled in an Optum plan for at least 1 year prior to their initial A1c test so that we can adequately assess whether they have previously been diagnosed with diabetes. It may be the case, however, that some individuals in our sample were misclassified as having no diabetes diagnosis prior to their first test when, in fact, they had already been diagnosed. This might be the case if, for example, they were diagnosed before entering the Optum data. In Appendix Tables A11 and A12, we conduct our analysis but only include those who were enrolled in an Optum plan for 2 years prior to the initial test. Approximately 70 percent of our main analytic sample met this criterion. Our spending results are very similar, indicating that our initial sample definition likely performed well at excluding those who were already diagnosed with diabetes. When we implement similar sample criteria in the UCLA data, we estimate a larger first stage with a 41 percentage point increase in diagnosis, but still find no evidence of health effects (Appendix Table A13). Omitted here in the interest of space, results on self-reported health and healthy behaviors are also similar under this sample refinement.

Finally, we conduct a bounding exercise to determine a lower bound on the treatment effect of receiving a diabetes diagnosis on spending. If doctors are not recording the diabetes diagnosis on their submitted claims (Optum) or on the electronic health record (EHR), some individuals with A1c values above the diagnosis cutoff may in fact receive a diagnosis even though it is not visible in the data. This would result in an underestimation of the first stage (i.e., the effect of an A1c above the cutoff on diagnosis) and an overestimation of the treatment effect of receiving a diagnosis on other outcomes (e.g., the effect of receiving a diagnosis on spending). In Appendix Table A14, we re-estimate our IV models assuming that everyone with an A1c value above 6.5 receives a diagnosis of diabetes, even if we do not observe it on the claim or EHR. That is, the variable indicating the individual has received a diabetes diagnosis is coded to be one for all individuals with A1c 6.5 or higher. This assumption results in a much larger first stage of about 56 percentage points, and smaller effects for 
the marginally diagnosed on spending outcomes. Although these lower bounds are, naturally, much smaller than the IV estimates reported in Table 2, the estimates indicate that a diagnosis of diabetes increases spending by at least $\$ 242$ in the first year following the initial A1c test.

\section{Conclusion}

The distribution of health in the population is such that many individuals with a chronic illness are near the margin of being diagnosed. This paper explores the impact of a diagnosis on such "marginal" patients. We find that individuals whose blood glucose levels are just above the threshold for a diabetes diagnosis have significantly higher spending on recommended care than similar patients whose blood glucose levels fall just below this cutoff. Receiving such a diagnosis appears to put patients on a path of persistently higher spending and utilization of diabetes-related care. Even after 5 years, patients whose initial test put them above the diagnosis cutoff have spending that is significantly higher than those with lab tests just below this cutoff. A back-of-the-envelope calculation suggests that even a small increase in the threshold at which diabetes is diagnosed would reduce total diabetes spending by over $\$ 1.8$ billion per year, while a small decrease in this threshold would increase spending by $\$ 2.4$ billion.

Among these marginally diagnosed patients, this additional spending appears to be associated with only minimal improvements in health. We observe a reduction in A1c in the first year following diagnosis, but this improvement does not persist through years 2 through 6 and is somewhat sensitive to model specification. We do not detect any improvements in blood pressure or BMI as measured on electronic health records, nor in total cholesterol or mortality rates. We also do not detect any changes in self-reported measures of health or healthy behaviors.

Our analysis has limitations, the most obvious being that we only observe patients for 6 years following the initial diagnosis of diabetes. It may be the case that improvements in health manifest in year 7 or later. Indeed, we find strong evidence that receiving a diagnosis of diabetes is associated with early diagnosis of several complications associated with diabetes, such as retinopathy, neuropathy, and diabetic kidney disease; since these complications were detected earlier, we might expect patients to experience improved health trajectories over a longer time horizon. However, the fact that we find minimal effects on intermediate measures of health such as blood sugar, blood pressure, cholesterol, and BMI reduces optimism about the likely magnitude of longer term health improvements.

Overall, results suggest that the effects of increased spending on relatively healthy diabetes pa- 
tients are likely modest, and would indicate that future revisions of diagnosis guidelines for chronic diseases should exercise caution when relaxing these guidelines to include healthier populations. 
Figure 1: Sample size by A1c Value, Optum and EHR
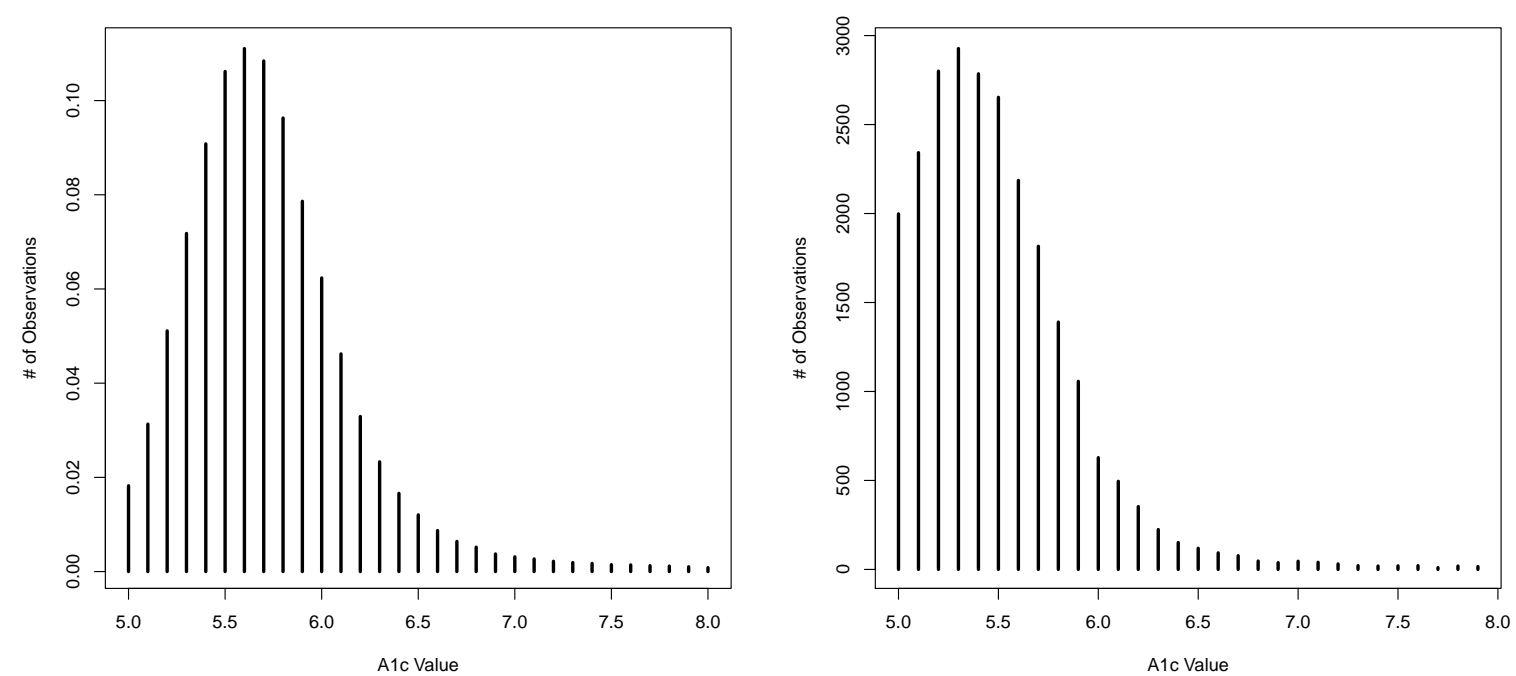

Source: Authors' calculations from the Optum claims data (left panel) and UCLA EHR data (right panel). Horizontal axis indicates each value of A1c. Vertical axis indicates sample size within each A1c bin.

Table 1: Demographic Statistics, Optum, HRA and UCLA EHR Data

\begin{tabular}{lccc}
\hline \hline & Optum & Health Risk Assessment & UCLA EHR \\
\hline Female & 0.523 & 0.554 & 0.612 \\
Age & 51.13 & 44.22 & 47.15 \\
White & $\mathrm{N} / \mathrm{A}$ & $\mathrm{N} / \mathrm{A}$ & 0.654 \\
Black & $\mathrm{N} / \mathrm{A}$ & $\mathrm{N} / \mathrm{A}$ & 0.048 \\
Hispanic & $\mathrm{N} / \mathrm{A}$ & $\mathrm{N} / \mathrm{A}$ & 0.111 \\
Asian & $\mathrm{N} / \mathrm{A}$ & $\mathrm{N} / \mathrm{A}$ & 0.105 \\
Medicare & 0.281 & 0.006 & 0.181 \\
Private & 0.719 & 0.994 & 0.749 \\
Medicaid & 0 & 0 & 0.016 \\
Self-Pay & 0 & 0 & 0.046 \\
$\mathrm{~N}$ & 142,541 & 16,916 & 23,882 \\
\hline
\end{tabular}

Note: Authors' calculations from Optum claims, Health Risk Assessment, and UCLA EHR data. This table contains descriptive statistics for patients with an A1c test who meet all sample criteria described in the text. 
Figure 2: Diabetes Diagnosis and Spending in 12 Months Following Initial Lab Test

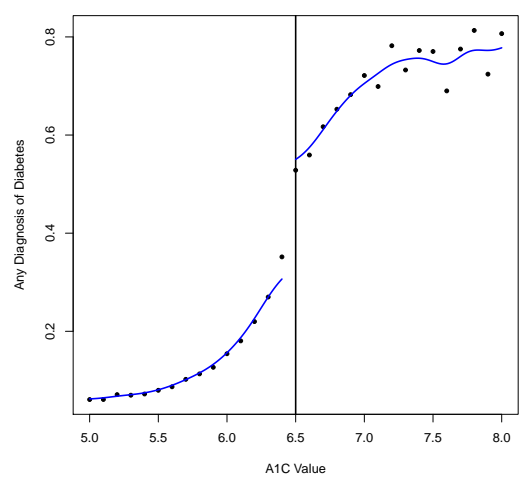

(a) Any Diagnosis

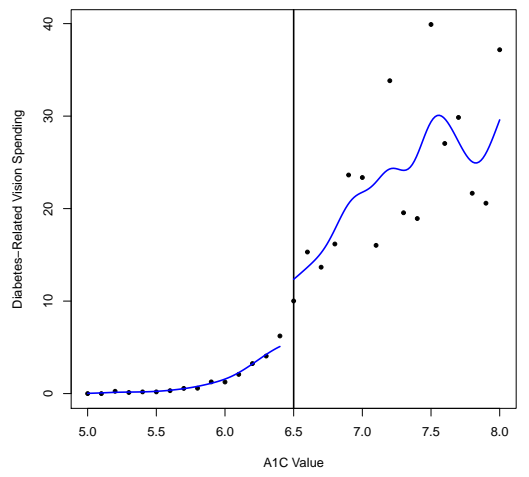

(d) Diabetes-related Vision Care

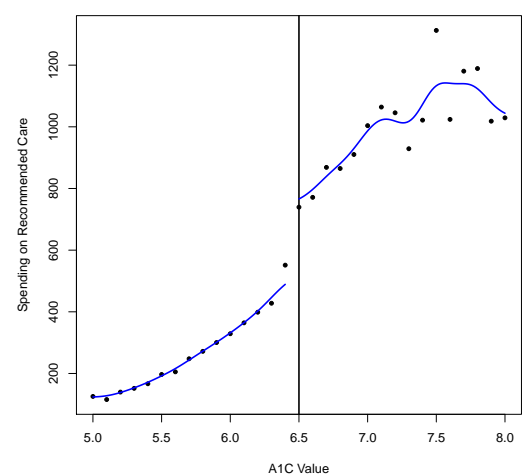

(b) Recommended Care

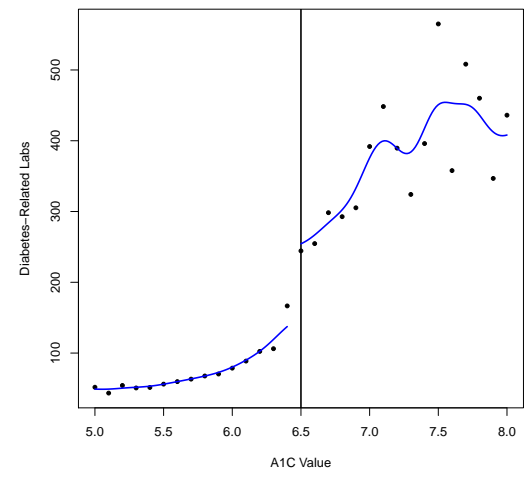

(e) Diabetes-related Labs

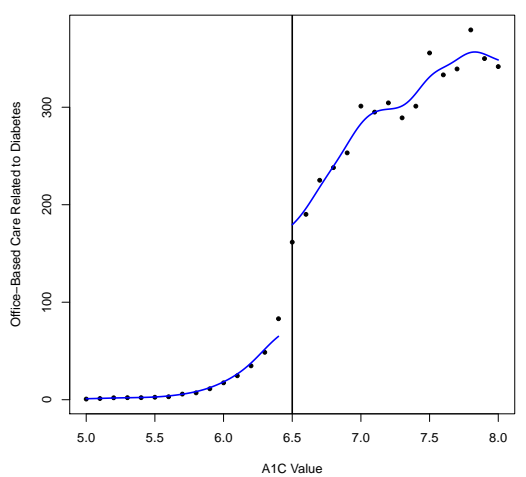

(c) Diabetes-related Office Visits

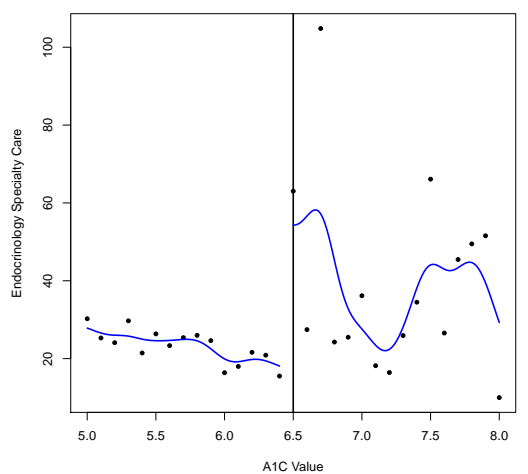

(f) Endocrinology Specialist Care

Source: Authors' calculations from the Optum claims data. Horizontal axis displays the test value. Vertical axis displays within test value averages of outcome variable. Vertical line at 6.5 is the diagnosis cutoff for diabetes. 
Figure 3: Drug Spending and Other Utilization Measures in 12 Months Following Initial Lab Test

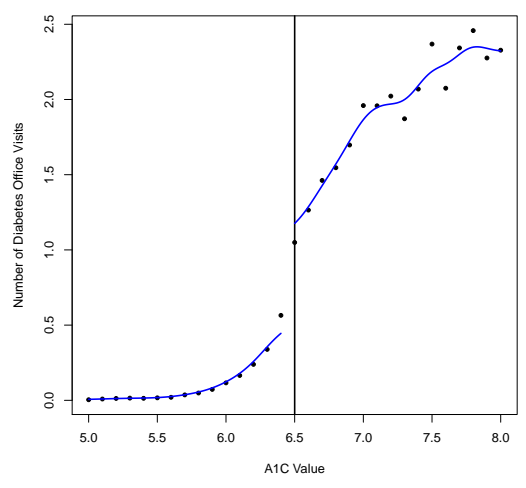

(a) \# of Diabetes-Related Office Visits

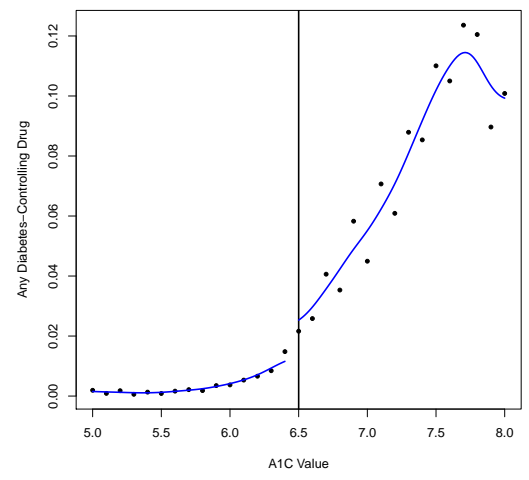

(d) Any Diabetes-Controlling Drug Spending

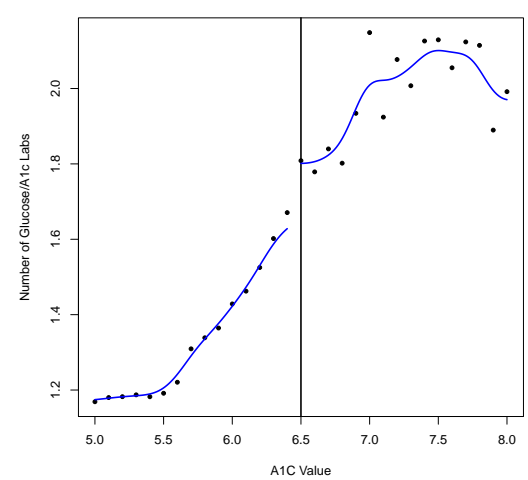

(b) \# Glucose/A1c Labs

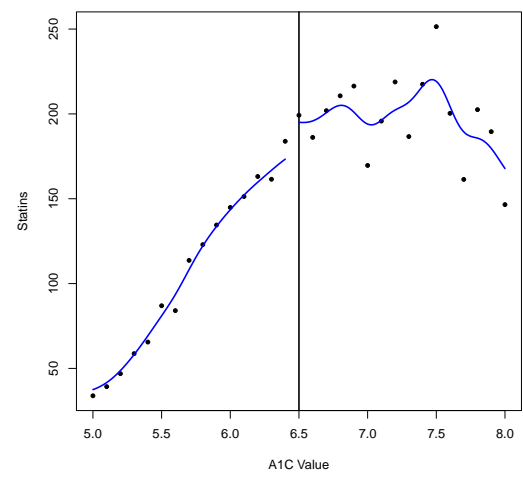

(e) Statins

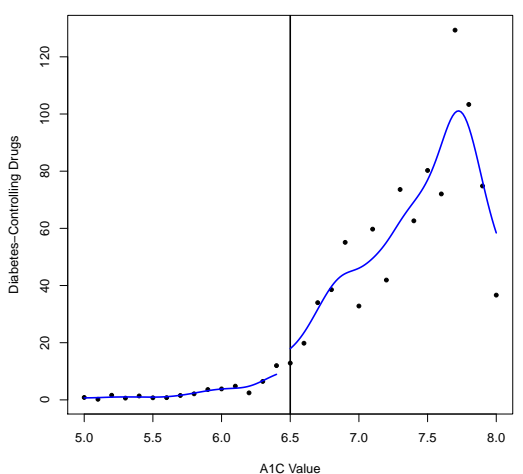

(c) Diabetes-Controlling Drugs

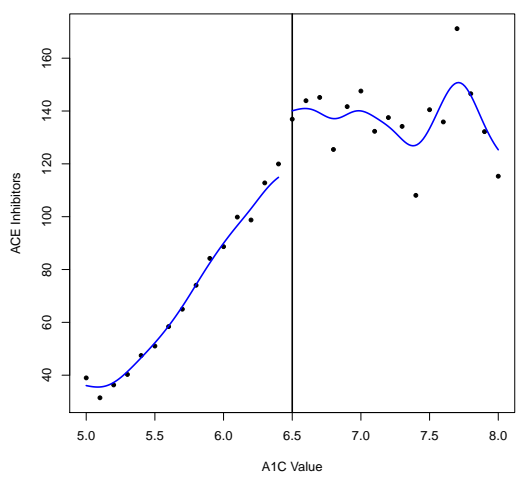

(f) ACE Inhibitors

Source: Authors' calculations from the Optum claims data. Horizontal axis displays the test value. Vertical axis displays within test value averages of outcome variable. Vertical line at 6.5 is the diagnosis cutoff for diabetes. 
Figure 4: Diagnosis of Complications Related to Diabetes and Optum Health Outcomes in 12 Months Following Initial Lab Test

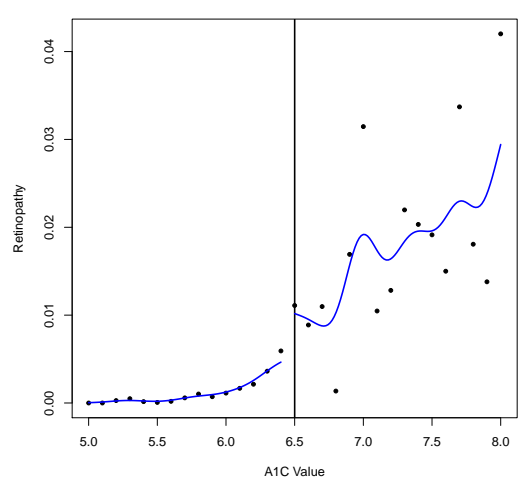

(a) Diabetic Retinopathy

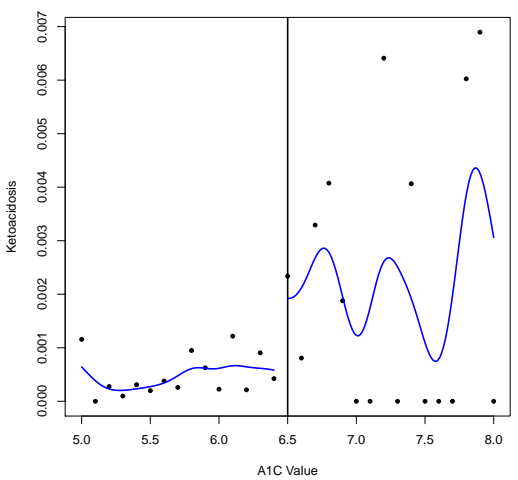

(d) Ketoacidosis

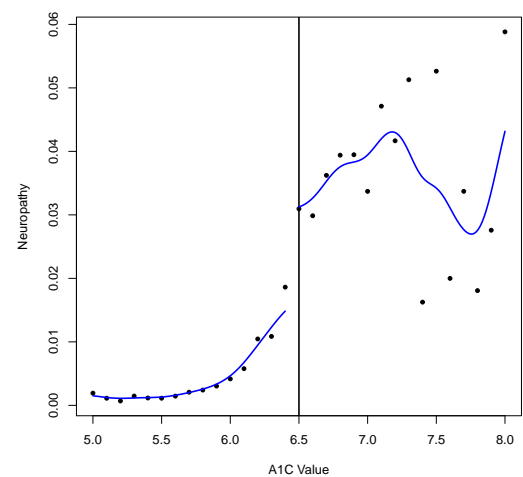

(b) Diabetic Neuropathy

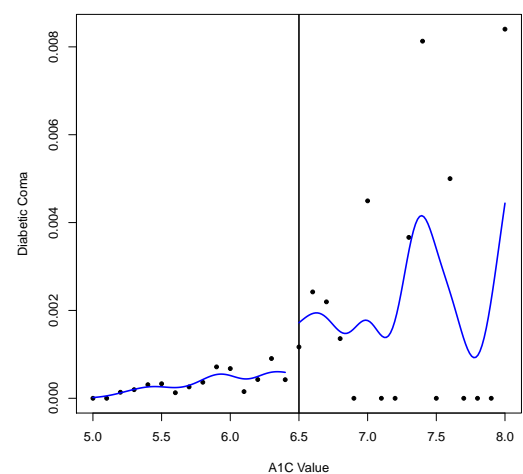

(e) Diabetic Coma

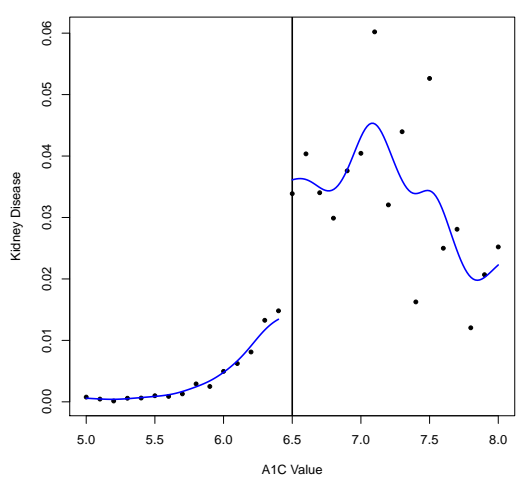

(c) Kidney Disease

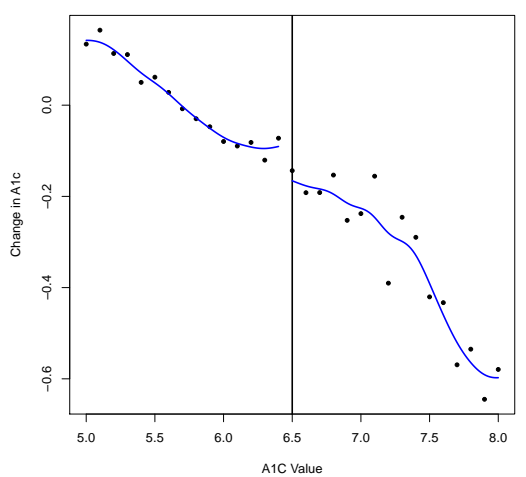

(f) Change in A1c

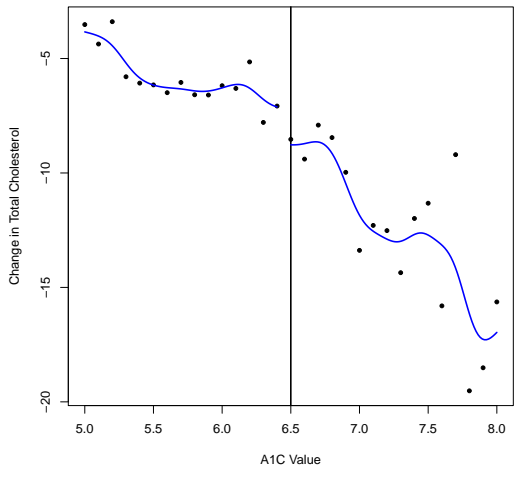

(g) Change in Total Cholesterol

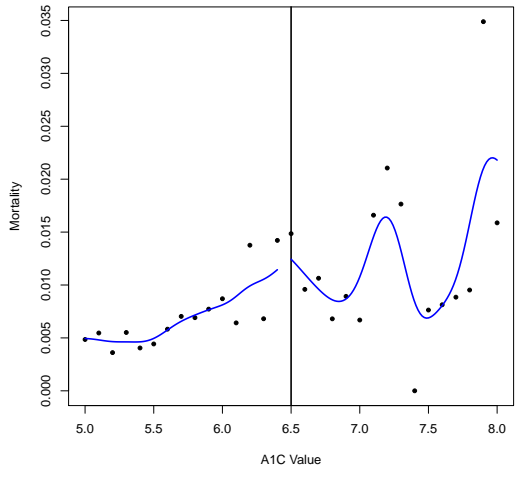

(h) Mortality

Source: Authors' calculations from the Optum claims data. Horizontal axis displays the test value. Vertical axis displays within test value averages of outcome variable. Vertical line at 6.5 is the diagnosis cutoff for diabetes. 
Figure 5: Clinical Measures of Health in 12 Months Following Initial Lab Test

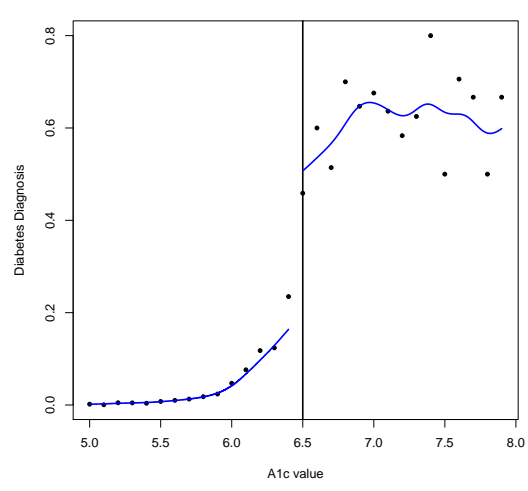

(a) Diagnosis of Diabetes

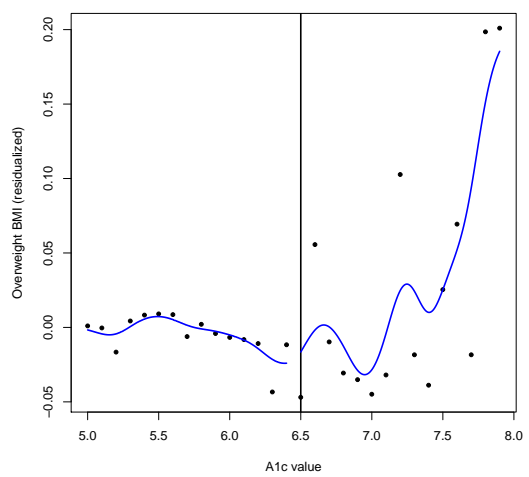

(d) Overweight

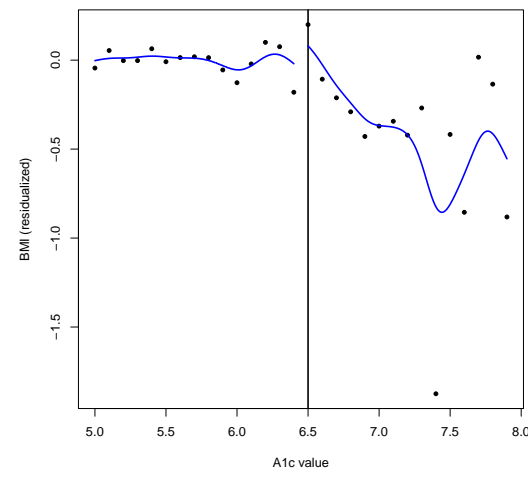

(b) BMI

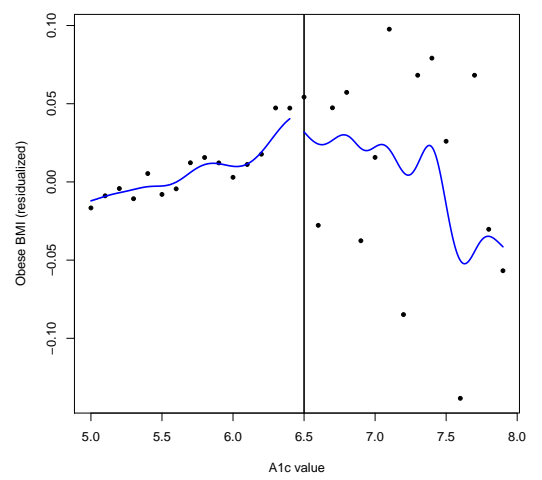

(e) Obese

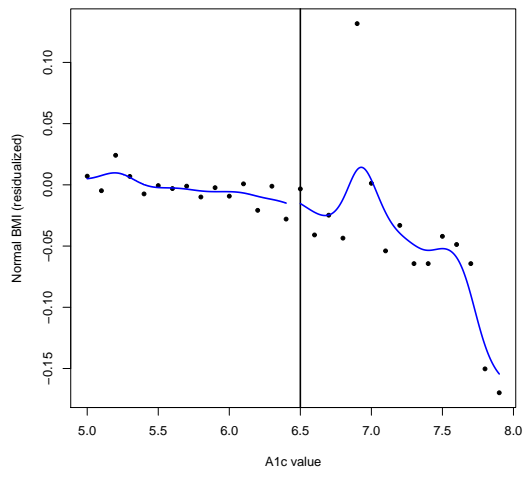

(c) BMI in normal range

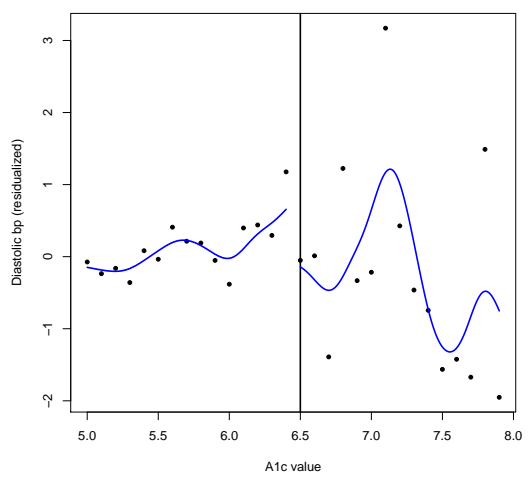

(f) Diastolic BP

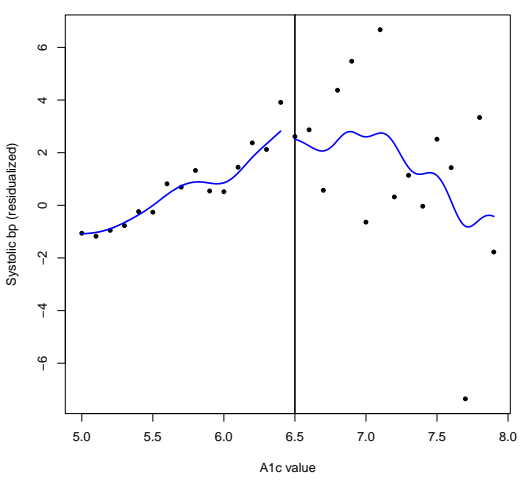

(g) Systolic BP

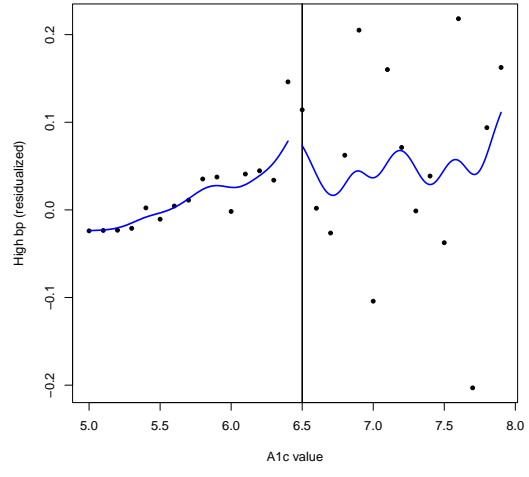

(h) High BP

Source: Authors' calculations from the UCLA Electronic Health Record data. Horizontal axis displays the test value. Vertical axis displays within test value averages of outcome variable. Vertical line at 6.5 is the diagnosis cutoff for diabetes. Note that all panels except panel (a) use data that is first residualized by regressing the outcome on the previous year's value. The resulting error term is then binned by test value and the average within each test value is plotted. 
Figure 6: Self-Reported Health and Behavior in 12 Months Following Initial Lab Test

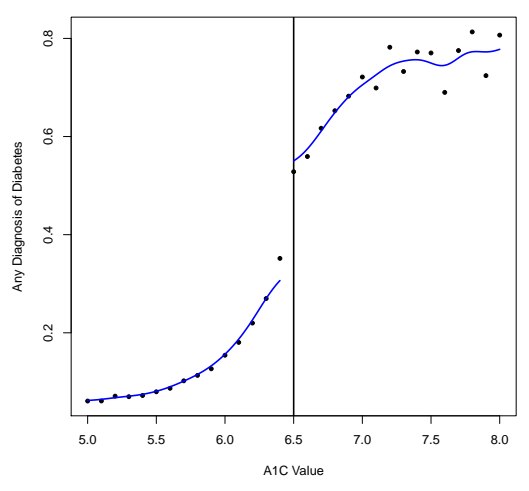

(a) Diabetes Diagnosis

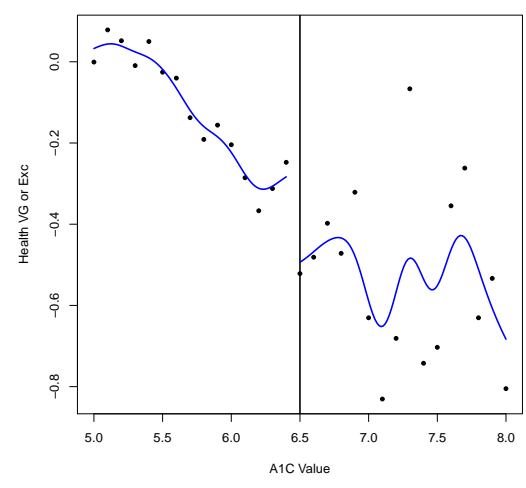

(b) Health VG or Exc

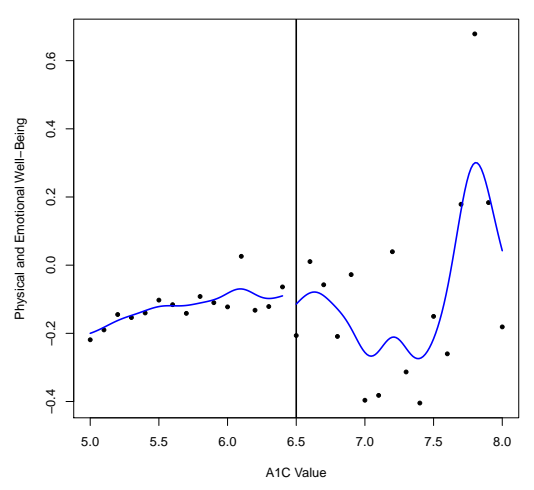

(c) Physical and Emotional Well-Being

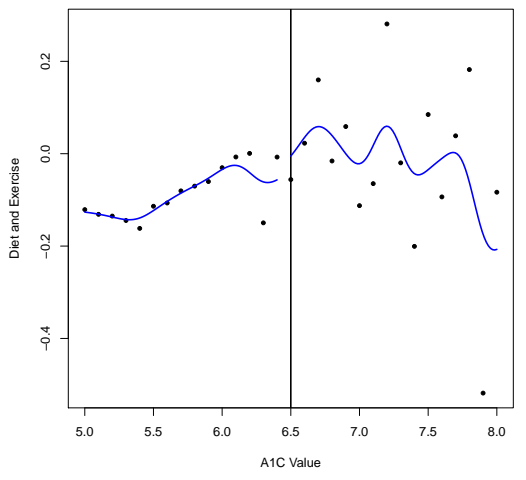

(d) Diet and Exercise

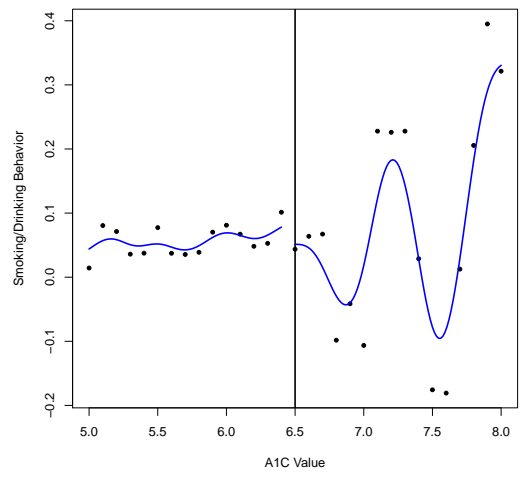

(e) Healthy Smoking and Drinking

Source: Authors' calculations from the Optum Health Risk Assessment data. Horizontal axis displays the test value. Vertical axis displays within test value averages of outcome variable. Vertical line at 6.5 is the diagnosis cutoff for diabetes. 
Figure 7: Optum Diagnosis and Spending Outcomes by Year After Initial Lab Test

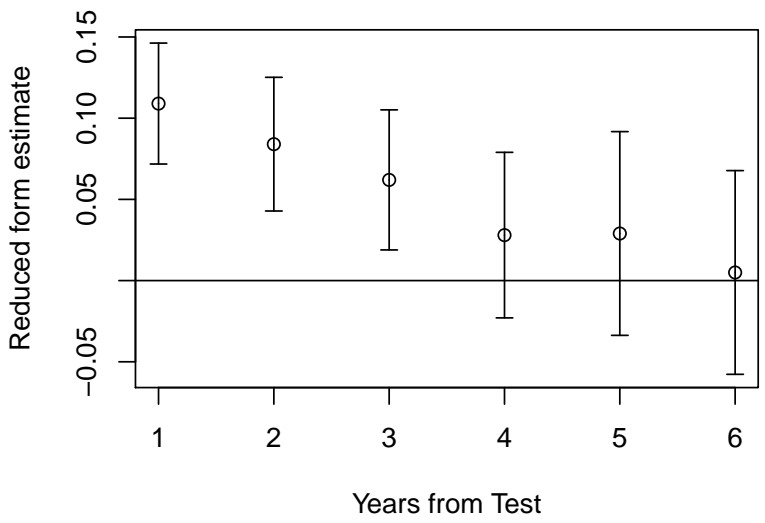

(a) Any Diagnosis of Diabetes

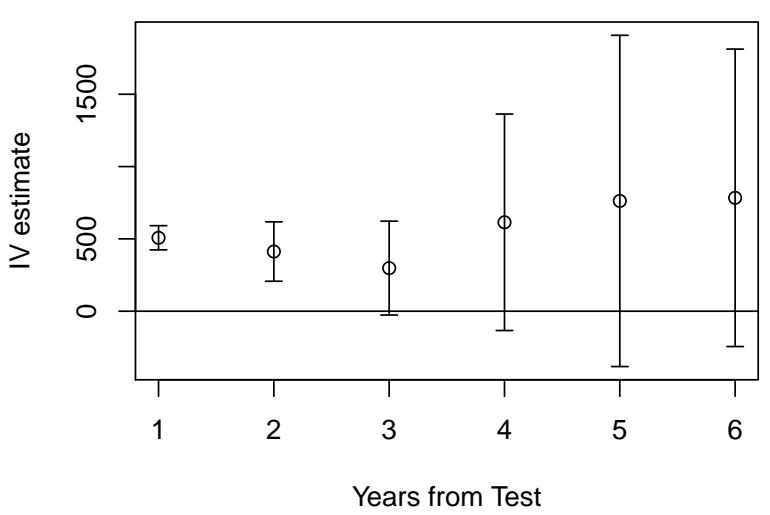

(c) Diabetes-related Office Visits

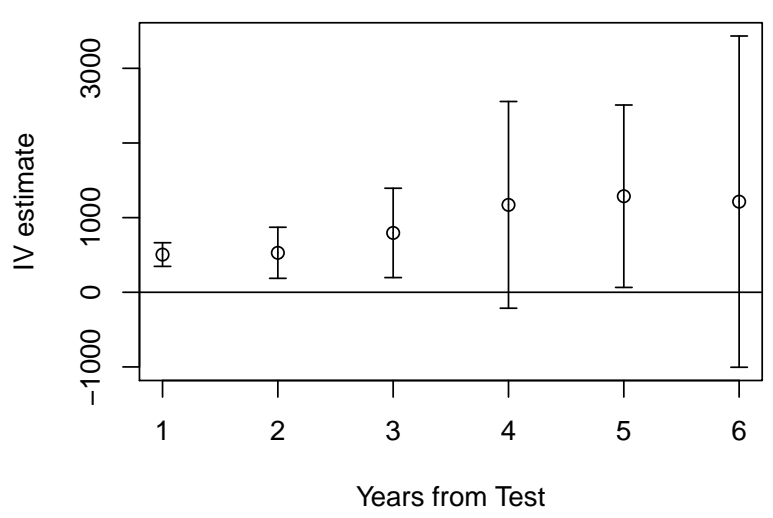

(e) Diabetes-related Labs

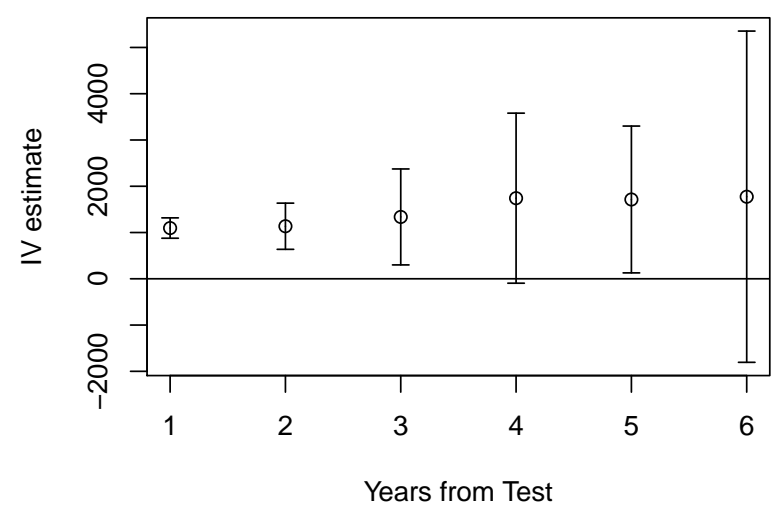

(b) Recommended Care

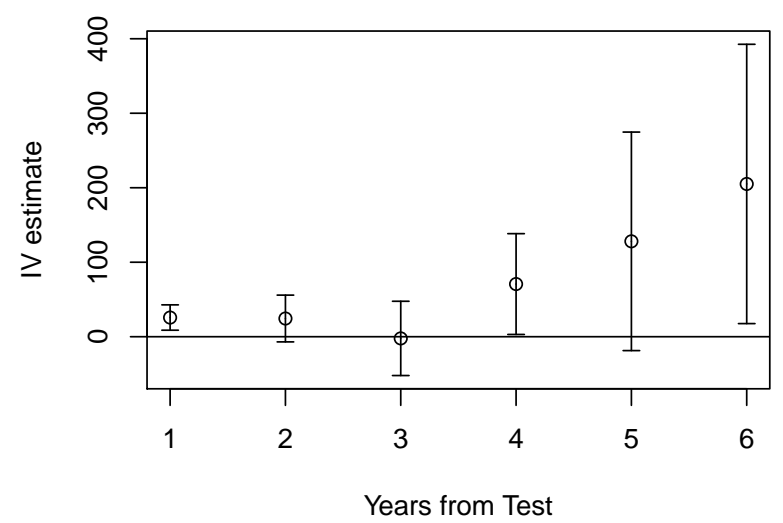

(d) Diabetes-related Vision Care

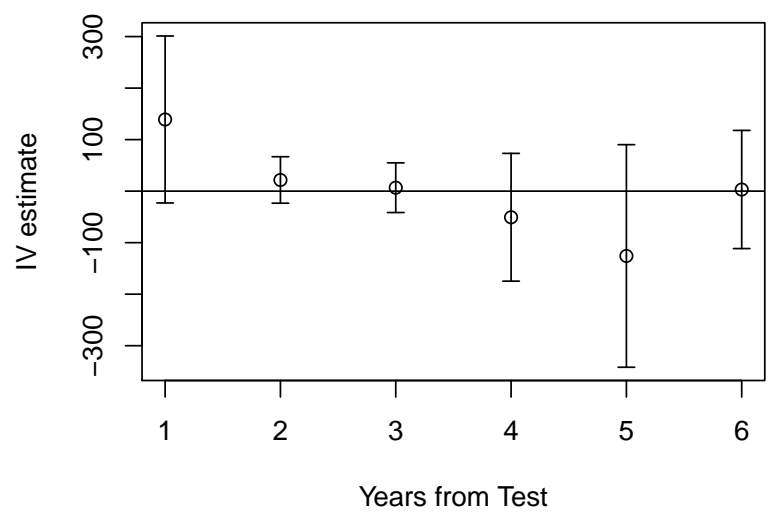

(f) Endocrinology Specialist Care

Source: Authors' calculations from the Optum claims data. Horizontal axis indicates the year relative to the initial lab test. Vertical axis indicates size of the regression discontinuity effect estimated using local linear regression. 95 percent confidence intervals displayed. 
Figure 8: Optum Utilization Outcomes by Year After Initial Lab Test

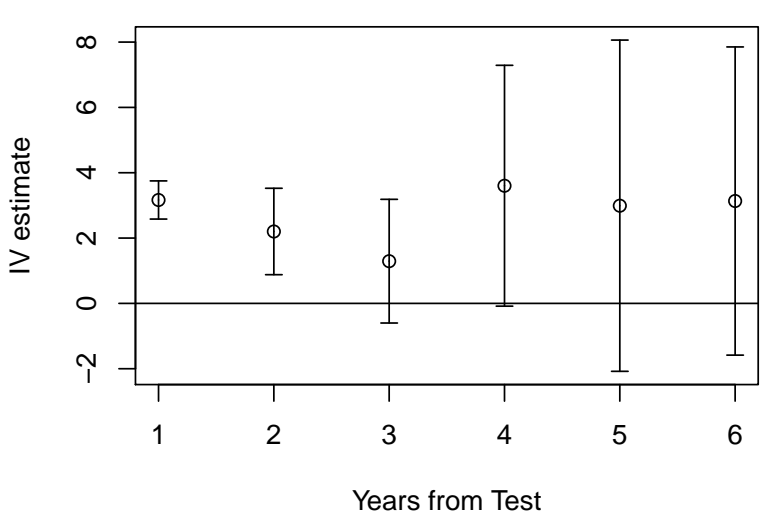

(a) \# of Diabetes-Related Office Visits

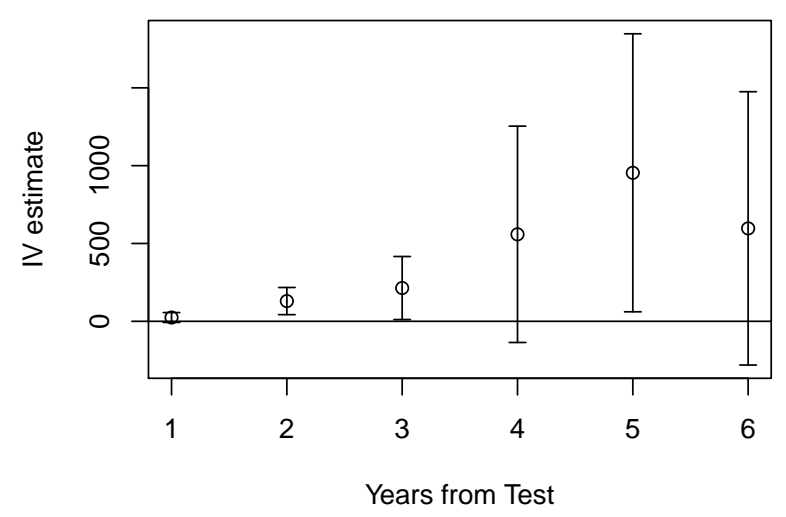

(c) Diabetes-Controlling Drugs

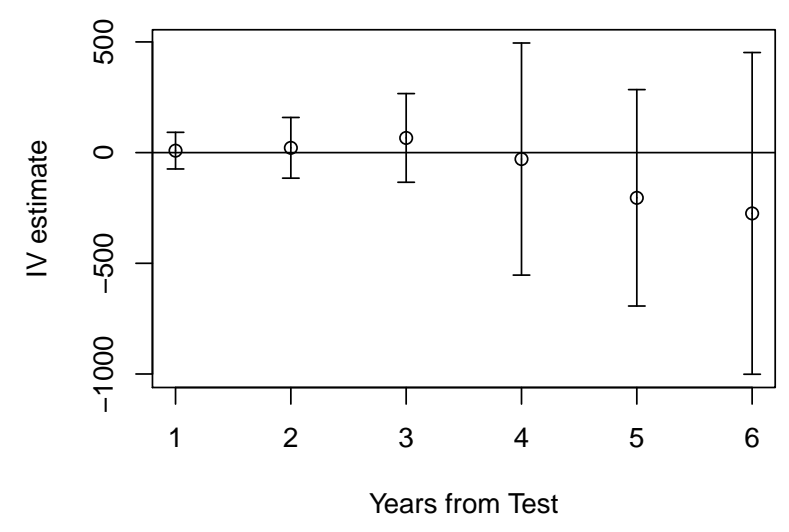

(e) Statins

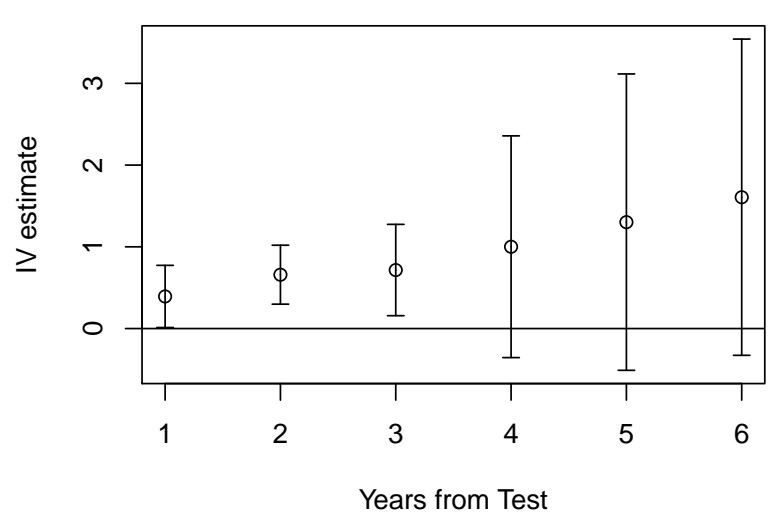

(b) \# Glucose or A1c Labs

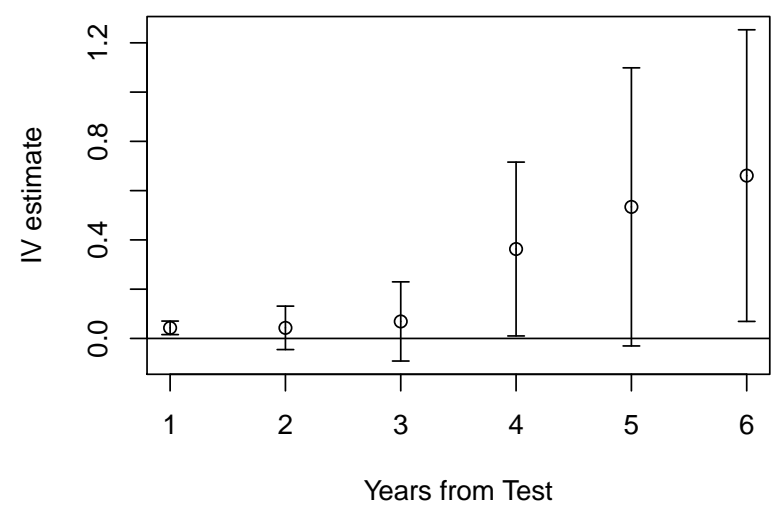

(d) Any Diabetes-Controlling Drug

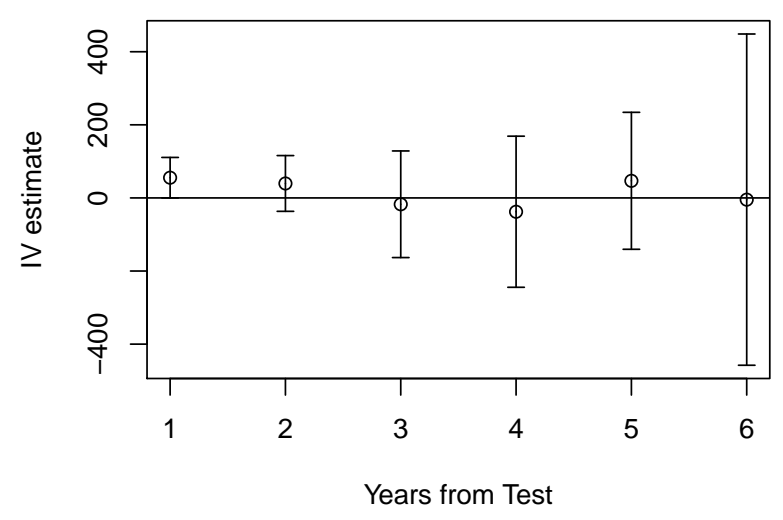

(f) ACE Inhibitors

Source: Authors' calculations from the Optum claims data. Horizontal axis indicates the year relative to the initial lab test. Vertical axis indicates size of the regression discontinuity effect estimated using local linear regression. 95 percent confidence intervals displayed. 
Figure 9: Incidence of Complications by Year After Initial Lab Test

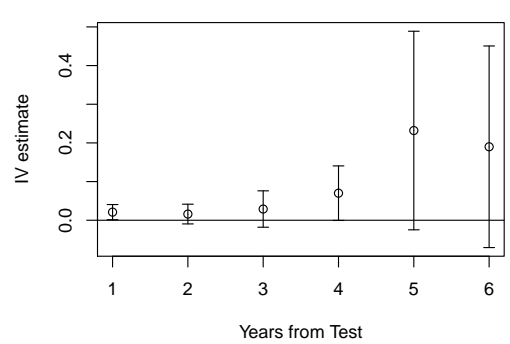

(a) Diabetic Retinopathy

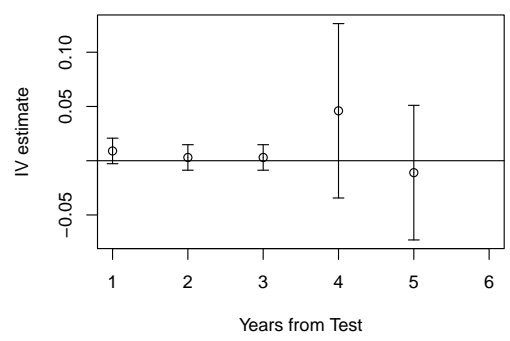

(d) Ketoacidosis

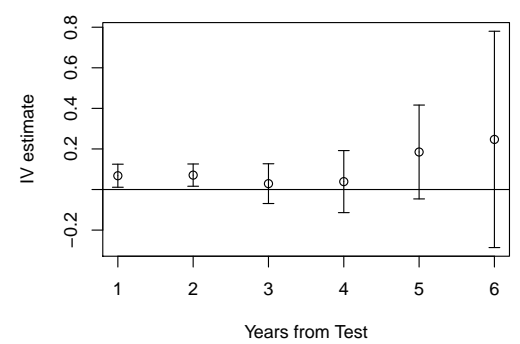

(b) Diabetic Neuropathy

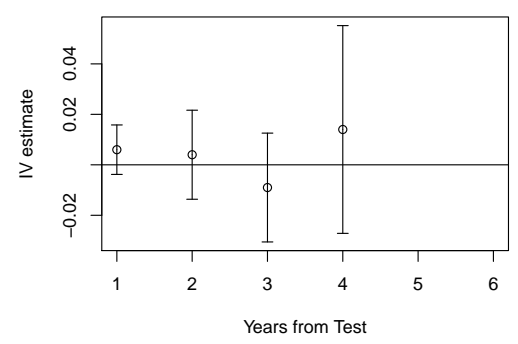

(e) Diabetic Coma

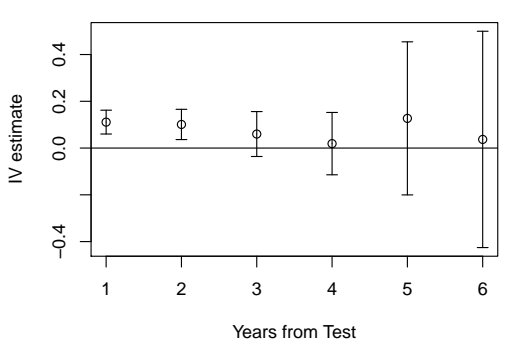

(c) Kidney Disease

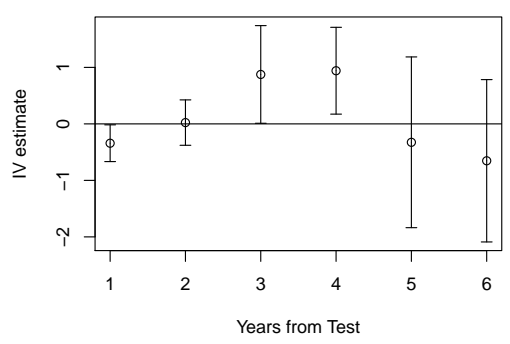

(f) Change in A1c

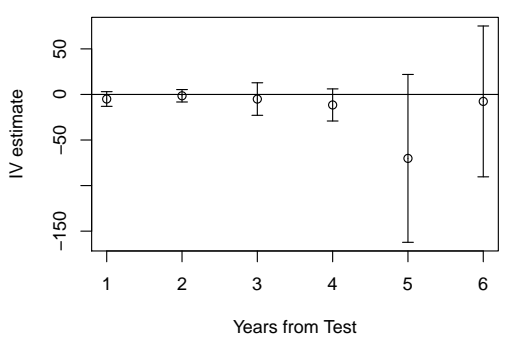

(g) Change in Total Cholesterol

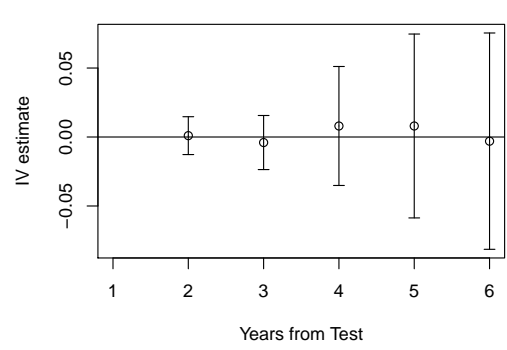

(h) Mortality

Source: Authors' calculations from the Optum claims data. Horizontal axis indicates the year relative to the initial lab test. Vertical axis indicates size of the regression discontinuity effect estimated using local linear regression. 95 percent confidence intervals displayed. 
Figure 10: Diagnosis and Health Outcomes in 12 Months Following Initial Lab Test, UCLA EHR Data

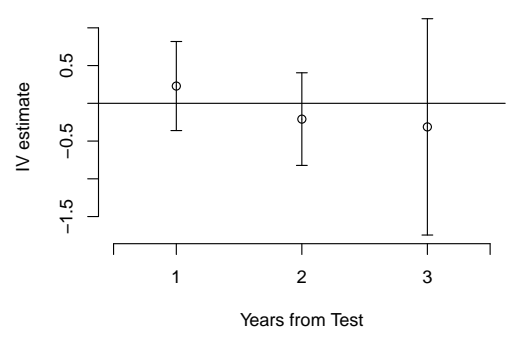

(a) BMI

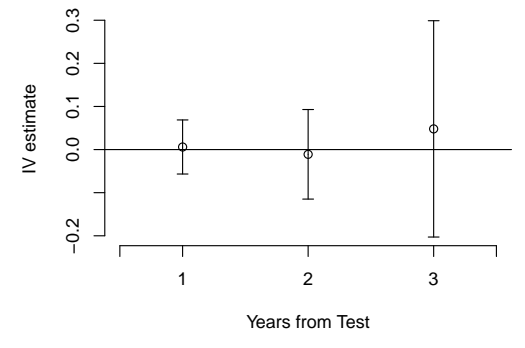

(b) BMI in normal range

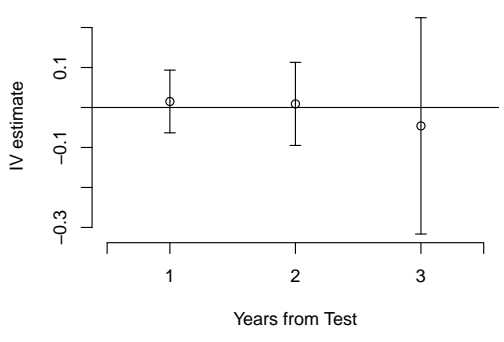

(c) Overweight

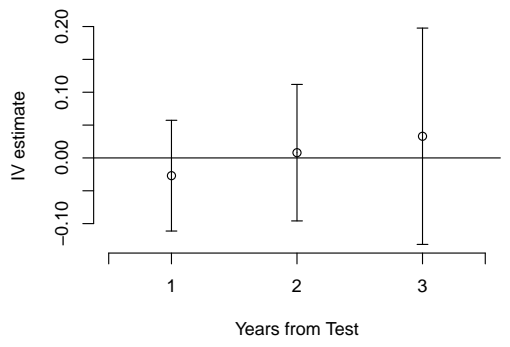

(d) Obese

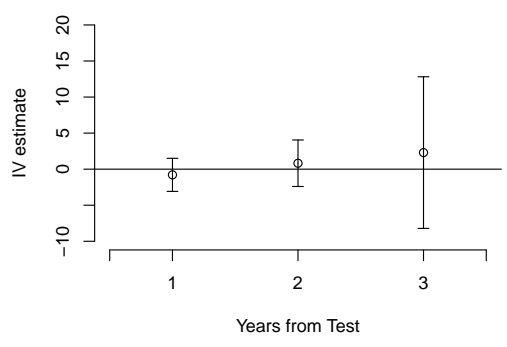

(f) Systolic BP

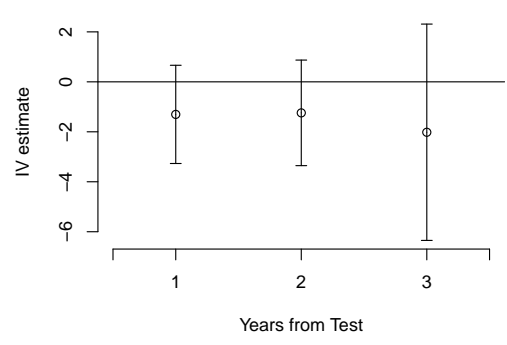

(e) Diastolic BP

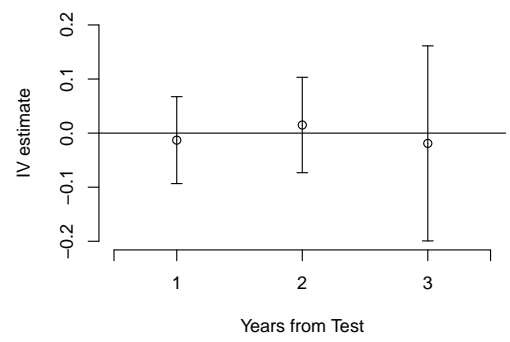

(g) High BP

Source: Authors' calculations from the UCLA EHR data. Horizontal axis indicates the year relative to the initial lab test. Vertical axis indicates size of the regression discontinuity effect estimated using local linear regression. 95 percent confidence intervals displayed. 
Figure 11: Optum Spending Outcomes Using a Balanced (red) vs. Unbalanced (black) Panel

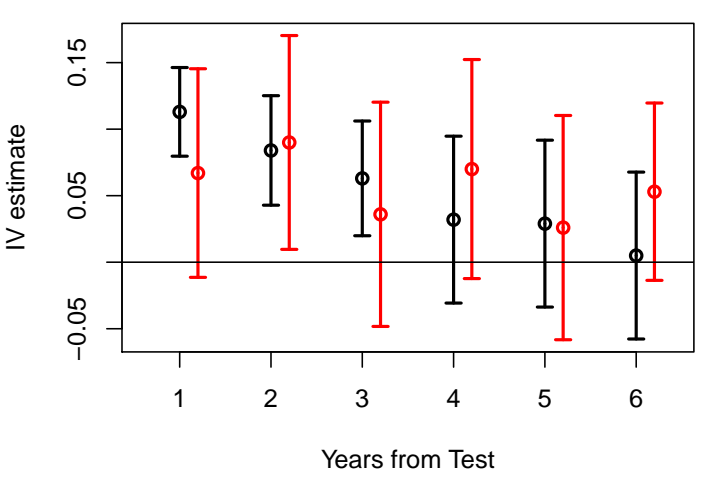

(a) Any Diagnosis of Diabetes

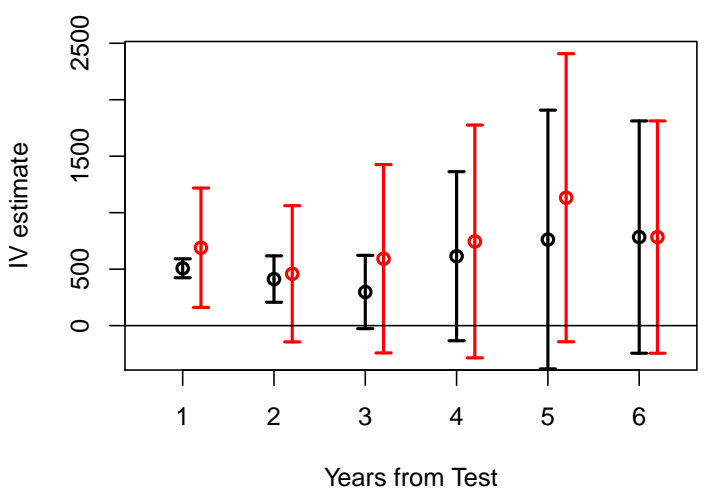

(c) Diabetes-related Office Spending

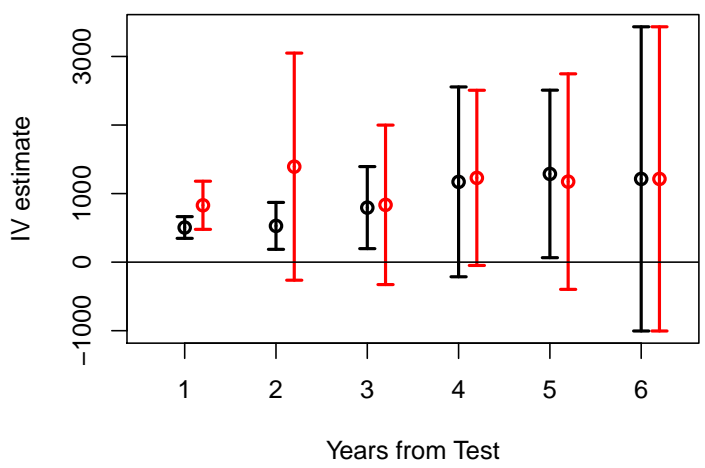

(e) Diabetes-related Labs

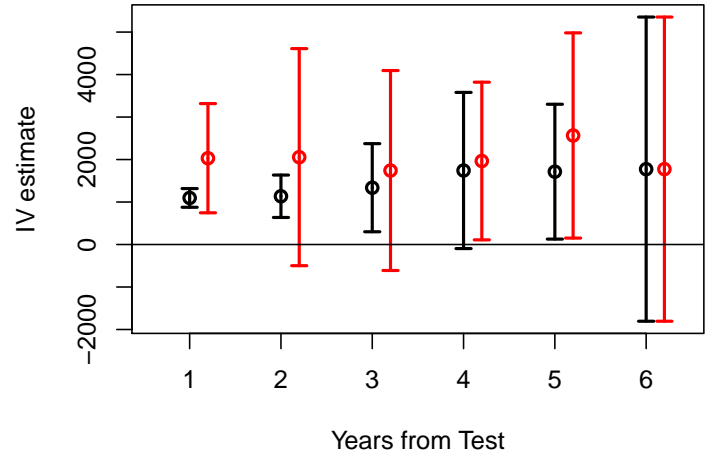

(b) Recommended Care

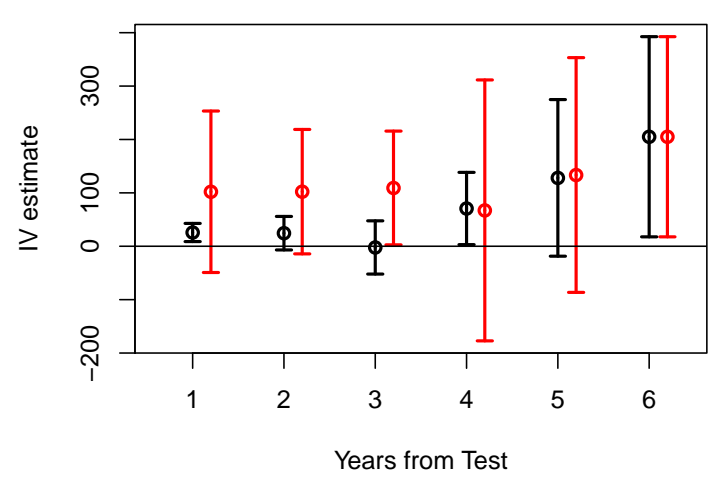

(d) Diabetes-related Vision Care

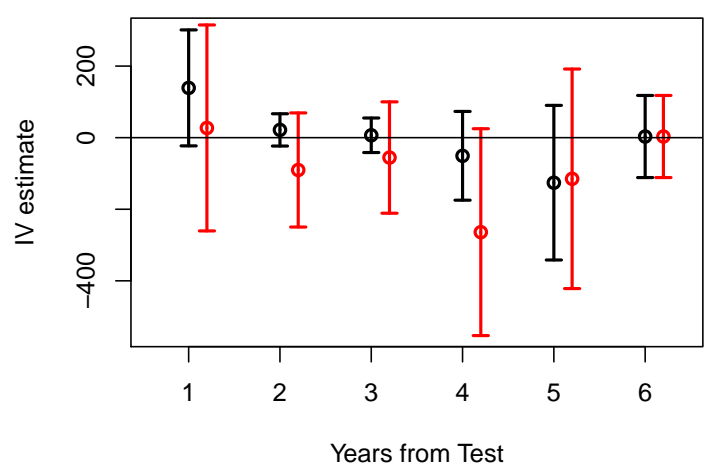

(f) Endocrinology Specialist Care

Source: Authors' calculations from the Optum Health Risk Assessment claims data. Horizontal axis indicates the year relative to the initial lab test. Vertical axis indicates size of the regression discontinuity effect estimated using local linear regression. 95 percent confidence intervals displayed. 
Figure 12: Optum Utilization Outcomes Using a Balanced (red) vs. Unbalanced (black) Panel

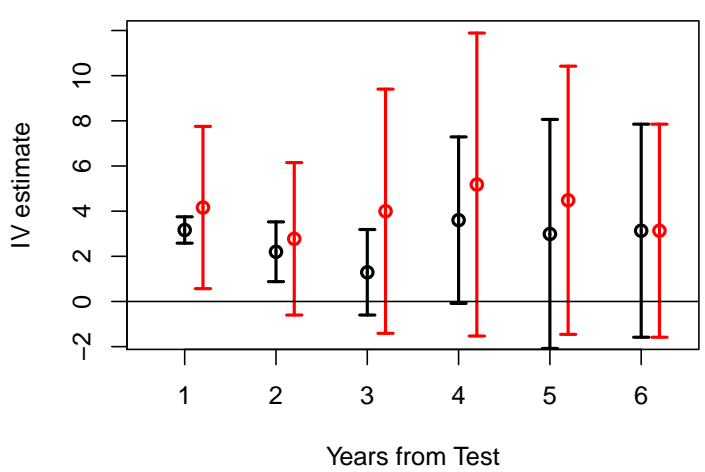

(a) \# Diabetes-Related Office Visits

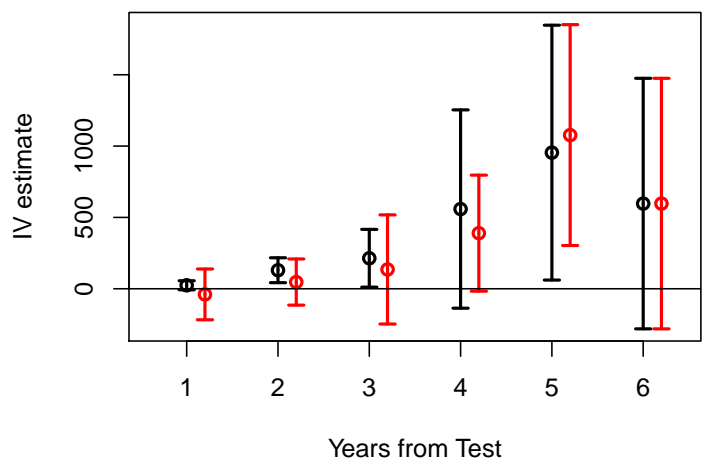

(c) Diabetes-controlling Drug Spending

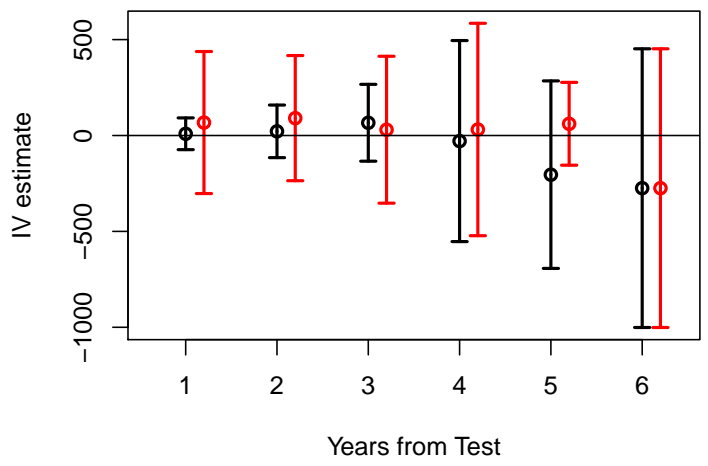

(e) Statins

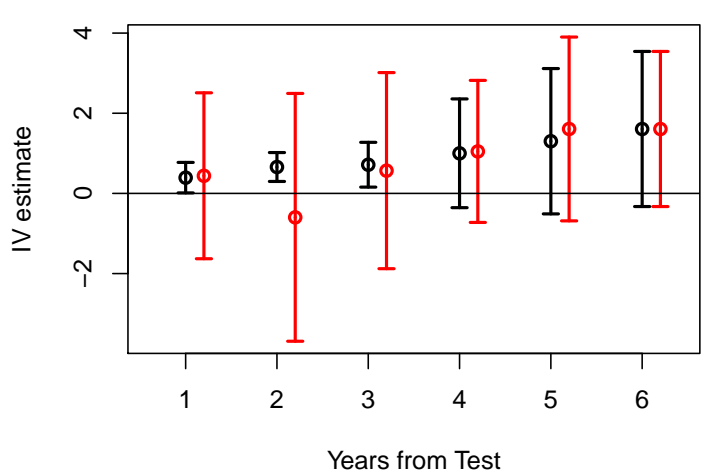

(b) \# Glucose/A1c Labs

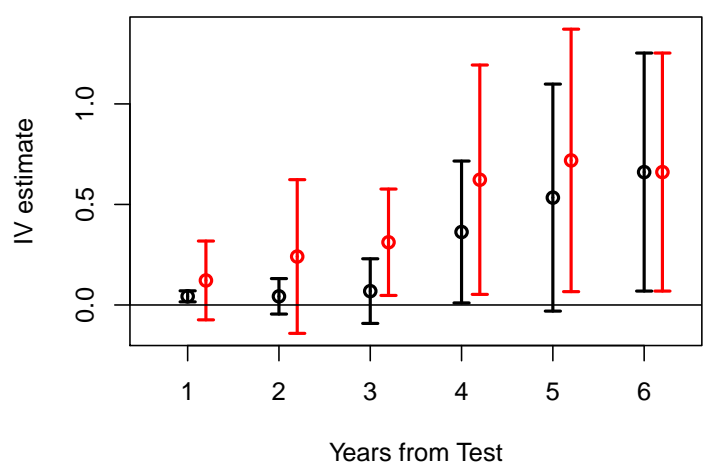

(d) Any diabetes-controlling drug spending

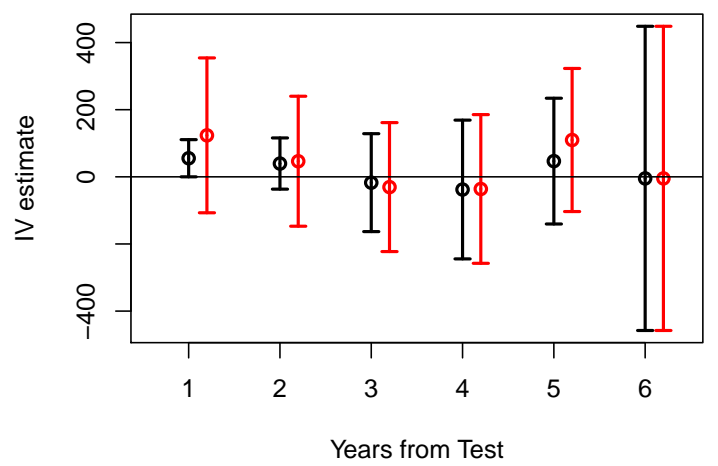

(f) ACE Inhibitors

Source: Authors' calculations from the Optum claims data. Horizontal axis indicates the year relative to the initial lab test. Vertical axis indicates size of the regression discontinuity effect estimated using local linear regression. 95 percent confidence intervals displayed. 
Figure 13: UCLA EHR Outcomes Using a Balanced (red) vs. Unbalanced (black) Panel

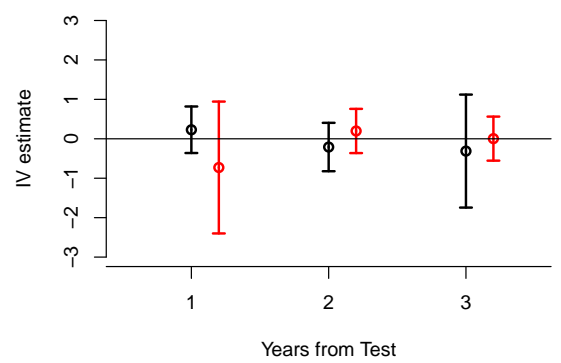

(a) BMI

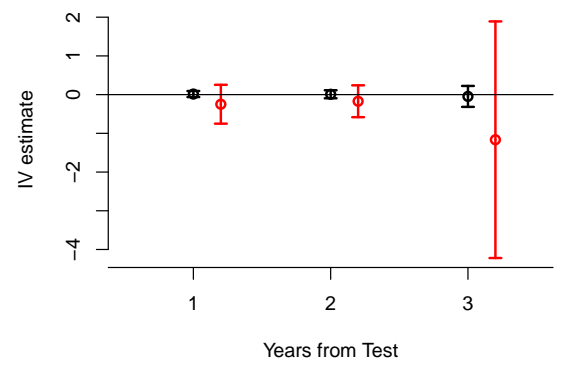

(c) Overweight

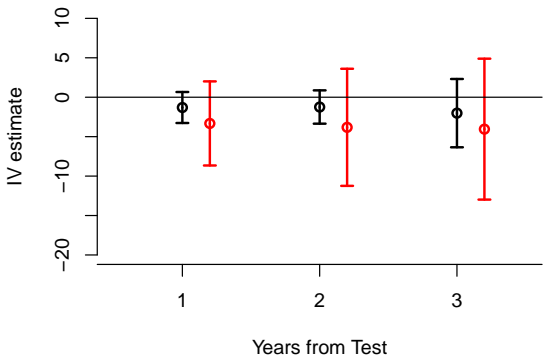

(e) Diastolic BP

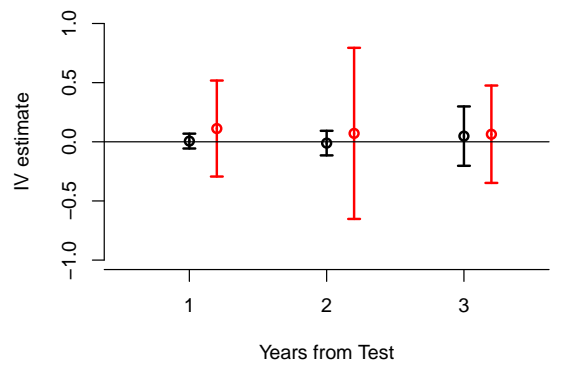

(b) BMI in normal range

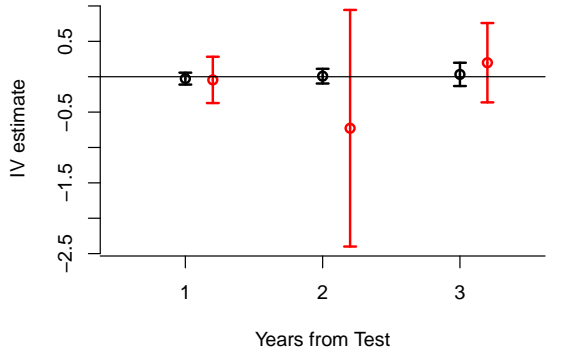

(d) Obese

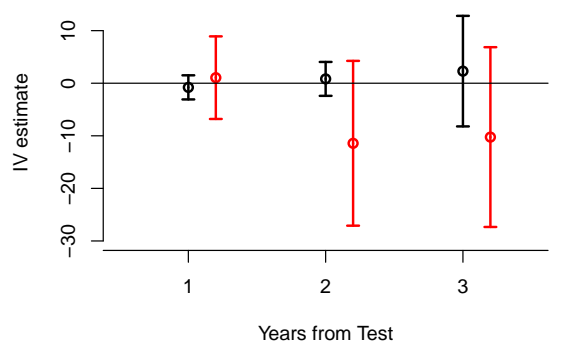

(f) Systolic BP

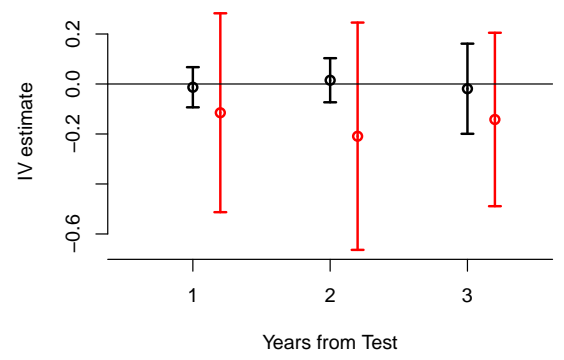

(g) High BP

Source: Authors' calculations from the Optum claims data. Horizontal axis indicates the year relative to the initial lab test. Vertical axis indicates size of the regression discontinuity effect estimated using local linear regression. 95 percent confidence intervals displayed. 
Table 2: RD Estimates of Effects of Diabetes Diagnosis on Spending by Category in First 12 Months Following A1c Test

\begin{tabular}{|c|c|c|c|}
\hline & Control Mean (Std Dev) & $\begin{array}{l}\text { Reduced Form } \\
\text { Estimate }\end{array}$ & $\begin{array}{c}\text { IV Estimate of } \\
\text { Effect of Diagnosis }\end{array}$ \\
\hline Diabetes Diagnosis & 0.183 & $\begin{array}{l}0.108^{* * *} \\
(0.019)\end{array}$ & NA \\
\hline $\begin{array}{l}\text { Spending on ADA- } \\
\text { Recommended Care }\end{array}$ & $362.03(718.09)$ & $\begin{array}{c}207.609^{* * * *} \\
(22.912)\end{array}$ & $\begin{array}{c}1,096.894^{* * *} \\
(112.295)\end{array}$ \\
\hline $\begin{array}{l}\text { Spending on Office-Based } \\
\text { Care Related to Diabetes }\end{array}$ & $26.17(122.28)$ & $\begin{array}{l}79.112^{* * *} \\
(6.912)\end{array}$ & $\begin{array}{c}507.661^{* * *} \\
(42.690)\end{array}$ \\
\hline $\begin{array}{l}\text { Spending on Diabetes- } \\
\text { Related Vision Services }\end{array}$ & $2.26(27.92)$ & $\begin{array}{l}5.483^{* * *} \\
(1.446)\end{array}$ & $\begin{array}{c}28.215^{* * *} \\
(7.360)\end{array}$ \\
\hline $\begin{array}{l}\text { Spending on Diabetes- } \\
\text { Related Labs }\end{array}$ & $89.10(353.69)$ & $\begin{array}{l}78.650 * * * \\
(13.891)\end{array}$ & $\begin{array}{c}505.367^{* * *} \\
(80.798)\end{array}$ \\
\hline $\begin{array}{l}\text { Endocrinology Specialist } \\
\text { Care Spending }\end{array}$ & $19.95(313.62)$ & $\begin{array}{l}38.741^{*} \\
(23.024)\end{array}$ & $\begin{array}{l}139.092^{*} \\
(82.668)\end{array}$ \\
\hline
\end{tabular}

Notes: Control means calculated using observations with A1c test values below 6.5 and greater than or equal to 6 . Coefficient estimates from local linear regression with optimal bandwidth calculation from Fuji, Imbens, and Kalyanaraman (2009). 
Table 3: RD Estimates of Effects of Diabetes Diagnosis on Drug Spending and Other Utilization Measures in First 12 Months Following A1c Test

\begin{tabular}{|c|c|c|c|}
\hline & Control Mean (Std Dev) & $\begin{array}{l}\text { Reduced Form } \\
\text { Estimate }\end{array}$ & $\begin{array}{c}\text { IV Estimate of } \\
\text { Effect of Diagnosis }\end{array}$ \\
\hline $\begin{array}{l}\text { Number of Diabetes- } \\
\text { Related Office Visits }\end{array}$ & $0.177(0.775)$ & $\begin{array}{l}0.450^{* * *} \\
(0.045)\end{array}$ & $\begin{array}{l}3.166^{* * *} \\
(0.298)\end{array}$ \\
\hline $\begin{array}{l}\text { Number of A1c } \\
\text { or Glucose Labs }\end{array}$ & $1.46(1.01)$ & $\begin{array}{l}0.063^{*} \\
(0.032)\end{array}$ & $\begin{array}{l}0.393^{* *} \\
(0.194)\end{array}$ \\
\hline $\begin{array}{l}\text { Spending on Diabetes- } \\
\text { Controlling Drugs }\end{array}$ & $4.37(97.04)$ & $\begin{array}{l}5.264 \\
(3.497)\end{array}$ & $\begin{array}{c}24.379 \\
(16.183)\end{array}$ \\
\hline $\begin{array}{l}\text { Any Spending on } \\
\text { Diabetes Drugs }\end{array}$ & 0.005 & $\begin{array}{l}0.009 * * * \\
(0.003)\end{array}$ & $\begin{array}{c}0.043^{* * *} \\
(0.014)\end{array}$ \\
\hline Spending on Statins & $151.21(436.84)$ & $\begin{array}{l}2.073 \\
(9.799)\end{array}$ & $\begin{array}{c}8.939 \\
(49.50)\end{array}$ \\
\hline $\begin{array}{l}\text { Spending on } \\
\text { ACE Inhibitors }\end{array}$ & $96.00(299.36)$ & $\begin{array}{c}13.767^{* *} \\
(7.020)\end{array}$ & $\begin{array}{l}55.420^{* *} \\
(28.258)\end{array}$ \\
\hline
\end{tabular}

Notes: Control means calculated using observations with A1c test values below 6.5 and greater than or equal to 6 . Coefficient estimates from local linear regression with optimal bandwidth calculation from Fuji, Imbens, and Kalyanaraman (2009). 
Table 4: RD Estimates of Effects of Diabetes Diagnosis on Subsequent Diagnoses of "Preventable" Conditions, Subsequent A1c, and Mortality in First 12 Months Following A1c Test

\begin{tabular}{|c|c|c|c|}
\hline & Control Mean (Std Dev) & $\begin{array}{l}\text { Reduced Form } \\
\text { Estimate }\end{array}$ & $\begin{array}{c}\text { IV Estimate of } \\
\text { Effect of Diagnosis }\end{array}$ \\
\hline Diabetic Retinopathy & 0.0018 & $\begin{array}{l}0.004^{* *} \\
(0.002)\end{array}$ & $\begin{array}{l}0.021^{* *} \\
(0.010)\end{array}$ \\
\hline Diabetic Neuropathy & 0.007 & $\begin{array}{l}0.010^{* *} \\
(0.004)\end{array}$ & $\begin{array}{c}0.068^{* * *} \\
(0.029)\end{array}$ \\
\hline Kidney Disease & 0.0063 & $\begin{array}{l}0.018^{* * *} \\
(0.004)\end{array}$ & $\begin{array}{l}0.111^{* * *} \\
(0.026)\end{array}$ \\
\hline Ketoacidosis & 0.0006 & $\begin{array}{c}0.002 \\
(0.001)\end{array}$ & $\begin{array}{c}0.009 \\
(0.006)\end{array}$ \\
\hline Diabetic Coma & 0.0006 & $\begin{array}{c}0.001 \\
(0.001)\end{array}$ & $\begin{array}{c}0.006 \\
(0.005)\end{array}$ \\
\hline $\begin{array}{l}\text { Change in A1c from } \\
\text { Previous Year }\end{array}$ & $-0.0564(0.460)$ & $\begin{array}{l}-0.059 * * \\
(0.027)\end{array}$ & $\begin{array}{c}-0.342^{* *} \\
(0.166)\end{array}$ \\
\hline $\begin{array}{l}\text { Change in Total Cholesterol } \\
\text { from Previous Year }\end{array}$ & $-6.429(32.62)$ & $\begin{array}{l}-1.471 \\
(1.212)\end{array}$ & $\begin{array}{l}-4.993 \\
(4.114)\end{array}$ \\
\hline Mortality & $0.005(0.073)$ & $\begin{array}{l}0.0002 \\
(0.001)\end{array}$ & $\begin{array}{c}0.001 \\
(0.007)\end{array}$ \\
\hline
\end{tabular}

Notes: Control means calculated using observations with A1c test values below 6.5 and greater than or equal to 6 . Coefficient estimates from local linear regression with optimal bandwidth calculation from Fuji, Imbens, and Kalyanaraman (2009). 
Table 5: RD Estimates of Effects of Diabetes Diagnosis on BMI and Blood Pressure in First 12 Months Following A1c Test (UCLA EHR Results)

\begin{tabular}{|c|c|c|c|}
\hline & Control Mean (Std Dev) & $\begin{array}{l}\text { Reduced Form } \\
\text { Estimate }\end{array}$ & $\begin{array}{c}\text { IV Estimate of } \\
\text { Effect of Diagnosis }\end{array}$ \\
\hline Diabetes Diagnosis & 0.080 & $\begin{array}{c}0.292^{* * *} \\
(0.041)\end{array}$ & NA \\
\hline BMI & $28.47(5.51)$ & $\begin{array}{c}0.137 \\
(0.245)\end{array}$ & $\begin{array}{c}0.430 \\
(0.767)\end{array}$ \\
\hline Normal BMI & 0.267 & $\begin{array}{c}0.001 \\
(0.025)\end{array}$ & $\begin{array}{c}0.004 \\
(0.070)\end{array}$ \\
\hline Overweight & 0.343 & $\begin{array}{c}0.004 \\
(0.030)\end{array}$ & $\begin{array}{c}0.010 \\
(0.082)\end{array}$ \\
\hline Obese & 0.356 & $\begin{array}{l}-0.003 \\
(0.026)\end{array}$ & $\begin{array}{c}0.010 \\
(0.083)\end{array}$ \\
\hline Diastolic blood pressure & $76.13(8.31)$ & $\begin{array}{l}-1.041 \\
(0.710)\end{array}$ & $\begin{array}{l}-4.016 \\
(2.764)\end{array}$ \\
\hline Systolic blood pressure & $129.34(14.29)$ & $\begin{array}{l}-0.148 \\
(0.910)\end{array}$ & $\begin{array}{l}-0.384 \\
(2.365)\end{array}$ \\
\hline High blood pressure & 0.225 & $\begin{array}{l}-0.009 \\
(0.032)\end{array}$ & $\begin{array}{l}-0.022 \\
(0.080)\end{array}$ \\
\hline
\end{tabular}

Notes: Control means calculated using observations with A1c test values below 6.5 and greater than or equal to 6. Coefficient estimates from local linear regression with optimal bandwidth calculation from Fuji, Imbens, and Kalyanaraman (2009). Models for all outcomes, with the exception of diabetes diagnosis, control for the baseline (pre-test) level of the outcome variable. 
Table 6: RD Estimates of Effects of Diabetes Diagnosis on Self-Reported Health and Behaviors in First 12 Months Following A1c Test (Health Risk Assessment Results)

\begin{tabular}{lcc}
\hline \hline & $\begin{array}{c}\text { Reduced Form } \\
\text { Estimate }\end{array}$ & $\begin{array}{c}\text { IV Estimate of } \\
\text { Effect of Diagnosis }\end{array}$ \\
\hline Diabetes Diagnosis & $0.159^{* * *}$ & NA \\
& $(0.040)$ & \\
Self Reported Health & -0.116 & -0.728 \\
Very Good or Excellent & $(0.083)$ & $(0.558)$ \\
& & \\
Physical and Emotional & -0.077 & -0.292 \\
Well-Being & $(0.058)$ & $(0.221)$ \\
& & \\
Diet and Exercise & -0.003 & -0.014 \\
& $(0.053)$ & $(0.289)$ \\
Healthy Smoking and & -0.054 & -0.323 \\
Drinking Choices & $(0.060)$ & $(0.369)$ \\
\hline
\end{tabular}

Notes: Coefficient estimates from local linear regression with optimal bandwidth calculation from Fuji, Imbens, and Kalyanaraman (2009). 


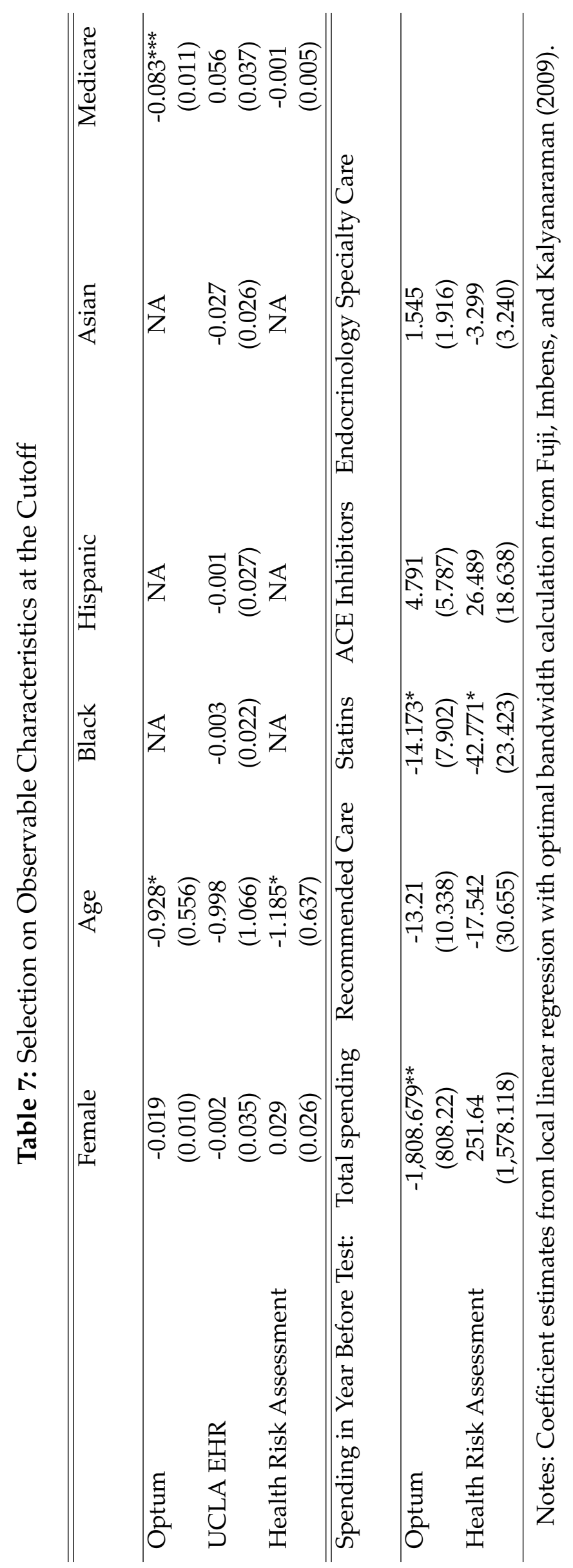


Table 8: RD Estimates for Sample Attrition

\begin{tabular}{ccc|cc}
\hline \hline & \multicolumn{3}{c}{ Optum } & \multicolumn{2}{c}{ UCLA EHR } \\
& Control Mean & Reduced Form Estimate & Control Mean & Reduced Form Estimate \\
\hline Year 2 & 0.754 & -0.017 & 0.986 & -0.009 \\
Year 3 & 0.484 & $(0.012)$ & & $(0.009)$ \\
& & $0.016^{*}$ & 0.207 & -0.010 \\
Year 4 & 0.300 & $(0.0097)$ & & \\
& & 0.003 & & \\
Year 5 & 0.200 & $(0.010)$ & \\
& & -0.005 & \\
Year 6 & 0.123 & $(0.009)$ & \\
& & -0.001 & & \\
\hline
\end{tabular}

Notes: Control means calculated using observations with A1c test values below 6.5 and greater than or equal to 6 . Coefficient estimates from local linear regression with optimal bandwidth calculation from Fuji, Imbens, and Kalyanaraman (2009). 


\section{References}

Almond, D., J. J. Doyle, A. E. Kowalski, and H. Williams (2010, May). Estimating Marginal Returns to Medical Care: Evidence from At-risk Newborns. The Quarterly Journal of Economics 125(2), 591-634.

Almond, D., A. Lee, and A. E. Schwartz (2016, March). Impacts of classifying New York City students as overweight. Proceedings of the National Academy of Sciences 113(13), 3488-3491.

American College of Cardiology (2017, November). New ACC/AHA High Blood Pressure Guidelines Lower Definition of Hypertension.

American Diabetes Association (2010, January). Diagnosis and Classification of Diabetes Mellitus. Diabetes Care 33(Suppl 1), S62-S69.

American Diabetes Association (2017). Standards of Medical Care in Diabetes - 2017. Diabetes Care 40(1).

American Diabetes Association (2018a, January). 2. Classification and Diagnosis of Diabetes: Standards of Medical Care in Diabetes-2018. Diabetes Care 41(Supplement 1), S13-S27.

American Diabetes Association (2018b, May). Economic Costs of Diabetes in the U.S. in 2017. Diabetes Care 41(5), 917-928.

Bharadwaj, P., K. V. Løken, and C. Neilson (2013, August). Early Life Health Interventions and Academic Achievement. American Economic Review 103(5), 1862-1891.

Centers for Disease Control and Prevention (2017). National Diabetes Statistics Report. Technical report, Department of Health \& Human Services.

Chyn, E., S. Gold, and J. S. Hastings (2019, April). The Returns to Early-life Interventions for Very Low Birth Weight Children. Working Paper 25753, National Bureau of Economic Research.

Coussens, S. (2018, August). Heuristic Thinking in the Emergency Department. Columbia School of Public Health Working Paper.

Dahlberg, M., K. Mani, M. Öhman, and A. Wanhainen (2016, January). Health Information and WellBeing: Evidence from an Asymptomatic Disease. Technical Report 2016:2, Uppsala University, Department of Economics.

Doyle, J. J. (2011, July). Returns to Local-Area Healthcare Spending: Evidence from Health Shocks to Patients Far From Home. American economic journal. Applied economics 3(3), 221-243.

Doyle, J. J., J. A. Graves, J. Gruber, and S. A. Kleiner (2015, February). Measuring Returns to Hospital Care: Evidence from Ambulance Referral Patterns. Journal of Political Economy 123(1), 170-214.

Finkelstein, A., S. Taubman, B. Wright, M. Bernstein, J. Gruber, J. P. Newhouse, H. Allen, and K. Baicker (2012, July). The Oregon Health Insurance Experiment: Evidence from the first year. The Quarterly Journal of Economics Advance Access.

Fisher, E. S., D. E. Wennberg, T. A. Stukel, D. J. Gottlieb, F. L. Lucas, and É. L. Pinder (2003a, February). The Implications of Regional Variations in Medicare Spending. Part 1: The Content, Quality, and Accessibility of Care. Annals of Internal Medicine 138(4), 273.

Fisher, E. S., D. E. Wennberg, T. A. Stukel, D. J. Gottlieb, F. L. Lucas, and É. L. Pinder (2003b, February). The Implications of Regional Variations in Medicare Spending. Part 2: Health Outcomes and Satisfaction with Care. Annals of Internal Medicine 138(4), 288. 
Frakes, M. (2013, February). The Impact of Medical Liability Standards on Regional Variations in Physician Behavior: Evidence from the Adoption of National-Standard Rules. American Economic Review 103(1), 257-276.

Fuji, D., G. Imbens, and K. Kalyanaraman (2009, September). Notes for Matlab and Stata Regression Discontinuity Software.

Gerteis, J., D. Izrael, D. Deitz, L. LeRoy, R. Ricciardi, T. Miller, and J. Basu (2014, April). Multiple Chronic Conditions Chartbook. Technical Report AHRQ Publications No, Q14-0038, Agency for Healthcare Research and Quality, Rockville, MD.

Hirst, J. A., A. J. Farmer, R. Ali, N. W. Roberts, and R. J. Stevens (2012, February). Quantifying the Effect of Metformin Treatment and Dose on Glycemic Control. Diabetes Care 35(2), 446-454.

Iizuka, T., K. Nishiyama, B. Chen, and K. Eggleston (2017, May). Is Preventive Care Worth the Cost? Evidence from Mandatory Checkups in Japan. Working Paper 23413, National Bureau of Economic Research.

Kim, H. B., S. A. Lee, and W. Lim (2019, May). Knowing is not half the battle: Impacts of information from the National Health Screening Program in Korea. Journal of Health Economics 65, 1-14.

Kling, J. R., J. B. Liebman, and L. F. Katz (2007). Experimental Analysis of Neighborhood Effects. Econometrica 75(1), 83-119.

Muntner, P., R. M. Carey, S. Gidding, D. W. Jones, S. J. Taler, J. T. Wright Jr., and P. K. Whelton (2018, January). Potential US Population Impact of the 2017 ACC/AHA High Blood Pressure Guideline. Circulation 137(2), 109-118.

Oster, E. (2018, October). Diabetes and Diet: Purchasing Behavior Change in Response to Health Information. American Economic Journal: Applied Economics 10(4), 308-348.

The International Expert Committee (2009, July). International Expert Committee Report on the Role of the A1c Assay in the Diagnosis of Diabetes. Diabetes Care 32(7), 1327-1334.

Tsugawa, Y., O. Takahashi, J. B. Meigs, R. B. Davis, F. Imamura, T. Fukui, W. C. Taylor, and C. C. Wee (2012, December). New Diabetes Diagnostic Threshold of Hemoglobin A1c and the 3-Year Incidence of Retinopathy. Diabetes 61(12), 3280-3284.

Vandorsten, J. P., W. C. Dodson, M. A. Espeland, W. A. Grobman, J. M. Guise, B. M. Mercer, H. L. Minkoff, B. Poindexter, L. A. Prosser, G. F. Sawaya, J. R. Scott, R. M. Silver, L. Smith, A. Thomas, and A. T. N. Tita (2013, March). NIH consensus development conference: diagnosing gestational diabetes mellitus. NIH consensus and state-of-the-science statements 29(1), 1-31.

Welch, H. G., L. M. Schwartz, and S. Woloshin (2011). Overdiagnosed: Making People Sick in the Pursuit of Health. Boston, MA: Beacon Press.

Whelton, P. K., R. M. Carey, W. S. Aronow, D. E. Casey, K. J. Collins, C. D. Himmelfarb, S. M. DePalma, S. Gidding, K. A. Jamerson, D. W. Jones, E. J. MacLaughlin, P. Muntner, B. Ovbiagele, S. C. Smith, C. C. Spencer, R. S. Stafford, S. J. Taler, R. J. Thomas, K. A. Williams, J. D. Williamson, and J. T. Wright (2018, May). 2017 ACC/AHA/AAPA/ABC/ACPM/AGS/APhA/ASH/ASPC/NMA/PCNA Guideline for the Prevention, Detection, Evaluation, and Management of High Blood Pressure in Adults: A Report of the American College of Cardiology/American Heart Association Task Force on Clinical Practice Guidelines. Journal of the American College of Cardiology 71(19), e127-e248.

Zhao, M., Y. Konishi, and P. Glewwe (2013, March). Does information on health status lead to a healthier lifestyle? Evidence from China on the effect of hypertension diagnosis on food consumption. Journal of Health Economics 32(2), 367-385. 


\title{
What Difference Does a Diagnosis Make? Evidence from Marginal Patients
}

\section{Appendix}

\author{
Mattan Alalouf Sarah Miller Laura R. Wherry
}

\section{Additional Results}

We include several additional results in the Appendix that are discussed in the text. These results are presented in Tables A2-A14.

\section{Health Risk Assessment Questions by Category}

Alcohol and Tobacco Use

- How many alcoholic drinks do you consume per week?

- Do you currently use cigarettes?

- Do you currently use cigars or pipes?

- Do you currently use smokeless tobacco?

Diet and Exercise

- How many servings of high-fat foods do you consume per day?

- During a typical week, how many days do you do physical activity outside your job?

- Have you made changes recently to manage your weight?

- Have you made an effort recently to change physical activity?

Health Status

- How would you rate your health?

Physical and Emotional Well-Being

- In general, how often is stress a problem for you?

- In the past year, how much effect has stress had on your health

- In the past year, how many days have you missed an entire workday due to physical or mental health problems?

- In the past two weeks, how often did physical/emotional problems make it difficult to work the required hours? 
- In the past two weeks, how often were you able to repeat the same motions working without difficulty cause by physical health

- In the past two weeks, how often did physical/emotional problems make it difficult to concentrate on work?

- In the past two weeks, how often did physical/emotional problems make it difficult to handle your workload?

- In the past two weeks, how often did physical/emotional problems make it difficult to help people get work done?

- In the past two weeks, how often did physical/emotional problems make it difficult to feel capable?

- In the past four weeks, how much did your health problems affect your ability to do your regular daily activities?

\section{Additional Details on UCLA EHR Data}

For the purposes of this research project, de-identified medical records data were acquired through the Informatics Program of the UCLA Clinical and Translational Science Institute. The data were extracted from UCLA's Integrated Clinical and Research Data Repository (xDR), a large scale clinical data warehouse that includes a full copy of the CareConnect Clarity data warehouse linked to

"legacy" data from older outpatient and hospital billing and managed care systems. Encounter data from $x D R$, which include hospitalizations, outpatient visits, and other encounter types, were used from the period January 1, 2006 to November 30, 2016. These data include information on the type of encounter, billing diagnoses, procedures completed (per billing data), and laboratory test results. Data on medication orders were only available starting in March 2, 2013 with the introduction of the CareConnect system at UCLA.

In contrast to Optum, the UCLA data include lab results for every lab ordered by a UCLA provider, including those processed by outside lab facilities. In addition, features of the medical records data that are unavailable in the Optum claims are the inclusion of vital sign data and problem lists, which are health conditions recorded by the physician during an encounter and are visible to the patient on the electronic patient portal and in printed visit summaries. The vital sign data and problem lists are only available starting in March 2, 2013 with the introduction of the current EHR CareConnect system at UCLA.

\section{Construction of Analytic Samples}

\subsection{Optum Data}

We identify each patient's initial A1c lab test in the Optum lab file. The lab file contains test descriptions and result values for lab tests provided by Optum affiliated laboratories. Patients who never receive A1c tests are not included in the analytic sample. We identified A1c tests as those with LOINC 
codes 4548-4, 27353-2, 17856-6, and 17855-8. We used the test description text to drop remaining inappropriate tests. We include only patients who were 18 or older at the time of the initial test. We do not include patients whose first A1c test occurred before 2009.

We drop patients who have any inpatient, outpatient, or drug spending related to diabetes prior to the date of the first observed lab test (see Appendix Table A15. We treat inpatient and outpatient spending as related to diabetes if any of the associated ICD-9 diagnosis codes begin with "249," or "250," or if the associated ICD-10 codes begin with "E08," "E09," “E10," “E11," "E13." Individuals with diabetes related lab tests (e.g. fasting plasma glucose, and random glucose tests) prior to the date of the first A1c test are also excluded. We also drop patients with pregnancy related diagnosis codes any time prior to the initial A1c test so that we can focus on standard diabetes diagnoses separately from gestational diabetes. We treat drug spending as related to diabetes if the prescription's National Drug Code (NDC) matches any of those in Appendix Table A16. We only observe the quarter in which a drug was prescribed, and we treat the first date of the quarter as the time of prescription.

We impose restrictions on how long patients must be present in the Optum data to ensure that we are identifying each patient's first A1c test. Without requiring that patients be present in the data prior to the date of the first test, we would likely mis-classify individuals with previously diagnosed diabetes (diagnosed and treated prior to their first Optum claim) with initial diabetes diagnoses. The Optum files provide records of insurance enrollment dates for each patient. We drop patients from our analysis if they were not enrolled in an Optum-covered insurance plan for at least 366 days prior to and following the date of the initial lab test. Many patients changed insurance plans during the sample period. We included these patients as long as they were covered under some Optum plan for the full 732 day period around the initial lab test, no matter how many times they switched plans. Some patients had brief breaks in coverage in the dates before and after the initial lab test. We dropped patients who had either had multiple breaks in coverage or had at least one break of more than 60 days.

\subsection{UCLA EHR Data}

The analytic sample was composed of all individuals with PCPs at UCLA aged 18 and older at the time of their first encounter with at least one A1c test for diabetes. Since LOINC codes were unavailable for the majority of labs, we identified A1c tests through text search of lab test descriptions to match the selection criteria used in the Optum data.

Since EHR vital records were only collected beginning in 2013, we exclude individuals with initial A1c tests that occurred prior to 2013. In order to preserve patient confidentiality, the EHR data have limited information available on dates of service. Each encounter is dated by the number of days relative to the patient's first encounter. In addition, we have information on the calendar year of the patient's last encounter. Therefore, we estimate the calendar year of the lab test by subtracting the difference in the number of days between the last encounter date and the lab test date divided by 365 from the calendar year of the patient's last encounter.

We required that each individual have at least one year of data prior to their initial diabetes test and that they have at least one encounter one year after the test date (i.e. remained in the data for at least one year following the test). Additional exclusions were made for individuals receiving a glucose test prior to the initial A1c test, individuals with diagnosis codes related to diabetes at any time prior to the test date, individuals with diagnosis codes related to pregnancy during the year prior to the test 
date, and anyone taking a drug for diabetes management prior to the test date. Similar to the Optum data, we have access to UCLA data prior to 2013 with information on encounters and labs dating back to 2006. We use this entire period to implement these sample exclusions, with the exception of the exclusion based on receipt of drugs for diabetes management. The last exclusion was only applied in 2013 or later since the prescription drug data are only available for these later years. 
Figure A1: Details on Sample Construction: Optum

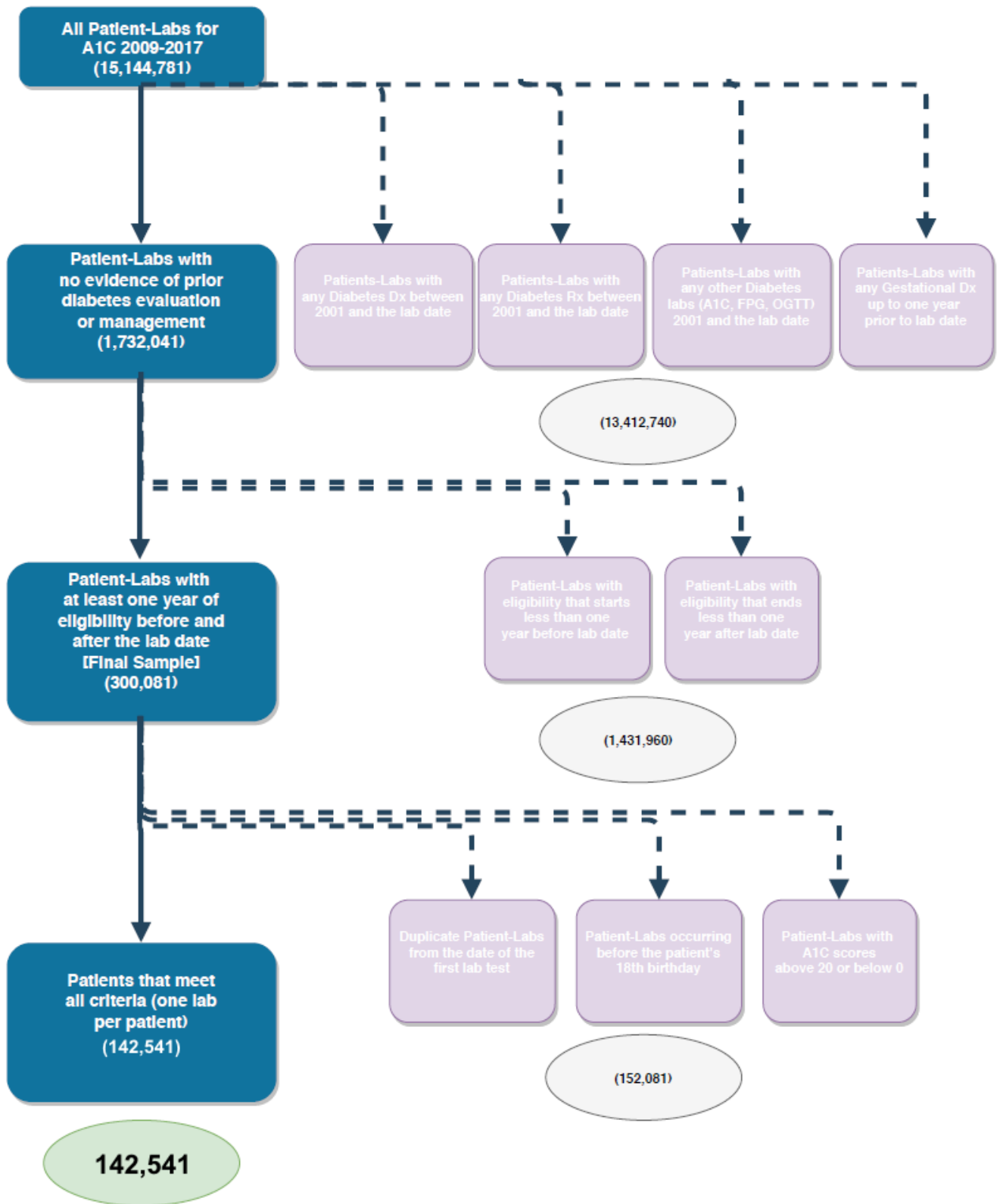


Figure A2: Details on Sample Construction: UCLA EHR

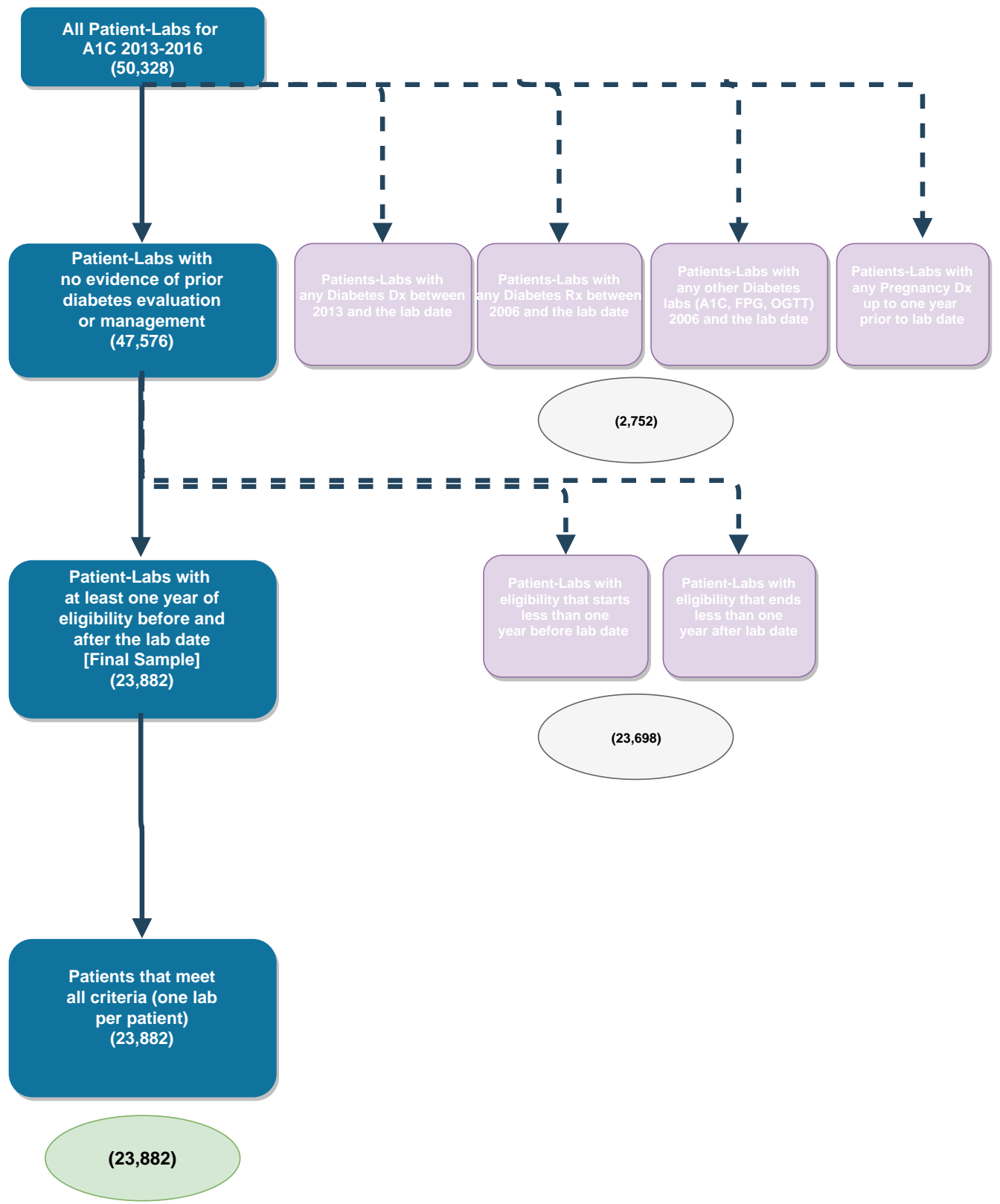


Figure A3: Optum Diagnosis and Spending Outcomes by Year After Initial Lab Test

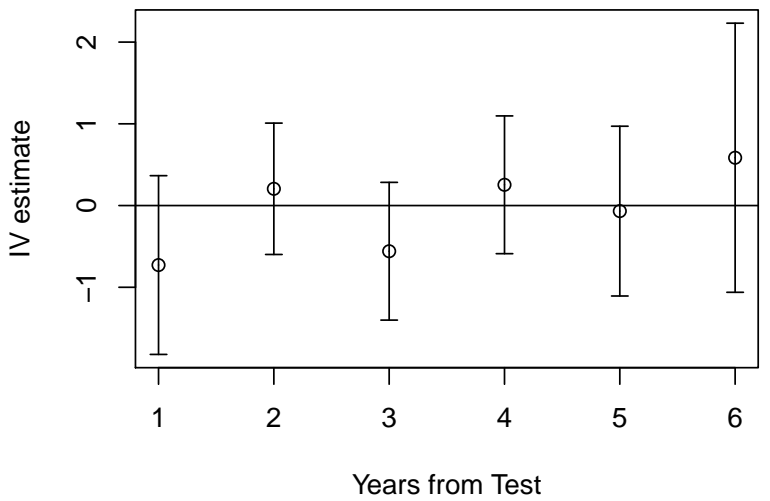

(a) Health Very Good or Excellent

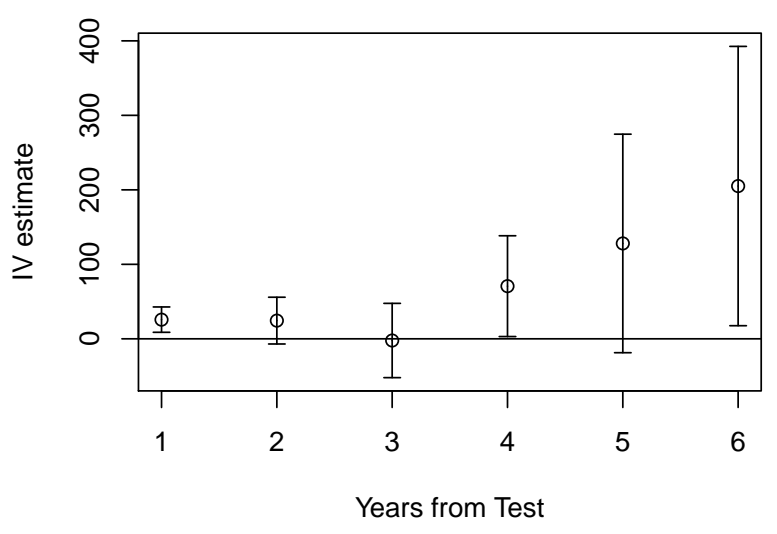

(d) Diet and Exercise

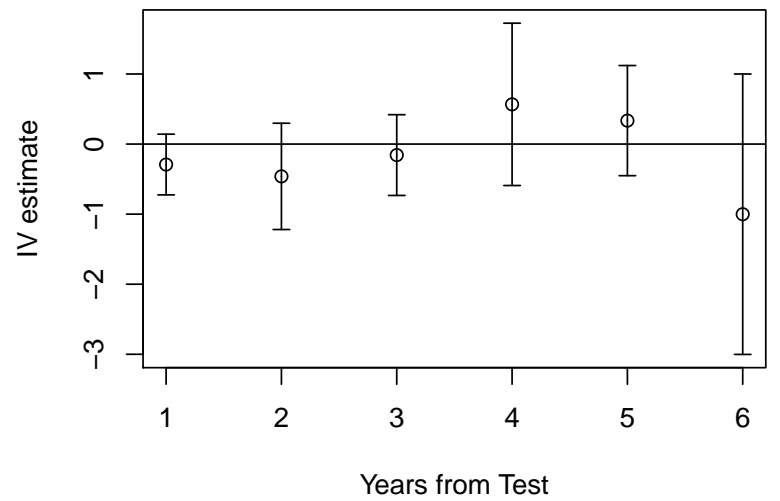

(b) Physical and Emotional Well-Being

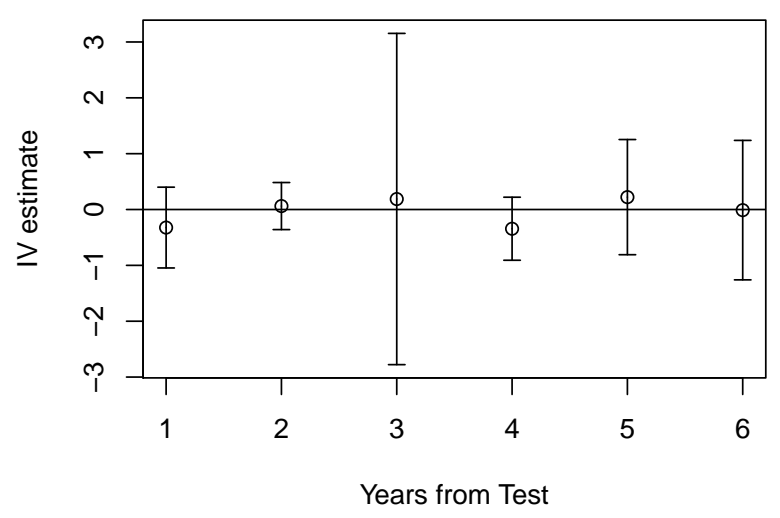

(e) Healthy Smoking and Drinking Choices

Source: Authors' calculations from the HRA survey data. Horizontal axis indicates the year relative to the initial lab test. Vertical axis indicates size of the regression discontinuity effect estimated using local linear regression. 95 percent confidence intervals displayed. 
Table A1: Diagnosis and Procedure Codes Used to Measure Spending Outcomes

\begin{tabular}{|c|c|c|c|}
\hline Description & ICD 9 Codes & ICD 10 Codes & CPT Codes \\
\hline Diabetes Related DX & 249,250 & $\begin{array}{l}\text { E08, E09, E10, } \\
\text { E11, E13 }\end{array}$ & $\mathrm{N} / \mathrm{A}$ \\
\hline Preventable Conditions & $\begin{array}{l}\text { 2501, 2502, 2504, } \\
2050,2506\end{array}$ & $\begin{array}{l}\text { E101, E111, E100, } \\
\text { E110, E102, E112, } \\
\text { E103, E113, E104, } \\
\text { E114 }\end{array}$ & $\mathrm{N} / \mathrm{A}$ \\
\hline Diabetic Ketoacidosis & 2501 & E101, E111 & $\mathrm{N} / \mathrm{A}$ \\
\hline Diabeteic Coma & 2502 & E100, E110 & $\mathrm{N} / \mathrm{A}$ \\
\hline Kidney Disease & 2504 & E102, E112 & $\mathrm{N} / \mathrm{A}$ \\
\hline Diabetic Retinopathy & 2505 & E103, E113 & $\mathrm{N} / \mathrm{A}$ \\
\hline Diabetic Neuropathy & 2506 & E104, E114 & $\mathrm{N} / \mathrm{A}$ \\
\hline Consultations & $\mathrm{N} / \mathrm{A}$ & $\mathrm{N} / \mathrm{A}$ & $\begin{array}{l}\text { 99201-99215, 99241- } \\
99245\end{array}$ \\
\hline Nutritional Therapy & $\mathrm{N} / \mathrm{A}$ & $\mathrm{N} / \mathrm{A}$ & $\begin{array}{l}\text { 98960, 98961, 98962, } \\
99078\end{array}$ \\
\hline Monitoring & $\mathrm{N} / \mathrm{A}$ & $\mathrm{N} / \mathrm{A}$ & 95250,95251 \\
\hline Self Management Training & $\mathrm{N} / \mathrm{A}$ & $\mathrm{N} / \mathrm{A}$ & $\begin{array}{l}\text { 98960, 98961, 98962, } \\
99078\end{array}$ \\
\hline Recommended Care & $\mathrm{N} / \mathrm{A}$ & $\mathrm{N} / \mathrm{A}$ & $\begin{array}{l}\text { All Codes in "Mon- } \\
\text { itoring," "Consultia- } \\
\text { tions," "Nutritional } \\
\text { Therapy," and "Self } \\
\text { Management and } \\
\text { Training" }\end{array}$ \\
\hline A1c or Random Glucose Labs & $\mathrm{N} / \mathrm{A}$ & $\mathrm{N} / \mathrm{A}$ & 82947,83036 \\
\hline Preventable Conditions & $\begin{array}{l}\text { 2501, 2502, 2504, } \\
2050,2506\end{array}$ & $\begin{array}{l}\text { E101, E111, E100, } \\
\text { E110, E102, E112, } \\
\text { E103, E113, E104, } \\
\text { E114 }\end{array}$ & $\mathrm{N} / \mathrm{A}$ \\
\hline
\end{tabular}


Table A2: RD Estimates of Effects of Diabetes Diagnosis in First 12 Months Following A1c Test (Health Risk Assessment Results)

\begin{tabular}{|c|c|c|c|}
\hline Diet and Exercise & Baseline Mean & $\begin{array}{c}\text { Reduced Form } \\
\text { Estimate }\end{array}$ & $\begin{array}{l}\text { IV Estimate of } \\
\text { Effect of Diagnosis }\end{array}$ \\
\hline $\begin{array}{l}\text { Eat } 3+\text { Servings of High Fat Food } \\
\text { per Day }\end{array}$ & 0.193 & $\begin{array}{l}-0.036 \\
(0.031)\end{array}$ & $\begin{array}{l}-0.138 \\
(0.120)\end{array}$ \\
\hline $\begin{array}{l}\text { Recently made Changes to } \\
\text { Improve Weight }\end{array}$ & 0.884 & $\begin{array}{c}0.019 \\
(0.044)\end{array}$ & $\begin{array}{c}0.189 \\
(0.467)\end{array}$ \\
\hline $\begin{array}{l}\text { Engage in Physical Activity } 3+ \\
\text { times per week }\end{array}$ & 0.519 & $\begin{array}{c}0.044 \\
(0.042)\end{array}$ & $\begin{array}{c}0.192 \\
(0.195)\end{array}$ \\
\hline $\begin{array}{l}\text { Recently Made Changes to } \\
\text { Increase Physical Activity }\end{array}$ & 0.903 & $\begin{array}{c}0.008 \\
(0.037)\end{array}$ & $\begin{array}{c}0.051 \\
(0.250)\end{array}$ \\
\hline $\begin{array}{l}\text { Physical and Emotional Well-Being } \\
\text { Health Interferes with Activities } \\
\text { of Daily Life }\end{array}$ & 0.131 & $\begin{array}{c}0.012 \\
(0.039)\end{array}$ & $\begin{array}{c}0.135 \\
(0.446)\end{array}$ \\
\hline $\begin{array}{l}\text { Stress Intereferes with Health } \\
\text { Quite a Bit or A Lot }\end{array}$ & 0.101 & $\begin{array}{c}0.005 \\
(0.029)\end{array}$ & $\begin{array}{c}0.026 \\
(0.167)\end{array}$ \\
\hline $\begin{array}{l}\text { Stress is a problem Sometimes, } \\
\text { Almost Always or Always }\end{array}$ & 0.371 & $\begin{array}{c}0.022 \\
(0.050)\end{array}$ & $\begin{array}{c}0.174 \\
(0.396)\end{array}$ \\
\hline \multicolumn{4}{|c|}{ In the past 2 weeks, physical/emotional problems made it difficult... (some of the time or more) } \\
\hline ...to feel capable & 0.147 & $\begin{array}{l}-0.014 \\
(0.036)\end{array}$ & $\begin{array}{l}-0.091 \\
(0.237)\end{array}$ \\
\hline ...to handle workload & 0.089 & $\begin{array}{l}-0.008 \\
(0.028)\end{array}$ & $\begin{array}{l}-0.043 \\
(0.149)\end{array}$ \\
\hline ...to help others with work & 0.152 & $\begin{array}{l}-0.001 \\
(0.035)\end{array}$ & $\begin{array}{l}-0.003 \\
(0.157)\end{array}$ \\
\hline ...to start work right away & 0.069 & $\begin{array}{l}-0.035 \\
(0.022)\end{array}$ & $\begin{array}{l}-0.16 \\
(0.103)\end{array}$ \\
\hline ...to concentrate at work & 0.18 & $\begin{array}{l}0.034 \\
(0.041)\end{array}$ & $\begin{array}{c}0.201 \\
(0.248)\end{array}$ \\
\hline ...to do repetitive tasks & 0.151 & $\begin{array}{l}-0.033 \\
(0.034)\end{array}$ & $\begin{array}{l}-0.13 \\
(0.141)\end{array}$ \\
\hline $\begin{array}{l}\text {...to work the number of hours } \\
\text { required by your job }\end{array}$ & 0.076 & $\begin{array}{l}-0.007 \\
(0.030)\end{array}$ & $\begin{array}{l}-0.054 \\
(0.235)\end{array}$ \\
\hline $\begin{array}{l}\text { of days missed work due to physical } \\
\text { or mental health problems }\end{array}$ & 0.151 & $\begin{array}{c}0.023 \\
(0.036)\end{array}$ & $\begin{array}{c}0.118 \\
(0.192)\end{array}$ \\
\hline Self-Reported Health & & & \\
\hline $\begin{array}{l}\text { Health is Very Good or Excellent } \\
\text { Smoking and Drinking Behavior }\end{array}$ & 0.514 & $\begin{array}{l}-0.058 \\
(0.041)\end{array}$ & $\begin{array}{l}-0.363 \\
(0.276)\end{array}$ \\
\hline Currently Smoke Cigarettes & 0.084 & $\begin{array}{l}0.045^{*} \\
(0.027)\end{array}$ & $\begin{array}{c}0.208 \\
(0.130)\end{array}$ \\
\hline Currently Smoke Cigars & 0.018 & $\begin{array}{l}-0.006 \\
(0.009)\end{array}$ & $\begin{array}{l}-0.028 \\
(0.040)\end{array}$ \\
\hline Currently Use Smokeless Tobacco & 0.014 & $\begin{array}{l}-0.003 \\
(0.005)\end{array}$ & $\begin{array}{l}-0.022 \\
(0.044)\end{array}$ \\
\hline Number of Alcoholic Drinks Weekly & 1.358 & $\begin{array}{c}0.022 \\
(0.181)\end{array}$ & $\begin{array}{c}0.091 \\
(0.758)\end{array}$ \\
\hline
\end{tabular}

Notes: Coefficient estimates from local linear regression with optimal bandwidth calculation from Fuji, Imbens, and Kalyanaraman (2009). 
Table A3: RD Estimates of Effects of Diabetes Diagnosis in First 12 Months Following A1c Test, Controlling for Medicare Advantage Enrollment and Baseline Spending

\begin{tabular}{|c|c|c|c|}
\hline & Control Mean (Std Dev) & $\begin{array}{l}\text { Reduced Form } \\
\text { Estimate }\end{array}$ & $\begin{array}{c}\text { IV Estimate of } \\
\text { Effect of Diagnosis }\end{array}$ \\
\hline Diabetes Diagnosis & 0.183 & $\begin{array}{l}0.109^{* * *} \\
(0.019)\end{array}$ & \\
\hline $\begin{array}{l}\text { Spending on ADA } \\
\text { Recommended Care }\end{array}$ & $362.03(718.09)$ & $\begin{array}{l}196.928^{* * *} \\
(22.797)\end{array}$ & $\begin{array}{c}1,025.114^{* * *} \\
(108.940)\end{array}$ \\
\hline $\begin{array}{l}\text { Spending on Office-Based } \\
\text { Care Related to Diabetes }\end{array}$ & $26.17(122.28)$ & $\begin{array}{l}79.876^{* * *} \\
(6.910)\end{array}$ & $\begin{array}{l}505.539^{* * *} \\
(42.050)\end{array}$ \\
\hline $\begin{array}{l}\text { Spending on Diabetes-Related } \\
\text { Labs }\end{array}$ & $89.10(353.69)$ & $\begin{array}{l}79.354^{* * *} \\
(13.914)\end{array}$ & $\begin{array}{c}502.903^{* * *} \\
(79.820)\end{array}$ \\
\hline $\begin{array}{l}\text { Spending on Diabetes-Related } \\
\text { Vision Services }\end{array}$ & $2.26(27.92)$ & $\begin{array}{l}4.595^{* * *} \\
(1.469)\end{array}$ & $\begin{array}{c}27.031^{* * *} \\
(8.559)\end{array}$ \\
\hline $\begin{array}{l}\text { Endocrinology Specialist Care } \\
\text { Spending }\end{array}$ & $19.95(313.62)$ & $\begin{array}{c}37.613 \\
(22.987)\end{array}$ & $\begin{array}{l}133.221 \\
(81.415)\end{array}$ \\
\hline $\begin{array}{l}\text { Number of Diabetes-Related } \\
\text { Office Visits }\end{array}$ & $0.177(0.775)$ & $\begin{array}{l}0.456^{* * *} \\
(0.045)\end{array}$ & $\begin{array}{l}3.160^{* * *} \\
(0.294)\end{array}$ \\
\hline Number of A1c/Glucose Labs & $1.46(1.01)$ & $\begin{array}{l}0.064^{* *} \\
(0.032)\end{array}$ & $\begin{array}{l}0.397^{* *} \\
(0.192)\end{array}$ \\
\hline $\begin{array}{l}\text { Spending on } \\
\text { Diabetes-Controlling Drugs }\end{array}$ & $4.37(97.04)$ & $\begin{array}{l}4.843 \\
(3.503)\end{array}$ & $\begin{array}{c}22.096 \\
(15.966)\end{array}$ \\
\hline $\begin{array}{l}\text { Any Spending on } \\
\text { Diabetes-Controlling Drugs }\end{array}$ & 0.005 & $\begin{array}{l}0.009 * * * \\
(0.003)\end{array}$ & $\begin{array}{l}0.041^{* * *} \\
(0.014)\end{array}$ \\
\hline Spending on Statins & $151.21(436.84)$ & $\begin{array}{l}-7.354 \\
(9.649)\end{array}$ & $\begin{array}{l}-31.242 \\
(41.094)\end{array}$ \\
\hline Spending on ACE Inhibitors & $96.00(299.36)$ & $\begin{array}{l}7.996 \\
(6.966)\end{array}$ & $\begin{array}{c}31.717 \\
(27.601)\end{array}$ \\
\hline
\end{tabular}

Notes: Control means calculated using observations with A1c test values below 6.5 and greater than or equal to 6 . Coefficient estimates from local linear regression with optimal bandwidth calculation from Fuji, Imbens, and Kalyanaraman (2009). 
Table A4: RD Estimates of Effects of Diabetes Diagnosis in First 12 Months Following A1c Test, Controlling for Medicare Advantage Enrollment And Baseline Spending

\begin{tabular}{lccc}
\hline \hline & Control Mean (Std Dev) & $\begin{array}{c}\text { Reduced Form } \\
\text { Estimate }\end{array}$ & $\begin{array}{c}\text { IV Estimate of } \\
\text { Effect of Diagnosis }\end{array}$ \\
\hline Diabetic Retinopathy & 0.002 & $0.005^{* *}$ & $0.023^{* *}$ \\
Ketoacidosis & 0.007 & $(0.002)$ & $(0.010)$ \\
Diabetic Coma & & 0.001 & 0.009 \\
& 0.006 & $(0.001)$ & $(0.006)$ \\
Diabetic Neuropathy & & 0.001 & 0.006 \\
& 0.0006 & $(0.001)$ & $(0.005)$ \\
Kidney Disease & & $0.011^{* *}$ & $0.075^{* * *}$ \\
& 0.0006 & $(0.004)$ & $(0.029)$ \\
Change in A1c & & $0.019^{* * *}$ & $0.118^{* * *}$ \\
from Previous Year & $-0.056(0.460)$ & $(0.004)$ & $(0.026)$ \\
Change in Total Cholesterol & $-6.429(32.62)$ & $-0.054^{* *}$ & $-0.293^{* *}$ \\
from Previous Year & & $(0.025)$ & $(0.141)$ \\
Change in Creatinine & & -0.928 & -3.169 \\
from Previous Year & $0.014(0.113)$ & $(1.208)$ & $(4.123)$ \\
Mortality & & 0.004 & 0.02 \\
& 0.005 & $(0.005)$ & $(0.025)$ \\
& & 0.001 & 0.004 \\
& & $(0.001)$ & $(0.007)$ \\
\hline
\end{tabular}

Notes: Control means calculated using observations with A1c test values below 6.5 and greater than or equal to 6 . Coefficient estimates from local linear regression with optimal bandwidth calculation from Fuji, Imbens, and Kalyanaraman (2009). ${ }^{\wedge}$ Note that mortality is measured 2 years after the initial test as we require individuals to be present in the data and alive for the first 12 months after the initial test. 
Table A5: Spending on Elements of Recommended Care Not Identified with a Diabetes Diagnosis Code

\begin{tabular}{lc}
\hline \hline & $\begin{array}{c}\text { IV Estimate of } \\
\text { Effect of Diagnosis }\end{array}$ \\
\hline Spending on All Office Care & 22.23 \\
Number of Evaluation and Management Visits & $(84.39)$ \\
& -0.339 \\
Spending on Statins, ACE inhibitors, diabetes-controlling & $(0.479)$ \\
drugs, glucose labs and endocrinology specialty care & $254.07^{* *}$ \\
\end{tabular}

Notes: Coefficient estimates from local linear regression with optimal bandwidth calculation from Fuji, Imbens, and Kalyanaraman (2009). 
Table A6: RD Estimates of Effects of Diabetes Diagnosis on Utilization in First 12 Months (UCLA EHR Results)

\begin{tabular}{lccc}
\hline \hline & Control Mean (Std Dev) & $\begin{array}{c}\text { Reduced Form } \\
\text { Estimate }\end{array}$ & $\begin{array}{c}\text { IV Estimate of } \\
\text { Effect of Diagnosis }\end{array}$ \\
\hline Diabetes Diagnosis & 0.08 & $\begin{array}{c}0.292^{* * *} \\
(0.041)\end{array}$ & N/A \\
& & $0.126^{* * *}$ & $0.309^{* * *}$ \\
Diabetes Diagnosis on Problem List & 0.03 & $(0.032)$ & $(0.072)$ \\
& & & $4.452^{* * *}$ \\
Number of Ambulatory Encounters & $0.27(1.58)$ & $2.035^{* * *}$ & $(0.354)$ \\
Related to Diabetes & & $(0.204)$ & $0.397^{*}$ \\
Number of A1c Labs & & $0.152^{*}$ & $(0.209)$ \\
& $0.73(0.98)$ & $(0.085)$ & $0.136^{* * *}$ \\
Prescription for Diabetes-Controlling & & & $(0.039)$ \\
Drug & 0.019 & $0.058^{* * *}$ & $(0.017)$ \\
\hline
\end{tabular}

Notes: Control means calculated using observations with A1c test values below 6.5 and greater than or equal to 6 . Coefficient estimates from local linear regression with optimal bandwidth calculation from Fuji, Imbens, and Kalyanaraman (2009). 
Table A7: Alternative models and bandwidths: Spending and Utilization Outcomes

\begin{tabular}{|c|c|c|c|c|}
\hline & Main model & $\begin{array}{c}\text { Global } \\
\text { quadratic model }\end{array}$ & $\begin{array}{c}\text { Optimal } \\
\text { Bandwidth } \times 2\end{array}$ & $\begin{array}{c}\text { Optimal } \\
\text { Bandwidth } \times 0.5\end{array}$ \\
\hline Diabetes Diagnosis & $\begin{array}{l}0.108^{* * *} \\
(0.019)\end{array}$ & $\begin{array}{l}0.292^{* * *} \\
(0.011)\end{array}$ & $\begin{array}{l}0.161^{* * *} \\
(0.013)\end{array}$ & $\begin{array}{l}0.178^{* * *} \\
(0.016)\end{array}$ \\
\hline $\begin{array}{l}\text { Spending on ADA } \\
\text { Recommended Care }\end{array}$ & $\begin{array}{l}207.609^{* * *} \\
(22.912)\end{array}$ & $\begin{array}{l}270.396^{* * *} \\
(18.260)\end{array}$ & $\begin{array}{l}268.938^{* * *} \\
(18.671)\end{array}$ & $\begin{array}{c}137.849^{* * *} \\
(32.218)\end{array}$ \\
\hline $\begin{array}{l}\text { Spending on Office-Based } \\
\text { Care Related to Diabetes }\end{array}$ & $\begin{array}{l}79.112^{* * *} \\
(6.912)\end{array}$ & $\begin{array}{l}140.478^{* * *} \\
(5.615)\end{array}$ & $\begin{array}{l}115.549^{* * *} \\
(5.566)\end{array}$ & $\begin{array}{c}52.189^{* * *} \\
(10.033)\end{array}$ \\
\hline $\begin{array}{l}\text { Spending on Diabetes-Related } \\
\text { Labs }\end{array}$ & $\begin{array}{c}78.650 * * * \\
(13.891)\end{array}$ & $\begin{array}{l}139.370^{* * *} \\
(9.964)\end{array}$ & $\begin{array}{l}114.484^{* * *} \\
(10.831)\end{array}$ & $\begin{array}{l}34.774^{*} \\
(20.660)\end{array}$ \\
\hline $\begin{array}{l}\text { Spending on Diabetes-Related } \\
\text { Vision Services }\end{array}$ & $\begin{array}{l}4.245^{* * *} \\
(1.489)\end{array}$ & $\begin{array}{l}9.249 * * * \\
(1.279)\end{array}$ & $\begin{array}{l}9.060^{* * *} \\
(1.196)\end{array}$ & $\begin{array}{c}3.214 \\
(2.157)\end{array}$ \\
\hline $\begin{array}{l}\text { Endocrinology Specialist } \\
\text { Care Spending }\end{array}$ & $\begin{array}{l}38.741^{*} \\
(23.024)\end{array}$ & $\begin{array}{l}30.525^{*} \\
(16.665)\end{array}$ & $\begin{array}{l}33.576^{*} \\
(19.218)\end{array}$ & $\begin{array}{c}44.18 \\
(27.185)\end{array}$ \\
\hline $\begin{array}{l}\text { Number of Diabetes-Related } \\
\text { Office Visits }\end{array}$ & $\begin{array}{l}0.442^{* * *} \\
(0.046)\end{array}$ & $\begin{array}{l}0.899^{* * *} \\
(0.034)\end{array}$ & $\begin{array}{c}0.260^{* * *} \\
(0.075)\end{array}$ & $\begin{array}{l}0.673^{* * *} \\
(0.035)\end{array}$ \\
\hline Number of A1c/Glucose Labs & $\begin{array}{l}0.063^{* *} \\
(0.032)\end{array}$ & $\begin{array}{l}0.102^{* * *} \\
(0.024)\end{array}$ & $\begin{array}{c}0.109^{* * *} \\
(0.024)\end{array}$ & $\begin{array}{c}0.06 \\
(0.048)\end{array}$ \\
\hline $\begin{array}{l}\text { Spending on } \\
\text { Diabetes-Controlling Drugs }\end{array}$ & $\begin{array}{c}5.264 \\
(3.497)\end{array}$ & $\begin{array}{c}-1.01 \\
(5.168)\end{array}$ & $\begin{array}{l}8.232^{* *} \\
(3.422)\end{array}$ & $\begin{array}{l}-1.157 \\
(4.627)\end{array}$ \\
\hline $\begin{array}{l}\text { Any Spending on } \\
\text { Diabetes-Controlling Drugs }\end{array}$ & $\begin{array}{c}0.010 * * * \\
(0.003)\end{array}$ & $\begin{array}{c}0.010^{* * *} \\
(0.003)\end{array}$ & $\begin{array}{c}0.013^{* * *} \\
(0.003)\end{array}$ & $\begin{array}{c}0.005 \\
(0.004)\end{array}$ \\
\hline Spending on Statins & $\begin{array}{c}2.073 \\
(9.799)\end{array}$ & $\begin{array}{l}-13.013 \\
(7.967)\end{array}$ & $\begin{array}{l}-0.991 \\
(8.209)\end{array}$ & $\begin{array}{c}9.522 \\
(13.486)\end{array}$ \\
\hline Spending on ACE Inhibitors & $\begin{array}{c}13.767^{* *} \\
(7.020)\end{array}$ & $\begin{array}{c}5.975 \\
(5.825)\end{array}$ & $\begin{array}{c}16.678^{* * *} \\
(5.949)\end{array}$ & $\begin{array}{l}13.999 \\
(9.447)\end{array}$ \\
\hline
\end{tabular}

Notes: Baseline means calculated using observations with A1c test values below 6.5 and greater than or equal to 6 . Coefficient estimates from local linear regression with optimal bandwidth calculation from Fuji, Imbens, and Kalyanaraman (2009). ^Note that mortality is measured 2 years after the initial test as we require individuals to be present in the data and alive for the first 12 months after the initial test. 
Table A8: Alternative model and bandwidths: Preventable Conditions and Optum Health Outcomes

\begin{tabular}{|c|c|c|c|c|}
\hline & Main model & $\begin{array}{c}\text { Global } \\
\text { quadratic model }\end{array}$ & $\begin{array}{c}\text { Optimal } \\
\text { Bandwidth } \times 2\end{array}$ & $\begin{array}{c}\text { Optimal } \\
\text { Bandwidth } \times 0.5\end{array}$ \\
\hline Diabetic Retinopathy & $\begin{array}{l}0.004^{* *} \\
(0.002)\end{array}$ & $\begin{array}{l}0.006^{* * *} \\
(0.002)\end{array}$ & $\begin{array}{l}0.006^{* * *} \\
(0.002)\end{array}$ & $\begin{array}{c}0.004 \\
(0.003)\end{array}$ \\
\hline Ketoacidosis & $\begin{array}{c}0.002 \\
(0.001)\end{array}$ & $\begin{array}{c}0.001 \\
(0.001)\end{array}$ & $\begin{array}{l}0.001^{*} \\
(0.001)\end{array}$ & $\begin{array}{c}0.001 \\
(0.001)\end{array}$ \\
\hline Diabetic Coma & $\begin{array}{c}0.001 \\
(0.001)\end{array}$ & $\begin{array}{c}0.001 \\
(0.001)\end{array}$ & $\begin{array}{c}0.001 \\
(0.001)\end{array}$ & $\begin{array}{c}0.001 \\
(0.001)\end{array}$ \\
\hline Diabetic Neuropathy & $\begin{array}{l}0.010^{* *} \\
(0.004)\end{array}$ & $\begin{array}{l}0.018^{* * *} \\
(0.003)\end{array}$ & $\begin{array}{l}0.017^{* * *} \\
(0.003)\end{array}$ & $\begin{array}{c}0.004 \\
(0.007)\end{array}$ \\
\hline Kidney Disease & $\begin{array}{l}0.018^{* * *} \\
(0.004)\end{array}$ & $\begin{array}{l}0.024^{* * *} \\
(0.003)\end{array}$ & $\begin{array}{l}0.023^{* * *} \\
(0.003)\end{array}$ & $\begin{array}{l}0.017^{* * *} \\
(0.006)\end{array}$ \\
\hline $\begin{array}{l}\text { Change in A1c } \\
\text { from Previous Year }\end{array}$ & $\begin{array}{l}-0.062^{* *} \\
(0.028)\end{array}$ & $\begin{array}{l}0.061^{* *} \\
(0.024)\end{array}$ & $\begin{array}{l}-0.014 \\
(0.019)\end{array}$ & $\begin{array}{c}-0.105^{* * *} \\
(0.039)\end{array}$ \\
\hline $\begin{array}{l}\text { Change in Total Cholesterol } \\
\text { from Previous Year }\end{array}$ & $\begin{array}{l}-5.26 \\
(4.03)\end{array}$ & $\begin{array}{l}-2.006^{*} \\
(1.172)\end{array}$ & $\begin{array}{l}3.686 \\
(2.757)\end{array}$ & $\begin{array}{l}-5.212 \\
(8.796)\end{array}$ \\
\hline $\begin{array}{l}\text { Change in Creatinine } \\
\text { from Previous Year }\end{array}$ & $\begin{array}{c}0.018 \\
(0.025)\end{array}$ & $\begin{array}{c}-0.004 \\
(0.004)\end{array}$ & $\begin{array}{c}-0.002 \\
(0.012)\end{array}$ & $\begin{array}{c}0 \\
(0.061)\end{array}$ \\
\hline Mortality $^{\wedge}$ & $\begin{array}{c}0.000 \\
(0.001)\end{array}$ & $\begin{array}{c}0.000 \\
(0.0004)\end{array}$ & $\begin{array}{c}0.000 \\
(0.001)\end{array}$ & $\begin{array}{c}0.000 \\
(0.001)\end{array}$ \\
\hline
\end{tabular}

Notes: Baseline means calculated using observations with A1c test values below 6.5 and greater than or equal to 6 . Coefficient estimates from local linear regression with optimal bandwidth calculation from Fuji, Imbens, and Kalyanaraman (2009). 
Table A9: Alternative model and bandwidths: Clinical Health Measures

\begin{tabular}{|c|c|c|c|c|}
\hline & Main model & $\begin{array}{c}\text { Global } \\
\text { quadratic model }\end{array}$ & $\begin{array}{c}\text { Optimal } \\
\text { Bandwidth } \times 2\end{array}$ & $\begin{array}{c}\text { Optimal } \\
\text { Bandwidth } \times 0.5\end{array}$ \\
\hline Diabetes Diagnosis & $\begin{array}{c}0.292^{* * *} \\
(0.041)\end{array}$ & $\begin{array}{c}0.300^{* * *} \\
(0.041)\end{array}$ & $\begin{array}{c}0.421^{* * *} \\
(0.032)\end{array}$ & $\begin{array}{c}0.210^{* * *} \\
(0.061)\end{array}$ \\
\hline BMI & $\begin{array}{c}0.137 \\
(0.245)\end{array}$ & $\begin{array}{c}0.242 \\
(0.271)\end{array}$ & $\begin{array}{c}0.068 \\
(0.196)\end{array}$ & $\begin{array}{c}0.23 \\
(0.302)\end{array}$ \\
\hline Normal BMI & $\begin{array}{c}0.001 \\
(0.025)\end{array}$ & $\begin{array}{c}-0.002 \\
(0.030)\end{array}$ & $\begin{array}{c}0.011 \\
(0.021)\end{array}$ & $\begin{array}{c}0.006 \\
(0.032)\end{array}$ \\
\hline Overweight & $\begin{array}{c}0.004 \\
(0.030)\end{array}$ & $\begin{array}{c}0.025 \\
(0.037)\end{array}$ & $\begin{array}{l}-0.019 \\
(0.026)\end{array}$ & $\begin{array}{c}0.015 \\
(0.041)\end{array}$ \\
\hline Obese & $\begin{array}{l}-0.003 \\
(0.026)\end{array}$ & $\begin{array}{l}-0.006 \\
(0.028)\end{array}$ & $\begin{array}{c}0.005 \\
(0.020)\end{array}$ & $\begin{array}{l}-0.027 \\
(0.043)\end{array}$ \\
\hline Diastolic blood pressure & $\begin{array}{l}-1.041 \\
(0.710)\end{array}$ & $\begin{array}{l}-0.807 \\
(0.737)\end{array}$ & $\begin{array}{l}-0.628 \\
(0.541)\end{array}$ & $\begin{array}{c}-1.302 \\
(1.004)\end{array}$ \\
\hline Systolic blood pressure & $\begin{array}{l}-0.148 \\
(0.910)\end{array}$ & $\begin{array}{c}-0.653 \\
(1.213)\end{array}$ & $\begin{array}{l}-0.089 \\
(0.794)\end{array}$ & $\begin{array}{l}-0.807 \\
(1.173)\end{array}$ \\
\hline High blood pressure & $\begin{array}{l}-0.009 \\
(0.032)\end{array}$ & $\begin{array}{l}-0.019 \\
(0.045)\end{array}$ & $\begin{array}{c}0 \\
(0.029)\end{array}$ & $\begin{array}{l}-0.013 \\
(0.041)\end{array}$ \\
\hline
\end{tabular}

Notes: Control means calculated using observations with A1c test values below 6.5 and greater than or equal to 6. Coefficient estimates from local linear regression with optimal bandwidth calculation from Fuji, Imbens, and Kalyanaraman (2009). Models for all outcomes, with the exception of diabetes diagnosis, control for the baseline (pre-test) level of the outcome variable. 
Table A10: Alternative model and bandwidths: Health Risk Assessment outcomes

\begin{tabular}{lcccc}
\hline & Main model & $\begin{array}{c}\text { Global } \\
\text { quadratic model }\end{array}$ & $\begin{array}{c}\text { Optimal } \\
\text { Bandwidth x 2 }\end{array}$ & $\begin{array}{c}\text { Optimal } \\
\text { Bandwidth x 0.5 }\end{array}$ \\
\hline Diet and Exercise & -0.003 & -0.014 & 0.002 & 0.07 \\
& $(0.053)$ & $(0.059)$ & $(0.044)$ & $(0.075)$ \\
Physical and Emotional & -0.077 & -0.023 & $-0.097^{*}$ & -0.044 \\
Well-Being & $(0.058)$ & $(0.067)$ & $(0.050)$ & $(0.073)$ \\
Self Reported Health & -0.116 & -0.048 & $-0.115^{*}$ & $-0.242^{* *}$ \\
Very Good or Excellent & $(0.083)$ & $(0.090)$ & $(0.067)$ & $(0.121)$ \\
Healthy Smoking and & -0.054 & -0.1 & -0.026 & -0.03 \\
Drinking Choices & $(0.060)$ & $(0.067)$ & $(0.050)$ & $(0.084)$ \\
\hline
\end{tabular}

Notes: Coefficient estimates from local linear regression with optimal bandwidth calculation from Fuji, Imbens, and Kalyanaraman (2009). 
Table A11: RD Estimates of Effects of Diabetes Diagnosis in First 12 Months Following A1c Test Including Only Those Enrolled for at least 2 Years Prior to Initial Test

\begin{tabular}{|c|c|c|c|}
\hline & Baseline Mean (Std Dev) & $\begin{array}{l}\text { Reduced Form } \\
\text { Estimate }\end{array}$ & $\begin{array}{c}\text { IV Estimate of } \\
\text { Effect of Diagnosis }\end{array}$ \\
\hline Diabetes Diagnosis & 0.172 & $\begin{array}{c}0.108^{* * *} \\
(0.022)\end{array}$ & \\
\hline $\begin{array}{l}\text { Spending on ADA Recommended } \\
\text { Care }\end{array}$ & $351.46(706.71)$ & $\begin{array}{l}211.666^{* * *} \\
(26.851)\end{array}$ & $\begin{array}{l}1,050.503^{* * *} \\
(124.805)\end{array}$ \\
\hline $\begin{array}{l}\text { Spending on Office-Based } \\
\text { Care Related to Diabetes }\end{array}$ & $25.13(120.05)$ & $\begin{array}{l}70.649^{* * *} \\
(9.316)\end{array}$ & $\begin{array}{l}499.217^{* * *} \\
(63.702)\end{array}$ \\
\hline $\begin{array}{l}\text { Spending on Diabetes-Related } \\
\text { Labs }\end{array}$ & $80.22(341.30)$ & $\begin{array}{l}80.121^{* * *} \\
(14.223)\end{array}$ & $\begin{array}{l}449.530^{* * *} \\
(71.981)\end{array}$ \\
\hline $\begin{array}{l}\text { Spending on Diabetes-Related } \\
\text { Vision Services }\end{array}$ & $2.17(28.01)$ & $\begin{array}{l}3.953^{* *} \\
(1.550)\end{array}$ & $\begin{array}{l}16.988^{* *} \\
(6.599)\end{array}$ \\
\hline $\begin{array}{l}\text { Endocrinology Specialist Care } \\
\text { Spending }\end{array}$ & $19.65(207.01)$ & $\begin{array}{c}33.653 \\
(28.627)\end{array}$ & $\begin{array}{l}111.773 \\
(95.055)\end{array}$ \\
\hline $\begin{array}{l}\text { Number of Diabetes-Related } \\
\text { Office Visits }\end{array}$ & $0.170(0.770)$ & $\begin{array}{l}0.427^{* * *} \\
(0.062)\end{array}$ & $\begin{array}{l}3.223^{* * *} \\
(0.444)\end{array}$ \\
\hline Number of A1c/Glucose Labs & $1.48(0.996)$ & $\begin{array}{c}0.054 \\
(0.036)\end{array}$ & $\begin{array}{c}0.28 \\
(0.179)\end{array}$ \\
\hline $\begin{array}{l}\text { Spending on } \\
\text { Diabetes-Controlling Drugs }\end{array}$ & $4.51(99.59)$ & $\begin{array}{c}2.644 \\
(4.371)\end{array}$ & $\begin{array}{c}11.177 \\
(18.462)\end{array}$ \\
\hline $\begin{array}{l}\text { Any Spending on } \\
\text { Diabetes-Controlling Drugs }\end{array}$ & $0.005(0.072)$ & $\begin{array}{c}0.006 \\
(0.004)\end{array}$ & $\begin{array}{c}0.027 \\
(0.018)\end{array}$ \\
\hline Spending on Statins & $151.7(436.06)$ & $\begin{array}{c}21.72 \\
(14.213)\end{array}$ & $\begin{array}{l}117.688 \\
(77.162)\end{array}$ \\
\hline Spending on ACE Inhibitors & $94.79(296.56)$ & $\begin{array}{l}15.313^{*} \\
(8.003)\end{array}$ & $\begin{array}{l}54.366^{*} \\
(28.455)\end{array}$ \\
\hline
\end{tabular}

Notes: Baseline means calculated using observations with A1c test values below 6.5 and greater than or equal to 6 . Coefficient estimates from local linear regression with optimal bandwidth calculation from Fuji, Imbens, and Kalyanaraman (2009). 
Table A12: RD Estimates of Effects of Diabetes Diagnosis in First 12 Months Following A1c Test Including Only Those Enrolled for at least 2 Years Prior to Initial Test

\begin{tabular}{lccc}
\hline \hline & Baseline Mean (Std Dev) & $\begin{array}{c}\text { Reduced Form } \\
\text { Estimate }\end{array}$ & $\begin{array}{c}\text { IV Estimate of } \\
\text { Effect of Diagnosis }\end{array}$ \\
\hline Diabetic Retinopathy & 0.002 & 0.004 & 0.021 \\
Ketoacidosis & $6 \mathrm{e}-04$ & $(0.003)$ & $(0.013)$ \\
& & 0.001 & 0.008 \\
Diabetic Coma & $7 \mathrm{e}-04$ & $(0.001)$ & $(0.007)$ \\
& & $-5 \mathrm{e}-04$ & -0.003 \\
Diabetic Neuropathy & 0.006 & $(0.001)$ & $(0.006)$ \\
& & $0.016^{* * *}$ & $0.097^{* * *}$ \\
Kidney Disease & 0.007 & $(0.005)$ & $(0.030)$ \\
& & $0.022^{* * *}$ & $0.121^{* * *}$ \\
Change in A1c & & $(0.005)$ & $(0.029)$ \\
from Previous Year & $-0.08(0.441)$ & $-0.085^{* *}$ & $-0.374^{* *}$ \\
Change in Total Cholesterol & & $(0.040)$ & $(0.186)$ \\
from Previous Year & $-6.691(32.47)$ & -1.915 & -5.663 \\
Change in Creatinine & & $(1.478)$ & $(4.378)$ \\
from Previous Year & $0.015(0.113)$ & 0.005 & 0.019 \\
Mortality^ & & $(0.005)$ & $(0.020)$ \\
& & 0.001 & 0.005 \\
& & $(0.001)$ & $(0.007)$ \\
\hline
\end{tabular}

Notes: Baseline means calculated using observations with A1c test values below 6.5 and greater than or equal to 6 . Coefficient estimates from local linear regression with optimal bandwidth calculation from Fuji, Imbens, and Kalyanaraman (2009). 
Table A13: RD Estimates of Effects of Diabetes Diagnosis in First 12 Months Following A1c Test Including Only Those Enrolled for at least 2 Years Prior to Initial Test

\begin{tabular}{|c|c|c|c|}
\hline & Control Mean (Std Dev) & $\begin{array}{l}\text { Reduced Form } \\
\text { Estimate }\end{array}$ & $\begin{array}{l}\text { IV Estimate of } \\
\text { Effect of Diagnosis }\end{array}$ \\
\hline Diabetes Diagnosis & 0.031 & $\begin{array}{c}0.410^{* * * *} \\
(0.044)\end{array}$ & - \\
\hline BMI & $28.49(5.54)$ & $\begin{array}{c}0.321 \\
(0.329)\end{array}$ & $\begin{array}{c}0.872 \\
(0.891)\end{array}$ \\
\hline Normal BMI & 0.262 & $\begin{array}{l}-0.001 \\
(0.029)\end{array}$ & $\begin{array}{l}-0.003 \\
(0.070)\end{array}$ \\
\hline Overweight & 0.337 & $\begin{array}{c}0.02 \\
(0.035)\end{array}$ & $\begin{array}{c}0.049 \\
(0.088)\end{array}$ \\
\hline Obese & 0.363 & $\begin{array}{l}-0.006 \\
(0.028)\end{array}$ & $\begin{array}{l}-0.017 \\
(0.080)\end{array}$ \\
\hline Diastolic blood pressure & $76.19(8.43)$ & $\begin{array}{l}-0.677 \\
(0.762)\end{array}$ & $\begin{array}{l}-1.969 \\
(2.189)\end{array}$ \\
\hline Systolic blood pressure & $129.67(14.10)$ & $\begin{array}{c}0.51 \\
(1.117)\end{array}$ & $\begin{array}{c}1.248 \\
(2.745)\end{array}$ \\
\hline High blood pressure & 0.23 & $\begin{array}{c}0.009 \\
(0.041)\end{array}$ & $\begin{array}{c}0.021 \\
(0.100)\end{array}$ \\
\hline
\end{tabular}

Notes: Baseline means calculated using observations with A1c test values below 6.5 and greater than or equal to 6 . Coefficient estimates from local linear regression with optimal bandwidth calculation from Fuji, Imbens, and Kalyanaraman (2009). 
Table A14: Coding All Individuals with A1c of 6.5\% or Higher As Receiving a Diagnosis

\begin{tabular}{lc}
\hline \hline & $\begin{array}{c}\text { IV Estimate of } \\
\text { Effect of Diagnosis }\end{array}$ \\
\hline Spending on ADA Recommended Care & $242.314^{* * *}$ \\
& $(30.471)$ \\
Spending on Office-Based Care Related to Diabetes & $134.602^{* * *}$ \\
& $(9.796)$ \\
Spending on Diabetes-Related Labs & $126.778^{* * *}$ \\
& $(21.583)$ \\
Spending on Diabetes-Related Vision Services & $5.437^{* * *}$ \\
& $(1.906)$ \\
Spending on Diabetes-Controlling Drugs & $7.574^{*}$ \\
& $(4.352)$ \\
Spending on Statins & 0.826 \\
& $(11.404)$ \\
Spending on ACE Inhibitors & $19.058^{*}$ \\
& $(9.950)$ \\
Endocrinology Specialist Care Spending & $54.409^{*}$ \\
Change in A1c from Previous Year & $(31.843)$ \\
& $-0.135^{* *}$ \\
Mortality^ & $(0.067)$ \\
& 0.001 \\
& $(0.002)$
\end{tabular}

Notes: Coefficient estimates from local linear regression with optimal bandwidth calculation from Fuji, Imbens, and Kalyanaraman (2009). ^Note that mortality is measured 2 years after the initial test as we require individuals to be present in the data and alive for the first 12 months after the initial test. 
Table A15: Diagnosis and Procedure Codes used in Sample Selection

\begin{tabular}{llllc}
\hline \hline Description & ICD 9 Codes & ICD 10 Codes & CPT Codes & LOINC Codes \\
Diabetes Related DX & 249,250 & $\begin{array}{l}\text { E08, E09, E10, } \\
\text { E11, E13 }\end{array}$ & N A & N/A \\
Pregnancy Related & 630-672, & O00-O99 & N/A & N/A \\
Diagnosis & V22-V23 & & & \\
Diabetes Lab Tests & N/A & N/A & 82947,83036, & $1558-6,20435-2$, \\
& & & 82947,82952 & $20437-0,20438-8$, \\
& & & $2345-7,74774-1$, \\
& & & $4548-4,27353-2$, \\
& & & $17856-6,17855-8$
\end{tabular}


Table A16: Drugs used to Determine Diabetic Drug Spending and for Sample Selection

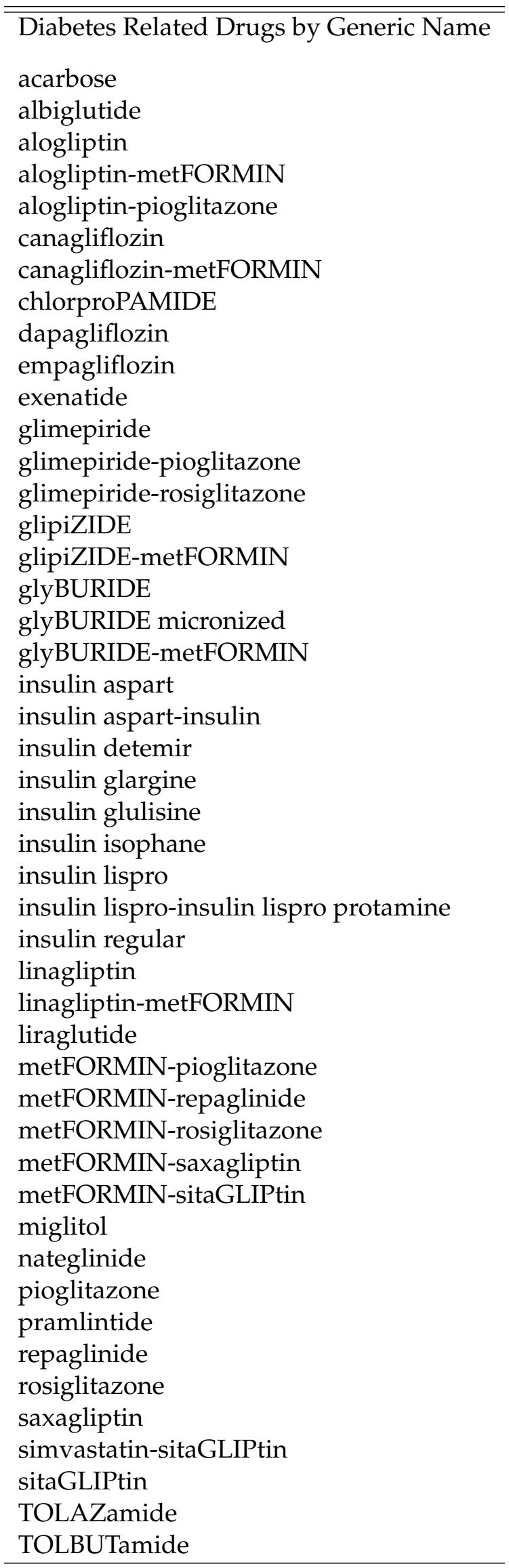


Table A17: RD Estimates of Effects of Diabetes Diagnosis in First 12 Months

\begin{tabular}{lccc}
\hline \hline & Control Mean (Std Dev) & $\begin{array}{c}\text { Reduced Form } \\
\text { Estimate }\end{array}$ & $\begin{array}{c}\text { IV Estimate of } \\
\text { Effect of Diagnosis }\end{array}$ \\
\hline $\begin{array}{l}\text { Number of A1c Tests at } \\
\text { Optum-Affiliated Lab }\end{array}$ & 0.436 & $0.046^{* *}$ & $0.205^{* *}$ \\
& & $(0.019)$ & $(0.081)$ \\
Any A1c Test at & 0.326 & 0.004 & 0.018 \\
Optum-Affiliated Lab & & $(0.011)$ & $(0.054)$ \\
& & & \\
Number of Cholesterol Tests at & 0.509 & 0.024 & 0.120 \\
Optum-Affiliated Lab & & $(0.020)$ & $(0.099)$ \\
& & & \\
$\begin{array}{l}\text { Any Cholesterol Test at } \\
\text { Optum-Affiliated Lab }\end{array}$ & 0.369 & 0.003 & 0.019 \\
\hline
\end{tabular}

Notes: Control means calculated using observations with A1c test values below 6.5 and greater than or equal to 6 . Coefficient estimates from local linear regression with optimal bandwidth calculation from Fuji, Imbens, and Kalyanaraman (2009). 